\title{
Sonificação para Apoio a Tarefas
}

de Visualização

Veridiana Christie Lucas Salvador

Orientação: Profa. Dra. Rosane Minghim

Dissertação apresentada ao Instituto de Ciências Matemáticas e de Computação - USP, como parte dos requisitos para a obtenção do título de Mestre em Ciências - Área de Ciências de Computação e Matemática Computacional.

USP - São Carlos

Abril de 1998. 
Ao meu marido Nelson e aos meus pais, Enide Lucas Salvador e Olavo Salvador por toda a paciência e apoio. 


\section{Agradecimentos}

À minha orientadora Profa. Dra. Rosane Minghim, por todo apoio dado e conhecimentos passados durante o período de estudos, além da dedicação no processo de revisão desta dissertação.

Aos colegas do laboratório LCAD: Profa. Maria Cristina Ferreira de Oliveira, Prof. Dr. Onofre Trindade Jr., Prof. Dr. Armando Fortuna, Sandra Mara Tutida, Luis Augusto Cassimiro, Eldis de Paula Oliveira, Paulo Renato Del Bianco e René Vieira Santin pela ajuda e compreensão durante o desenvolvimento do projeto.

Ao colega Magnus Lanzillotti Pacheco pela dedicação ao projeto de iniciação científica que foi incorporado ao projeto de mestrado, além de toda ajuda prestada.

À FAPESP pelo financiamento dos estudos que envolveram o projeto de mestrado.

Ao colega Milton H. Shimabukuro, pela disposição do conjunto de dados dentários empregado nos casos de teste.

Ao Dr. A. M. Day (School of Information System - UEA) e Dr. Sue Turner (School of Environmental Sciences- UEA) pela autorização do uso dos dados marítimos empregados nos casos de teste. Os dados foram coletados no R.R.S. Challenger como parte do Projeto de Pesquisa Comunidade Mar do Norte( NERC, 1988 - 1989). 


\section{Resumo}

A Visualização Científica (VisC) é uma área da computação gráfica que ajuda cientistas e outros profissionais a capturar o significado dos seus dados. Essa área tem como objetivo a geração de imagens a partir de um conjunto de dados (geralmente obtidos a partir de dispositivos de detecção ou simulações numéricas), as quais são interpretados por usuários que desejam ganhar entendimento do fenômeno que gerou os dados.

Algumas vezes esses conjuntos de dados formam imagens complexas, dificultando o seu entendimento, ou possuem muita informação, tornando difícil a sua apresentação no ambiente bidimensional da tela do computador. Nesses casos o som é uma boa alternativa de representação em apoio às técnicas visuais. Sonificação é a área da computação que tratqa do mapeamento sonoro de conjuntos de dados com a intenção de exibir informaçðes.

Esta dissertação mostra um estudo sobre o uso de som para o desenvolvimento de um sistema de sonificação para visualização. Esse sistema compreende a implementação de funções de som para visualização volumétrica baseada em superfícies desenvolvidas anteriormente em SSound, no ambiente orientado a objetos de uma biblioteca de visualização de baixo custo e ampla utilização ( 0 VTK - Visualization Toolkit).

Os resultados desta dissertação identificam a utilidade do som integrado com a visualização para representar e reforçar dados, além de uma série de recursos para suportar a interpretação de informações complexas. 


\section{Abstract}

The Scientific Visualization (VisC) is an area of the Computer Graphics that helps scientists and other professionals to capture their data meaning. The aim of this area is to produce images starting from a data group (usually got starting from detection gadgets or numeric simulations), which will be interpreted by the users that want to get the understanding of its meaning.

Sometimes this data groups constitute complex images that make its understanding difficult, or have too much information becoming hard its presentation on the bidimensional ambient of the computer screen. When this happens, sound is a good alternative of representation as a support to visual techniques. Sonification is the area that treats the sound mapping of the data group intenting on exhibiting information.

This thesis shows a study and a implementation of a sonification system. This system consists of the implementation of sound functions to a $3 \mathrm{D}$ visualization based on previously developed surfaces in SSound, on a large utilization visualization library (VTK).

The results of this thesis identify the sound utility together with the visualization to represent and strengthen data, beyond a series of means to support the interpretation of complex information. 


\section{Índice}

\section{INTRODUÇÃO}

2. ACÚSTICA E PERCEPÇÃO SONORA

2.1 Canal auditivo e acústica

2.1.1 O Canal Auditivo

2.1.2 Acústica

2.2 Percepçāo Sonora

2.2.1 Psicologia Gestalt aplicada à Audição

3. SONIFICAÇÃO

3.1 Contribuiçōes do Uso do Som na Visualização

3.2 Vantagens e Desvantagens do Uso do Som

3.3 Paradigmas de Exibições Sonoras

3.4 Trabalhos Prévios de Som como Ferramenta para Aplicaçōes Computacionais

4. VISUALIZAÇÃO E SOM

4.1 Visualização e Percepção

4.1.1 Marching Cubes

4.1.2 Percepção em Visualização

4.2 A Biblioteca VTK

4.2.1 Descriçāo Geral

4.2.2 Tipos de Dados

4.2.3 Pipeline de Visualização

4.2.4 Geração de Isosuperfícies em VTK

4.2.5 Diretrizes para Implementação

4.3 Exemplo do Uso de Som (Sonda Sonora) 
$\begin{array}{lr}\text { 4.5 Sonificações Passiva e Interativa } & 67\end{array}$

$\begin{array}{lr}4.6 \text { Especificação do SVol } & 68\end{array}$

5. SVOL - MÓDULO MULTIMODAL PARA VISUALIZAÇÃO VOLUMÉTRICA

5.2 OMT (Object Modeling Technique)

5.2.1 Conceitos de Orientação a Objetos

5.2.2 Modelagem Orientada a Objetos

5.3 MIDI Kernel e Sound Tools Library

5.3.1 MIDI Kernel

5.3.2 Sound Tools Library

5.4 Panorama Geral do Projeto SVol

5.5 Display Progressivo

5.5.1 Sonificaçōes do Display Progressivo

5.6 Sonda Sonora

5.6.2 Sonificações da Sonda Sonora

5.7 Display da Malha

5.7.1 Filtro vtkProjectionFilter 


\section{Índice de Figuras}

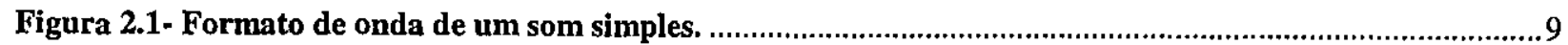

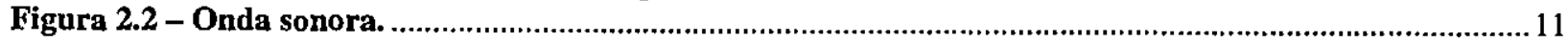

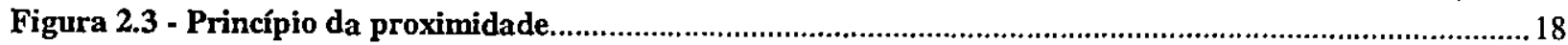

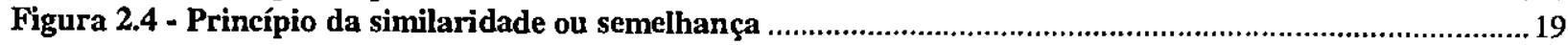

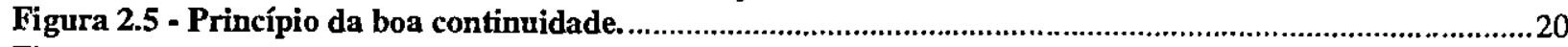

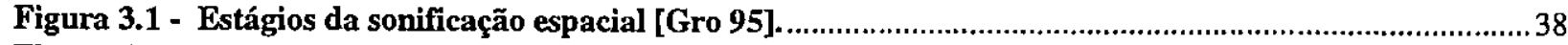

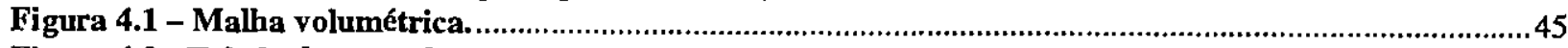

Figura 4.2 - Tabela de casos de triangulações para o marching cubes [Min 97b].........................................48

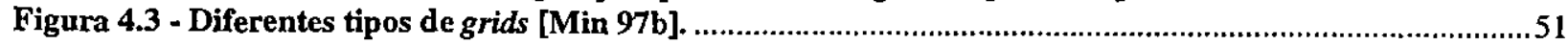

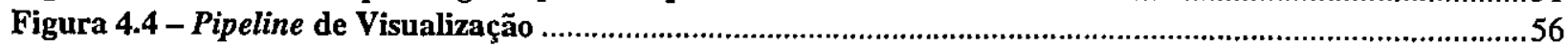

Figura 4.5 - Exemplo de acesso ao filtro vtkMarchingCubes com seu pipeline...................................................58

Figura 4.6 - Sonda sonora implementada em SSound [Min 95a].................................................................61

Figura 4.7 • Sequência de passos da função da sonda sonora no SSound [Min 95a]........................................6. 62

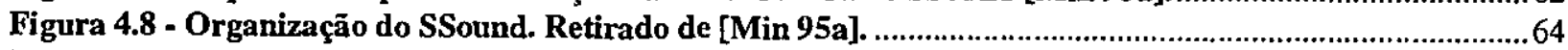

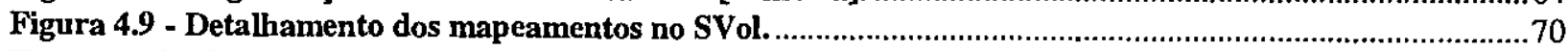

Figura 4.10 - Organizaçāo física do sistema de sonificação .............................................................................70

Figura 5.1 - Modelo de Objetos para locaçāo de dispositivos [Sch 97]. .........................................................76

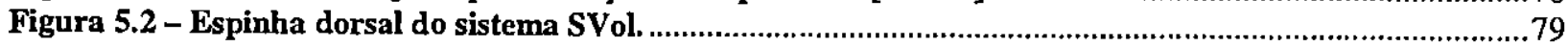

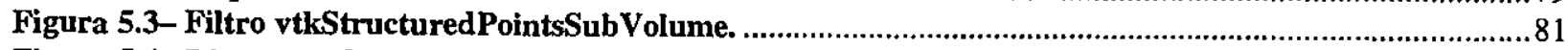

Figura 5.4- Diagrama de ojetos do VTK incluindo o novo filtro...........................................................8 82

Figura 5.5 -Linhas de código do Display Progressivo, apresentando a coordenada z..........................................8 83

Figura 5.6 - Interface da sonificação das coordenadas de um volume do sistema SVol. .......................................8. 84

Figura 5.7 - Sequência de passos do Display Progressivo............................................................................... 85

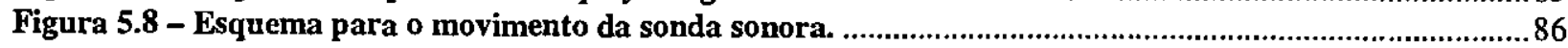

Figura 5.9 - Interface de escolha da parte gráfica Sonda Sonora desenvolvida em SVol.................................90

Figura 5.10 - Display da Malha. O Grid 3D é representado em tela por um grid 2D. .......................................91

Figura 5.11 - Linhas de código do display da malha. ...............................................................................99

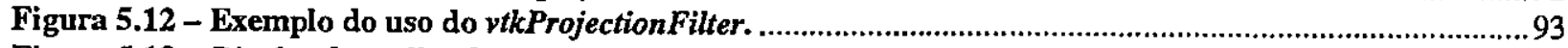

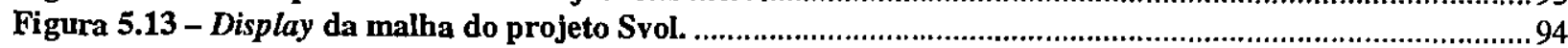

Figura 5.14 -Sonda Sonora de SVol apresentada com dados de imagens dentárias. .......................................96

Figura 5.15 - Sequência de passos do display progressivo de SVol, utilizando dados de imagens dentárias. ...96 


\section{Índice de Tabelas}

Tabela 2.1 - Tabela de princípios da psicologia Gestalt, sua definição e seus conceitos de primitivas de agrupamento sonoro.

Tabela 3.1 - Tabela de sistemas com uso de som e seus resultados.

Tabela 4.1 - Sonificações implementadas pelo SSound, funcões exercidas por elas e propriedades utilizadas. 67

Tabela 5.1 - Pontos encontrados pela função score. Isovalor é o valor de interesse, responsável pela geração da isosuperfície dentro do volume.

Tabela 5.2 - Sonificações do SVol e extensões planejadas..........................................................................95

Tabela 5.3 - Exemplos de conjuntos de dados aplicados a SVol com sonificações aplicadas e suas utilidades. 97 


\section{Introdução}

A maneira mais eficiente de captar e entender informações é mentalizando imagens, ou seja, visualizando. A computação gráfica e a visualização usam essa capacidade do homem para representar vários tipos de dados em áreas diferenciadas através do computador. A Visualização Científica (VisC) usa técnicas da Computação Gráfica para ajudar cientistas e outros profissionais a capturar o significado dos seus dados. A visualização tem se desenvolvido muito nos últimos anos, a partir de uma iniciativa americana, que reconheceu essa disciplina como uma área separada, devido às suas características próprias em relação à computação gráfica convencional e também às disciplinas que visa apoiar [CG 87]. A partir desse reconhecimento, um grande desenvolvimento da visualização tem sido observado.

O objetivo da visualização científica é renderizar ${ }^{1}$ imagens a partir de um conjunto de dados (tipicamente obtidos a partir de dispositivos de deteç̧ão ou de simulações numéricas). Esses dados são normalmente interpretados por usuários que desejam ganhar entendimento de seu significado. Apesar de suas limitações, as ferramentas de visualização utilizadas atualmente fornecem ajuda para usuários que poderiam estar perdidos no mar de números e medidas produzido pela maioria das aplicações atuais [Min 95b].

Existem alguns casos onde os dados são muito complexos, gerando, portanto, imagens complexas, o que pode carregar o canal visual, isto é, gerar imagens com muita informação, fazendo com que o usuário tenha dificuldade de interpretá-las. Outras vezes, os dados possuem muitas informações, tornando difícil apresentá-los visualmente no ambiente bidimensional da

\footnotetext{
'Do inglês rendering, significa gerar uma imagem na tela, com base na sua representação gráfica e propriedades físicas.
} 
tela do computador. Muitas vezes eles formam imagens confusas, com partes escondidas, ou difíceis de serem entendidas. Nesses casos o som pode ser útil como uma alternativa de representação em apoio às técnicas visuais [Min 95b].

A palavra sonificação (sonification) tem sido usada para indicar o mapeamento sonoro de dados numéricos com a intenção de exibir informações. De acordo com a definição de Scaletti [Sca 94]:

\section{"Sonificação é o mapeamento de relações numericamente representadas em algum domínio em estudo para relações em um domínio acústico com o propósito de interpretação e entendimento no domínio em estudo".}

Esse é um campo de pesquisa relativamente novo e é direcionado a transformar dados em informações auditivas. Em sistemas gráficos, o som é usado em conjunto com a imagem para reforçar a informação visual ou para representar informações adicionais, as quais não puderam ser representadas através da informação gráfica.

O som está sendo pesquisado e usado como suporte à apresentação gráfica pelo fato da audição ser o segundo sentido mais poderoso do ser humano. Portanto, pode-se dizer que, excluindo a visão, ele tem uma maior capacidade para perceber informações que os demais sentidos. Além disso, a menos que se tenha algum problema auditivo, seres humanos estão constantemente usando a audição no seu dia-a-dia, como, por exemplo, para se responder ao telefone ou para detectar a aproximação de pessoas ou animais.

Treinando e desenvolvendo seu sentido auditivo, o ser humano pode entender mais facilmente informações sonoras. Como exemplo de desenvolvimento da audição temos os músicos, que geralmente expressam em suas músicas cenas ou fatos que visualizam em suas mentes, além de serem capazes de detectar mais informação pela audição. Outros exemplos típicos são: profissionais que interpretam informações de sonar e indivíduos com problemas sérios de visão.

Também pode ser citada, como evidência em favor da sonificação, a observação de que o ser humano tende a esperar algum tipo de som associado com imagens, especialmente imagens em movimento. Como exemplo temos a era do cinema mudo, no começo do século, onde os filmes 
não possuíam informações sonoras, só visuais. Naquela época, as pessoas conseguiam ter um bom entendimento do filme. Com o aparecimento de som nos filmes, hoje em dia as pessoas estão acostumadas a esperar sons para acompanhar imagens. O mesmo pode acontecer com a visualização, a exemplo do que já vem acontecendo com animações computacionais e aplicações de realidade virtual.

Um problema a ser considerado é a geração de ruído no ambiente de trabalho. Vamos então assumir que se tenha um ambiente de trabalho com silêncio absoluto. John Cage registrou em uma anedota que após ficar por meia hora em um ambiente absolutamente sem barulhos ele descobriu que ouvia dois sons: um era seu sistema nervoso e o outro seu sistema circulatório [Bux 90]. Essa anedota serve para nos mostrar que não há um silêncio absoluto, que o ser humano está rodeado de sons, e que os sons fazem parte do dia-a-dia. Alguns sons ajudam, que são as informações, e outros atrapalham, que são os ruídos.

As interfaces computacionais são ainda essencialmente visuais, com exceção de algumas aplicações onde o som é uma parte necessária do processo, como na geração de filmes, em realidade virtual, na produção de jogos e em música computacional. Em muitas aplicações, principalmente em visualização científica, a grande maioria das ferramentas para interpretação de dados é puramente gráfica [Min 95a], e os limites das representações gráficas podem ser sentidos pela maioria dos pesquisadores e usuários desses sistemas de visualização. Nesses casos são necessários outros meios de representação da informação para que se possa ganhar maior entendimento sobre o conjunto de dados [Reu 90].

Em documentos científicos relacionados com o uso de sinais sonoros para representar informação em aplicações computacionais, existem alguns termos que são usados para definir os passos envolvidos no processo. Alguns desses termos são: sonificação, auralização, audificação e audibilidade [Min 95a]. Eles são definidos a seguir.

Audificação (audification) denota a translação direta do dado para o sinal sonoro sem nenhuma elaboração intermediária. Um exemplo é colocar a saída de um gerador gráfico em um autofalante para produzir vibrações diferentes para sinais diferentes. 
Auralização (auralization) é o processo de representação do som que necessita de memória para a experiência sonora ou envolve sequência de sons. Esse termo tem sido usado para definir o mapeamento de informação para sons tridimensionais, isto é, a definição de parâmetros para meio ambiente acústico.

Audibilização (audibilization) é a palavra empregada para definir a geração de saídas sonoras por meio dos mesmos princípios físicos, ou o mesmo algoritmo, usado na renderização gráfica do objeto ou animação. Em outras palavras é a geração de sons e gráficos por congruência de algoritmos, geralmente com o objetivo de produzir trilhas sonoras automáticas para filmes ou animações.

Sonificação, como já foi definido, relaciona o uso de sinais sonoros de maneira estruturada, com o objetivo de representar informações.

Exibição sonora significa o uso de sinais sonoros para representar informação, algum tipo de informação em algum contexto. Isso inclui números, cálculos, objetos e eventos.

Com base nas motivações apresentadas acima, esta dissertação mostra um estudo sobre o uso de som para o desenvolvimento de um sistema de sonificação para visualização, como extensão ao trabalho desenvolvido anteriormente [Min 95a,b,c], e que está sendo aprimorado no âmbito do ICMC - USP. Além disso, este trabalho compreende a implementação, no contexto de um sistema de visualização de propósito geral (VTK), de processos de sonificação para visualização volumétrica baseada em superfícies, desenvolvidos anteriormente.

Além de fomecer os conceitos básicos utilizados na parte prática do trabalho, esta dissertação pretende oferecer uma coletânea dos conhecimentos essenciais para o desenvolvimento da área de sonificação em visualização científica, como extensão do trabalho exposto em [Min 95a]. Isso inclui aspectos fundamentais de visualização, sonificação, acústica e percepção sonora, visando fornecer a base para a continuidade do desenvolvimento de SVol, no projeto de sonificação para visualização em andamento no âmbito do ICMC - USP. 
Os Capítulos 2 e 3 mostram a revisão bibliográfica sobre temas de relevância para a área de visualização, realizada no período de desenvolvimento do projeto. O Capítulo 4 apresenta a área de visualização e as bases gráficas para a tese, além da estrutura usada para as sonificações. $O$ Capítulo 5 apresenta o SVol, o sistema de sonificação para apoio a tarefas de visualização, sua implementação, e os resultados obtidos. O Capítulo 6 apresenta as conclusões deste trabalho. 


\section{Acústica e Percepção Sonora}

Já era esperado, através de resultados publicados nos últimos anos por vários pesquisadores, que a exploração e interação de dados seriam beneficiadas pelo uso do canal auditivo [Bux 90] [Kra 94]. Recentemente, o uso do som como forma de representação de informação passou de uma possibilidade quase remota em sistemas computacionais a uma parte integral de estudos em várias áreas de pesquisa e desenvolvimento tecnológicos [Min 95a] [Axe 96] [Bar 96] [Wil 96] [Mar 97] [Day 97].

Este Capítulo apresenta uma revisão bibliográfica de tópicos estudados que suportam a questão apresentada no parágrafo acima. A Seção 2.1 deste Capítulo discute o canal auditivo e acústica e a Seção 2.2 apresenta a percepção sonora, temas essenciais para a área de sonificação. Serão apresentados os sons falados, sua síntese e reconhecimento e também sons não falados, cada vez mais usados em sistemas computacionais. Adicionalmente, será dada uma introdução básica para termos e conceitos usados quando se trata de som e audição, como acústica, propriedades do som e psicologia Gestalt aplicada à audição.

\subsection{Canal auditivo e acústica}

Esta Seção mostra um estudo sobre o canal auditivo e acústica. Ela apresenta os aspectos mais importantes desses dois temas para sistemas de sonificação. 


\subsubsection{O Canal Auditivo}

Um dos motivos para que o som não seja muito usado em sistemas computacionais é que ele ainda possui muitos aspectos que precisam ser entendidos pelos seres humanos, como, por exemplo, o processo de associação de objetos com sons. Duas classes de som podem ser consideradas em aplicações computacionais: os sons falados e os sons não falados.

\section{Sons Falados}

A primeira forma de comunicação por som é a fala, pois é a maneira como a maioria dos seres humanos se comunica. Alguns dos sistemas que usam o som falado são sistemas de síntese da fala e sistemas de reconhecimento da fala.

A síntese da fala por computador é o uso mais comum da fala em interações homemcomputador porque as tecnologias para síntese de fala compreensível são agora bem acessíveis e já existem como equipamento padrão em muitos computadores pessoais. Algumas das categorias de sistemas de síntese da fala são:

- Fonema-para-Fala: são sistemas que geram suas sínteses através de uma descrição fonêmica;

- Texto-para-Fala: são sistemas que transformam arquivos texto em fala; e

- Mensagem Armazenada: são sistemas que usam mensagens faladas pré-gravadas.

Os sistemas de reconhecimento da fala reconhecem palavras faladas, ou sejam, fazem a "tradução", através da máquina, de discursos falados em textos escritos [Bre 97]. Geralmente, esses sistemas não analisam o significado das palavras, eles simplesmente verificam que palavras são. Os sistemas de reconhecimento da fala ainda apresentam algumas limitações como:

- Necessidade de treinamento. O sistema deve ser treinado separadamente para cada usuário diferente. 
- Número de palavras. Os sistemas de reconhecimento de fala podem reconhecer desde algumas dezenas de palavras até a ordem de milhares de palavras.

- Separação de palavras consecutivas. O sistema deve reconhecer quando uma palavra termina e outra começa. Esse é um dos maiores problemas encontrados em reconhecimento de fala. Alguns sistemas determinam que o usuário deve falar separando as palavras o que não é um meio muito natural.

Além desses, existem ainda problemas de contexto, aplicação, jargões técnicos e culturais.

\section{Sons Não Falados}

O canal auditivo não está restrito somente à fala. Existe também uma grande variedade de outras interações baseadas em som, pois mesmo em sistemas de computadores, os sons não falados realizam um importante papel. Classificados como sons não falados estão todos aqueles sons que utilizamos no nosso dia a dia, como, por exemplo, ruídos de motores de carros, sons de batidas de portas, além dos sons musicais e naturais.

Funcionalmente, os sons não falados podem nos dar um entre três tipos de informações: eles podem ser alarmes, indicadores de status e monitoramento, e mensagens codificadas [Bux 90].

O tipo de informação mais comum representada por som não falado em sistemas computacionais são os alarmes. Alarmes e mensagens de aviso como, por exemplo, a sirene de uma ambulância, são sinais que levam prioridade sobre outras informações. A função desse tipo de informação é alertar o usuário de que alguma coisa está requerendo atenção imediata. Para se ter o efeito desejado, portanto, tais sons devem ser ensinados ao usuário e ser preferencialmente significativos.

Os indicadores de status e monitoramento fornecem informações sobre uma tarefa corrente. O "clique" produzido quando se pressiona uma tecla em um teclado convencional é um exemplo de som indicador de status. O som produzido só indica se a tecla foi realmente pressionada ou não. 
Seres humanos são capazes de monitorar mais do que um sinal sonoro de fundo, quando os sons são suficientemente diferenciados.

As mensagens codificadas servem para apresentar dados numéricos (qualitativos ou quantitativos) em forma de sons, como, por exemplo, a análise e apresentação de dados estatísticos apresentados de forma sonora.

Como é possível observar, os sons falados são representações de textos e por isso dependentes da linguagem. Muitas vezes eles são ambíguos, e sujeitos a diferenças culturais. Esse tipo de som geralmente não é bom para representação de informação. Em contrapartida, os sons não falados não dependem tão fortemente da linguagem e cultura e são bons para representar informações. Como o objetivo deste trabalho é a representação de informação, o restante deste texto se concentra em sons não falados.

\subsubsection{Acústica}

O que se ouve como som é uma classe de energia cinética física chamada energia acústica. Ela consiste de ondas de pressão em um meio físico, geralmente o ar [Dav 89]. Essas ondas de pressão provocam o movimento do ar, e podem ser analisadas de várias maneiras. $\mathrm{O}$ formato da onda de som pode ser mostrado no domínio do tempo, como mostra a figura 2.1.

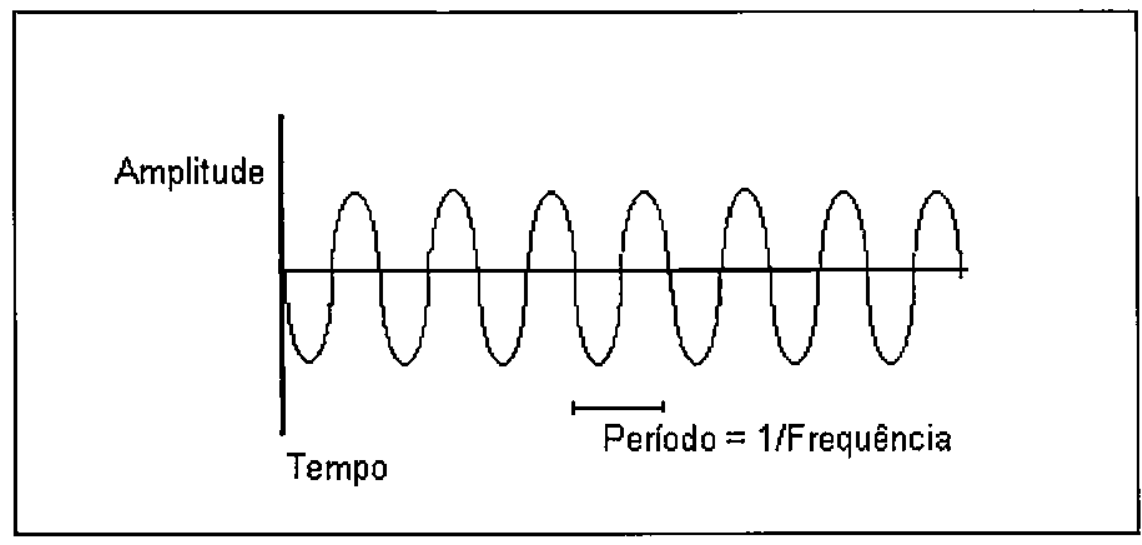

Figura 2.1- Formato de onda de um som simples.

O gráfico acima mostra uma onda sonora no domínio do tempo. Esse é um exemplo de onda periódica, isto é, ela se repete num período fixo de tempo. 
Em instrumentos acústicos, o movimento do ar (onda) é realizado por alguma vibração física, como a de uma corda, ou por qualquer outra parte do instrumento. Já em instrumentos eletrônicos, onde se encaixam os sintetizadores, o movimento do ar é realizado por um altofalante. Essas ondas chegam ao ouvido humano onde se encontra o tímpano, e fazem com que ele vibre. Mudanças fisiológicas ocorrem e transformam o movimento físico do tímpano em sinais elétricos analógicos, os quais caminham pelos nervos em direção ao cérebro. Quando esses sinais chegam ao cérebro, o som é finalmente percebido [Mas 87].

Um ciclo simples completo de uma onda de pressão acústica consiste de um meio ciclo de compressão das moléculas do ar, ou seja, alta pressão, seguido de uma outra metade do ciclo de rarefação dessas moléculas, isto é, baixa pressão. A taxa de flutuação da pressão do ar é chamada de frequência da onda. Essa frequência corresponde, como atributo musical, à entoação (pitch) que corresponde à altura do som (quão grave ou agudo ele é) [Dav 89]. A unidade Hertz (Hz) é usada para indicar a frequência em ciclos por segundo:

\section{$1 \mathrm{~Hz}=1$ ciclo por segundo (cps)}

Para ser classificada como som, as ondas de pressão devem flutuar no ar entre 20 e 20.000 ciclos completos por segundo, o espectro audível pelo ser humano.

O tempo que a onda leva para percorrer um ciclo completo é chamado período da onda. Ele é expresso em segundos por ciclo e é dado pela equação:

\section{Período $=1 /$ Frequência}

As ondas sonoras viajam pelo ar a uma velocidade de 344 metros por segundo (1.130 pés por segundo) em um ambiente a nível do mar em uma temperatura de aproximadamente 15 graus Celsius (59 graus Farenheit). A velocidade da onda é independente da sua frequência. A distância física coberta por um ciclo completo de uma dada frequência do som é chamada tamanho da onda e é obtida por:

Tamanho da Onda $=$ Velocidade do Som $/$ Frequência 
A onda exibida na figura 2.1 é chamada de senóide e é raramente resultado de eventos naturais. A maioria dos sons têm energia de frequências diferentes que formam ondas complexas. Esse tipo de formato de onda é muito mais típico nos sons do dia-a-dia encontrados no mundo. Outro exemplo de onda sonora é dado na figura 2.2, que mostra uma onda sonora de uma corneta. Pode-se perceber que ela é uma onda sonora regular composta de várias frequências.
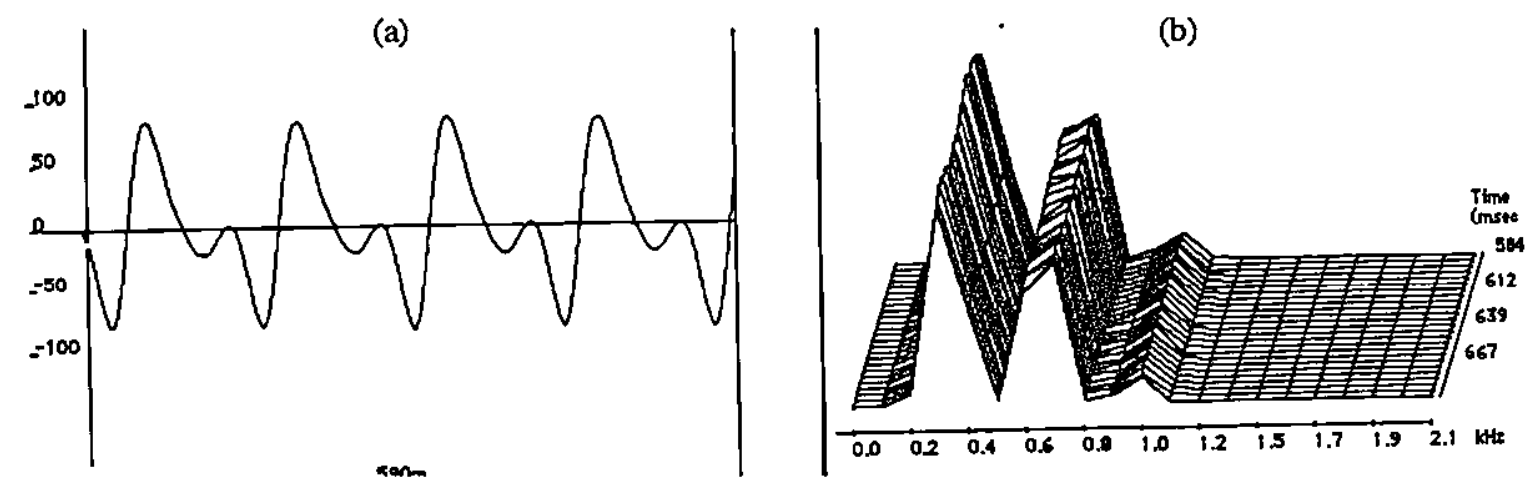

Figura 2.2 - Onda sonora.

(a) onda sonora de uma corneta.

(b) mesma onda sonora no domínio da frequência

Pode-se usar a Transformada de Fourier para mapear uma onda (amplitude $\mathrm{x}$ distância) para $\mathrm{o}$ domínio do tempo (frequência $x$ tempo).

\subsection{Percepção Sonora}

O ser humano não nasceu sabendo o significado dos sons, como, por exemplo, o som de uma sirene de ambulância, de um alarme de incêndio ou até mesmo de um pássaro. Para que um som tenha um significado determinado, ele deve ser aprendido. Isso serve também para sistemas computacionais que fazem o uso do som como uma de suas ferramentas. Além disso, para que os sons sejam empregados em sistemas computacionais, eles devem ser claros e de fácil entendimento.

Para executar corretamente um projeto sonoro é necessário conhecer os aspectos de percepção que influenciam no entendimento de um som. Muitos fatores que influenciam a percepção sonora são conhecidos hoje em dia, mas existem muitos pontos que ainda estão obscuros e que 
precisam de muito estudo. Por exemplo, na associação de cores com sons, algumas pessoas associam a cor branca a sons agudos e algumas a sons graves. Abaixo serão explicados alguns tópicos de psico-acústica, importantes para a modelagem de interfaces sonoras.

\section{Audição do Dia-a-Dia e Audição Musical}

Audição do dia-a-dia e Audição Musical são os dois principais tipos de interpretação de sons reconhecidos. A audição do dia-a-dia relaciona a fonte do som e suas propriedades com o que é ouvido como, por exemplo, o reconhecimento de tipos de veículos motorizados através do ronco do motor. $O$ uso da audição do dia-a-dia em interfaces de sistemas computacionais é análogo ao uso de ícones representativos em gráficos [Bux 90].

A audição musical relaciona a percepção, identificação e distinção das propriedades de um som. Através desse tipo de audição consegue-se determinar parâmetros de um estímulo sonoro (entoação, volume, ritmo, etc.).

Para se explicar melhor as diferenças entre as duas interpretações dos sons citadas acima será dado como exemplo alguém serrando um pedaço de madeira. A audição do dia-a-dia permite reconhecer que alguém está usando um serrote em um objeto de madeira, enquanto que, usando a audição musical, pode-se determinar que existe um ruído rítmico contínuo de baixa entoação no ambiente. A audição do dia-a-dia é dependente da familiaridade com o evento enquanto que na audição musical o conhecimento prévio não é essencial. O primeiro tipo de audição apóia a identificação do fenômeno gerador. O segundo tipo permite separar suas propriedades individuais. Os dois tipos de audição estão presentes em quaisquer eventos sonoros, e são úteis de maneiras diversas para o reconhecimento de um estímulo sonoro.

\section{Faixa Crítica (Critical Band)}

Faixa Crítica é um importante conceito na aplicação prática de som. Elas são regiões de frequência nas quais energias sonoras interagem, afetando a percepção. Parece ser explicável em termos da resposta de vibração na membrana basilar. Pode-se dizer, grosseiramente, que uma faixa crítica é a terça parte de uma oitava [Bux 90]. 
Dentro da faixa crítica, a distinção de diferentes frequências apresentadas simultaneamente é prejudicada. Essa situação é identificada como mascaramento (masking), que é um resultado na percepção sonora e cuja consideração é fundamental para o display auditivo [Min95a]. Alguns aspectos de mascaramento (masking) podem ser explicados pela faixa crítica.

A faixa crítica também ajuda a explicar harmonia e discordância, ou seja, sons que se encontram dentro de uma faixa crítica soam rudes, grosseiros, enquanto que somente aqueles que estão fora dela podem ser consonantes.

\section{Ilusões Psico-acústicas}

Ilusões psico-acústicas são geradas pela combinação de sons e de efeitos sonoros, principalmente se eles provocam uma associação qualquer para algum ouvinte em particular. Isso pode ser ilusório ou esconder o verdadeiro significado do som.

Um exemplo de ilusão psico-acústica é quando se confunde o miado de um gato com o choro de uma criança.

\section{Propriedades do Som}

São apresentadas abaixo algumas das principais propriedades de sons.

\section{Entoação (pitch)}

É uma impressão subjetiva que corresponde bem à frequência. Por exemplo, a entoação de um tom senóide é uma função de sua frequência; a entoação de um tom harmônico é uma função da frequência fundamental ${ }^{2}$; e a entoação de um tom não-harmônico (ruído) é uma função de sua agudeza (brightness).

Apesar dessa associação, a entoação não é uma função linear da frequência, ou seja, dobrar a entoação não significa dobrar a frequência. Ela é, aproximadamente, uma função logarítmica da

\footnotetext{
${ }^{2}$ A frequência que se sobressai sobre o conjunto de frequências que compõem um som por ser percebida com uma maior potência.
} 
frequência. Além disso, outros parâmetros também influenciam na sua percepção. A percepção da entoação depende, entre outros fatores, do volume (loudness). A percepção da entoação de tons senóides abaixo de $1.000 \mathrm{~Hz}$ cai conforme o som aumenta de intensidade; já a entoação de tons senóides acima de $1.000 \mathrm{~Hz}$ aumenta conforme o som se torna mais forte. A percepção da entoação também é afetada pelo timbre da nota tocada.

A entoação não é uma dimensão perceptiva simples. Em adição à altura da entoação, existe um componente circular de percepção de entoação. Para o ouvinte, sons de oitavas separadas são similares, talvez mais similares que tons com frequências próximas.

A maioria das pessoas não fazem um bom julgamento absoluto da entoação. A entoação perfeita é rara e não pode ser ensinada com toda confiança. As pessoas têm graus variados de habilidade para julgar relativamente esta propriedade. Essa habilidade varia de acordo com a habilidade musical e pode ser ensinada com uma confiabilidade razoável. A habilidade do ser humano de ouvir sons de alta entoação, especialmente os suaves, diminui com o avanço da idade.

\section{Volume do som (Loudness)}

É uma impressão subjetiva que corresponde bem à amplitude. Relaciona-se com intensidade de acordo com a lei:

$$
\mathbf{L}=\mathbf{k} \mathbf{I}^{\mathbf{0 . 3}}
$$

onde loudness (L) é medida em sones ${ }^{3}$, e intensidade (I) como decibeis (dB). Esse relacionamento significa que $10 \mathrm{~dB}$ de aumento na intensidade resulta no dobro do volume.

$O$ volume depende da frequência. Em geral, tons em uma dada amplitude com frequências entre 1.000 e $5.000 \mathrm{~Hz}$ são percebidos mais altos do que aqueles com frequências maiores ou menores; o volume também depende da duração. Por exemplo, para sons mais curtos que 1 segundo, o volume aumenta com a duração; já para sons mais longos que isso, o volume permanece constante.

\footnotetext{
${ }^{3}$ Medição padrão internacional que define volume a $1.000 \mathrm{~Hz}$ tonificado a $40 \mathrm{~dB}$ como sendo 1 sone.
} 
Essa propriedade também é afetada pela largura de banda. Sons com uma grande largura de banda são mais altos que sons com estreita largura de banda, mesmo quando eles possuem a mesma energia. Como para entoação, o ser humano também não faz um bom julgamento absoluto do volume. E sua habilidade para julgar relativamente esta propriedade está limitada a uma escala de 3 (três) diferentes níveis.

\section{Duração}

Para a maioria dos sons, essa propriedade corresponde muito bem à duração física. É o período de tempo do início ao fim de um som. A duração afeta o ritmo. Por exemplo, se duas notas de igual duração são tocadas a cada 4 (quatro) unidades de tempo, percebe-se um ritmo regular. Se uma delas mudar para $3 / 4$ (três quartos) da duração da outra, a sua percepção irá mudar de acordo.

\section{Ritmo}

No contexto musical, ritmo é um distinto agrupamento de sons e silêncio no tempo, baseado na duração das notas, tensões fortes e fracas e outros fatores [Min 95a]. O ritmo se relaciona muito com a duração do som. É uma importante característica da percepção de eventos de som, principalmente em sons musicais. O ritmo também está relacionado com a cultura e é um importante parâmetro para se detectar a fonte de som.

\section{Timbre}

Também conhecido como "a cor do som", pode ser definido como "o atributo de sensação auditiva que permite que dois sons similares com o mesmo volume e a mesma entoação possam ser julgados como sendo diferentes" [Bux 90].

A percepção de timbre é um tema que ainda necessita de uma teoria consistente. O timbre é multidimensional, mas suas dimensões são apenas parcialmente conhecidas. A percepção do timbre depende de características temporais. Além disso, ela depende da forma da onda, ou seja, mudando-se as parciais ${ }^{4}$ de um som muda-se o timbre.

\footnotetext{
${ }^{4}$ Diferentes frequências, com diferentes pontos de energia, que compöem uma onda sonora.
} 
Grey (1977) encontrou três dimensões de timbre usando uma escala multidimensional [Bux 90]:

1. distribuição de energia spectral (agudeza);

2. a quantidade relativa de energias de alta frequência na investida ${ }^{5}$;

3. o grau no qual as funções de amplitude das parciais são síncronas.

\section{Mascaramento (Masking)}

O mascaramento existe quando a presença de um som deturpa ou encobre o reconhecimento de outro som [Gav 90]. Mascaramento depende do volume, ou seja, em geral um som muito alto "mascara" um som suave. O mascaramento depende também da frequência, ou seja, normalmente sons mascaram altas frequências mais do que baixas frequências; e também sons em uma faixa crítica mascaram outros, na mesma faixa, mais do que aqueles que estão fora dela.

$O$ efeito do mascaramento pode vir do meio ambiente em que se encontra o ouvinte. Um som pode ser mascarado por sons que vêm antes ou depois dele, isto é, não precisam ocorrer ao mesmo tempo. O mascaramento pode ser previsível com razoável precisão se as características de ruídos do meio ambiente forem conhecidas.

Além dessas propriedades também podemos citar outras como a localização espacial, que é a propriedade que permite um ouvinte identificar o ponto no espaço onde o som foi originado. Ela está relacionada com a bi-audição humana (utilização de ambos ouvidos). Outra propriedade da audição humana é a segregação de sons, que é a capacidade do ouvinte de identificar um determinado som em um ambiente cheio de sons. A segregação é a contrapartida de uma outra propriedade da audição, que é o agrupamento, isto é, a fusão de sons emitidos separadamente como um único som.

\footnotetext{
${ }^{5}$ Traçando o contomo de uma onda, o resultado deverá ser o esboço do envelope do som, normalmente formado por investida, decaída, sustentaçäo e escape (atack, delay, sustain, release) [Bux 90].
} 


\subsubsection{Psicologia Gestalt aplicada à Audição}

A Psicologia Gestalt é o estudo da tendência humana de reconhecer padrões e configurações que aparecem no meio ambiente. Ela propõe que a habilidade de perceber formas é inata e enfatiza que o todo é mais do que a soma de suas partes [Wil 94].

A palavra Gestalt é alemã e significa uma entidade independente que tem contorno ou forma definida. A teoria Gestalt começou seu estudo com características da visão mas seu conceito tem sido estendido e aplicado no estudo de outros sentidos, incluindo a audição. Os princípios fundamentais dessa psicologia são a estabilidade e o "pragnanz", definidos abaixo.

A estabilidade, que também é conhecida como conjunto, afirma que tendo alcançado uma interpretação de uma representação, essa interpretação tende a permanecer fixa com pequenas mudanças de parâmetros da representação. Ou seja, um objeto pode mudar algumas de suas características e ainda assim ser reconhecido como o mesmo objeto.

“Pragnanz", termo introduzido por Wertheimer [Wil 94], é um termo alemão que declara que uma figura tem a tendência de se tornar regular, simétrica, simples, e estável. Assim, seres humanos tendem a coletar evidências para associar elementos de uma cena, ou grupo. Os processos que promovem "pragnanz" têm sido identificados no contexto da percepção, com maiores resultados nas pesquisas da visão e explicação de ilusões visuais. Mas pesquisas psicoacústicas fornecem evidências de que muitos desses processos identificados para a visão também são válidos na audição.

A psicologia Gestalt [Wil 94][Min 95a] afirma que o ser humano forma grupos baseado em vários princípios básicos. Tomando como exemplo o sentido da visão, pode-se dizer que o ser humano, quando olha para uma cena, vê objetos agrupados em um primeiro plano; depois desse primeiro contato, ele consegue observar, e talvez, se necessário, separar melhor cada detalhe da cena. Esse fenômeno não ocorre somente para a visão como também para outros sentidos humanos. Pesquisas psico-acústicas fornecem evidências para a existência de muitos princípios de agrupamento [Wil 94]. Alguns, que serão apresentados abaixo, exemplificam os conceitos 
identificados na visão e em outras pesquisas de Gestalt e os associam com processos de agrupamento de sons.

Como já foi dito antes, a psicologia Gestalt afirma que o ser humano se baseia em alguns princícios básicos para gerar agrupamentos. Alguns desses princípios serão citados e exemplificados a seguir. O princípio da proximidade estabelece que alguns grupos que podem ser percebidos pelos humanos são formados por componentes que se encontram próximos, ou seja, se formam grupos mais facilmente por elementos que estão juntos do que pelos que se encontram separados por uma distância maior. A figura abaixo exemplifica este princípio para o sentido da visão:

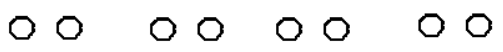

Figura 2.3 - Princípio da proximidade

Como é possível perceber na figura 2.3, as circunferências que se encontram mais próximas tendem a serem agrupadas visualmente, ou seja, quatro duplas de circunferências são formadas visualmente.

Quando se trata da audição, pode-se dizer que existem primitivas de agrupamento sonoro que demonstram esse princípio. Uma delas é a proximidade temporal, isto é, sons que ocorrem em tempos próximos tem a tendência de ser percebidos como relacionados. Por exemplo, se uma pessoa percebe a batida de uma porta e logo em seguida o barulho de um livro caindo no chão, ela pode associar esses dois sons com o mesmo evento, ou seja, ela pode imaginar que uma rajada de vento bateu a porta e derrubou o livro.

A outra primitiva que demonstra o princípio da proximidade é a proximidade de frequência, isto é, sons que possuem entoações próximas podem ser agrupados. O agrupamento por proximidade de frequência é sensível à taxa de apresentação dos tons; quanto maior a diferença entre dois grupos de tons alternados, menor deve ser a taxa de apresentação para evitar a percepção de duas fontes de sons independentes. 
O princípio da proximidade traz alguns problemas à audição se comparada à análise visual. Um deles é que em uma taxa de apresentação rápida, a proximidade temporal aparenta ser inversamente relacionada à proximidade de frequência, ambas calculadas entre dois sons distintos. Um outro problema é que se for discutida a distância relativa em um plano nas seguintes dimensões: frequência, tempo e amplitude, a razão entre suas escalas deve ser estabelecida; contudo, ela pode variar, por exemplo, de acordo com a frequência local. Isso não acontece com a análise visual já que a distância entre um eixo de um gráfico pode ser comparada diretamente com os outros eixos.

Outro princípio Gestalt é o da similaridade ou semelhança, o qual mostra que componentes que apresentam os mesmos atributos podem ser percebidos como agrupados, isto é, componentes de uma cena que possuem aparência similar tendem a formar grupos. Um exemplo desse princípio para a visão é ilustrado na figura 2.4. Pode-se perceber grupos de quadrinhos pretos e grupos de quadrinhos brancos, ou seja, grupos de componentes com atributos semelhantes, formando trilhas.

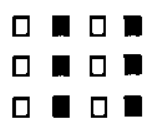

Figura 2.4 - Princípio da similaridade ou semelhança

Para a audição existem alguns conceitos de primitivas de agrupamento sonoro que demonstram o princípio da similaridade. $O$ início comum e o fim comum entre dois sons são dois desses conceitos, ou seja, sons que começam ou terminam ao mesmo tempo podem ser agrupados. Outro conceito que demonstra esse princípio é a frequência comum, isto é, sons com mesma frequência tendem a se agrupar. Também existem a modulação de frequência comum e a modulação de amplitude comum. Pode-se dizer que dois sons com igual modulação de suas frequências ou igual modulação de suas amplitudes são percebidos como relacionados e podem ser agrupados.

Já o princípio da boa continuidade diz que componentes que apresentam transiçōes suaves de um estado para outro podem ser percebidos como relacionados, ou melhor dizendo, no caso da visão elementos que seguem outros em uma determinada direção tendem a serem percebidos 
juntos, como mostra a figura 2.5, na qual percebe-se os pontos em dois caminhos, caminho A e caminho B.

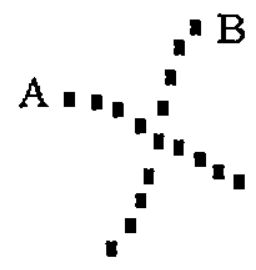

Figura 2.5 - Princípio da boa continuidade.

No caso do sentido auditivo, considere dois sons separados por um som ou silêncio curto. Eles são mais comumente considerados contínuos se a frequência inicial do segundo som coincidir com a última frequência do primeiro som.

Alguns exemplos de primitivas de agrupamento sonoro que demonstram esse princípio serão apresentados a seguir. Proximidade no tempo final de um componente com o inicial do componente seguinte, ou seja, se um primeiro som terminar e logo em seguida um segundo som começar, eles podem ser percebidos como relacionados. Outro conceito é a proximidade de frequências de componentes consecutivos, ou seja, se dois sons consecutivos tiverem frequências próximas eles podem ser percebidos como relacionados. As transições suaves de um estado para outro de um mesmo parâmetro é também um conceito que demonstra o princípio da boa continuidade.

O próximo princípio Gestalt a ser considerado é o da familiaridade. Ele se refere à primeira expectativa sobre agrupamentos sonoros dos quais já se teve uma experiência, ou seja, um som para o qual foi atribuído algum significado específico no passado tende a ter o mesmo significado quando ocorrer novamente.

Como exemplo para esse princípio pode ser citado uma pessoa ouvindo uma música que possui uma melodia muito próxima da melodia de uma outra música já conhecida por essa pessoa. Provavelmente ela vai relacionar a nova música com a primeira música já conhecida, talvez achando que a música que está tocando no momento é aquela que ela já conhecia. Alguns exemplos de conceitos de primitivas de agrupamento sonoro que demonstram o princípio da 
familiaridade são: boa razão harmônica e razão de amplitude inversamente relacionada à razão harmônica.

Outro princípio Gestalt é o da pertinência, que diz que uma componente pode normalmente fazer parte de somente um objeto disjunto ao mesmo tempo e sua percepção é relativa ao resto da figura à qual ele pertence. Como exemplo para o sentido auditivo, a informação de segregação de localização afeta a qualidade de percepção de sons persistentes.

A pertinência causa problemas em exibições auditivas quando a percepção relacionada a um atributo particular de um dado está escondida ou distorcida por seu contexto ou quando itens de dados que devem ser contrastados são atribuídos a diferentes linhas ou objetos. Isto é, quando sons que deveriam ser percebidos separadamente são percebidos como relacionados ou vice versa. Quando o ser humano funde alguns sons, dificilmente ele consegue separá-los, mesmo que inicialmente estes sons tinham sido percebidos separadamente; ou então quando ele os separa é difícil conseguir uní-los mesmo que inicialmente ele os percebece como relacionados.

Existe ainda o princípio Gestalt do destino comum que afirma que componentes que sofrem o mesmo tipo de mudança ao mesmo tempo podem ser percebidos como relacionados. Por exemplo, dois sons que sofrem a mesma mudança nas suas frequências no mesmo momento podem ser percebidos como relacionados.

Alguns exemplos de primitivas de agrupamento sonoro que demonstram este princípio serão mostrados a seguir. Início comum e fim comum entre dois sons são dois exemplos, isto é, sons que começam ou terminam ao mesmo tempo tendem a ser agrupados. Outros dois princípios são a modulação comum de frequência e a modulação comum de amplitude.

Por fim, o princípio Gestalt do encerramento diz que formas incompletas tendem a ser completadas. Esse princípio é tão claro na audição quanto na visão, pois temos uma boa memória auditiva para esse caso específico. Por exemplo, se for tocada parte de uma música já conhecida, ela é facilmente "completada" mentalmente. A tabela 2.1 resume os princípios Gestalt apresentados acima. 


\begin{tabular}{|c|c|c|}
\hline $\begin{array}{c}\text { Princípios da } \\
\text { Gestalt }\end{array}$ & Definição & $\begin{array}{l}\text { Conceitos de primitivas de } \\
\text { agrupamento sonoro }\end{array}$ \\
\hline Similaridade & $\begin{array}{l}\text { Componentes que compartilham os } \\
\text { mesmos atributos podem ser percebidos } \\
\text { como relacionados. }\end{array}$ & $\begin{array}{l}\text { Início comum, fim comum, frequência } \\
\text { comum, modulação comum de } \\
\text { frequência e modulaçāo comum de } \\
\text { amplitude. }\end{array}$ \\
\hline Proximidade & $\begin{array}{l}\text { Componentes que se encontram próximos } \\
\text { de outros podem ser percebidos como } \\
\text { relacionados. }\end{array}$ & $\begin{array}{l}\text { Proximidade temporal e proximidade de } \\
\text { frequência. }\end{array}$ \\
\hline Boa Continuação & $\begin{array}{l}\text { Componentes que apresentam transições } \\
\text { suaves de um estado para outro podem ser } \\
\text { percebidos como relacionados. }\end{array}$ & $\begin{array}{l}\text { Proximidade no tempo final de um } \\
\text { componente com o inicial do } \\
\text { componente seguinte, proximidade de } \\
\text { frequência entre sons consecutivos e } \\
\text { tran sição suave entre um estado e outro } \\
\text { para o mesmo parâmetro. }\end{array}$ \\
\hline Familiaridade & $\begin{array}{l}\text { Componentes que possuem um significado } \\
\text { particular devido à experiência prévia } \\
\text { tendem a ter o mesmo significado quando } \\
\text { apresentados novamente. }\end{array}$ & $\begin{array}{l}\text { Boa razão harmônica e razão de } \\
\text { amplitude inversamente proporcional à } \\
\text { razão harmônica. }\end{array}$ \\
\hline Pertinência & $\begin{array}{l}\text { Um componente pode normalmente } \\
\text { formar parte de um único objeto disjunto } \\
\text { ao mesmo tempo, e a forma com que ele é } \\
\text { percebido está relacionada com o resto da } \\
\text { figura à qual ele pertence. }\end{array}$ & Localização espacial. \\
\hline Destino Comum & $\begin{array}{l}\text { Componentes que sofrem o mesmo tipo de } \\
\text { modificações ao mesmo tempo sāo } \\
\text { percebidos como relacionados. }\end{array}$ & $\begin{array}{l}\text { Início comum, fim comum, modulação } \\
\text { comum de frequência e modulação } \\
\text { comum de amplitude. }\end{array}$ \\
\hline Encerramento & $\begin{array}{l}\text { Formas imcompletas tendem a ser } \\
\text { completadas. }\end{array}$ & Sequências familiares de notas. \\
\hline
\end{tabular}

Tabela 2.1 - Tabela de princípios da psicologia Gestalt, sua definiçăo e seus conceitos de primitivas de agrupamento sonoro. 
Os conceitos acústicos e princípios de percepção apresentados neste Capítulo são fundamentais na escolha de sons e suas propriedades para sonificação. Neste trabalho, o estudo dos conceitos aqui apresentados são úteis no momento de orientar a utilização de propriedades sonoras para representação, bem como sua variação. O poder de representação do projeto sonoro é dependente da manipulação correta dos aspectos perceptivos aqui apresentados. Isso é indicado pela maioria das técnicas e métodos de sonificação desenvolvidos até o momento. Essas técnicas são apresentadas no próximo Capítulo. 


\section{Sonificação}

O som e a habilidade auditiva humana, quando usados em apresentações gráficas, podem resolver, ou pelo menos melhorar, o entendimento da representação de dados problemáticos.

Como já citado anteriormente, o som pode servir como um auxílio em sistemas de visualização, ou seja, pode reforçar as imagens produzidas pelas técnicas visuais. Adicionalmente, o som pode ser um meio de representar dados que não puderam ser representados visualmente no caso de sobrecarga do canal visual e também em casos de dados difíceis de serem representados em duas dimensões.

Esses fatores têm sido reconhecidos pela comunidade científica, e hoje já existem foro de discussões de renome (sound.acm.org) e congressos dedicados ao display auditivo (ICAD International Community for Auditory Display - www.santafe.edu/ icad).

Este Capítulo apresenta uma análise geral de trabalhos prévios que usam sinais sonoros em interfaces computacionais, além de algumas técnicas de sonificação.

A Seção 3.1 do Capítulo em questão apresenta algumas das possíveis contribuições do uso de som na visualização. A Seção 3.2 mostra algumas vantagens e desvantagens do uso do som em sistemas de visualização. Na Seção 3.3 serão mostrados alguns paradigmas usados em exibições sonoras. Na Seção 3.4 serão apresentados alguns trabalhos prévios de som para interface computacional incluindo sistemas já desenvolvidos que usaram som como auxílio ou como complemento para sistemas com saídas gráficas. 


\subsection{Contribuições do Uso do Som na Visualização}

Uma contribuição do uso de som em sistemas de visualização é a representação dos dados. O som pode complementar as apresentações visuais, ou seja, adicionar algumas dimensões, como pode também suplementar estas apresentações, isto é, promover redundância.

Deve-se reconhecer que apresentações gráficas nem sempre são a melhor maneira de representar alguns tipos de informações científicas. Para esses tipos de informações, representação por som pode ser uma boa ferramenta para o usuário obter maior entendimento de seus dados. Dados lineares ou quadráticos com característica temporal e tarefas de comparação de valores escalares caem nessa categoria.

Ainda pode-se citar que, até hoje, só se conseguiu representar dados visualmente até uma determinada dimensão, limitada pela dimensão da tela do computador. A representação sonora pode ajudar aumentando esse limite.

Além disso, a representação sonora pode ajudar na validação dos dados gráficos. Em muitos casos, é difícil saber se os dados representados graficamente estão corretos. O mapeamento sonoro desses dados ou das entidades gráficas formadas por eles pode confirmar ou questionar o resultado obtido na representação gráfica.

Podem ser citados também os resultados perceptivos. A audição tem propriedades diferentes da visão, o que pode auxiliar a identificar padrões e estruturas não observados na imagem. Nas apresentações complementares (onde o som complementa a visualização) a visão e o som devem ser combinados, e nas apresentações suplementares (onde o som dá redundância à visualização) os dados que sobrecarregam o canal visual podem ser representados duplamente por som.

A adição da dimensão tempo é outra contribuição do som em visualização. $O$ tempo pode ser naturalmente representado por mapeamentos sonoros. Quando o tempo é representado por som, enquanto uma variável é apresentada, o usuário tem noção da progressão daquela variável no tempo. Isso ocorre porque o som tem natureza temporal. 
Existem, portanto, várias possibilidades do uso de som em sistemas computacionais, tanto quando usado como um elemento aditivo ao sistema ou como um elemento auxiliar à visão. Apesar disso, existem problemas que podem surgir por causa das limitações de nossa capacidade auditiva. Algumas das vantagens e desvantagens do uso de som em sistemas computacionais serão apresentados a seguir.

\subsection{Vantagens e Desvantagens do Uso do Som}

\section{Beneficios Gerais de Exibições Sonoras}

A capacidade de orientação de sinais sonoros é uma vantagem do uso do som em sistemas computacionais pois, como disse Wenzel [Kra 94c], o ouvido diz aos olhos para onde olhar. Orientação também ocorre, de uma maneira diferente, em tarefas de exploração de dados. Uma sonificação pode indicar uma área de interesse que o analista pode explorar por outros significados, como por exemplo em análise estatística.

A liberdade de visão (eyes-free) é muito importante nos casos em que o operador do sistema tem que manter contato visual com outros elementos do meio onde a visão pode ser prejudicada ou obstruída [Kra 94c] [Ast 92].

O papel de alarme de displays sonoros também é uma vantagem do uso do som [Reu 90] [Ast 92] [Min 95a]. Sinais acústicos são 6timos para alertar usuários para algum evento importante do sistema porque o usuário não precisa estar olhando para uma determinada direção para ouvir um alarme, porque a detecção da fonte é rápida, e porque os alarmes orientam esses usuários.

Como foi dito acima, a rápida detecção faz com que sinais sonoros assumam um importante papel nas interfaces. Pesquisas mostram que sinais acústicos tem melhor tempo de resposta que sinais visuais, portanto o homem pode perceber o som com maior rapidez do que ele consegue captar imagens [Kra 94c].

A grande afetividade do ser humano com o som permite que ele aprenda e grave mais facilmente usando sinais sonoros e também dá a ele maior facilidade de converter informações qualitativas e 
sutís [Kra 93]. O uso de trilhas sonoras em softwares computacionais, jogos e outros aplicatimos têm as mesmas vantagens que as trilhas sonoras dos filmes [Kra 94c]. Medo, expectativa, calma, humor e outras emoções podem ser sugeridas acusticamente.

A habilidade do homem de escutar paralelamente, ou seja, vários sons simultaneamente, permite que o usuário de sistemas que empregam o som como ferramenta de monitoração assista múltiplos processos ao mesmo tempo. Essa habilidade permite ao sistema representar por som conjuntos de dados multi-dimensionais.

Além dessas vantagens gerais de exibições sonoras, existem outras, como grande habilidade de detecção e memória. O homem está acostumado a esperar som na grande maioria das situações do seu dia a dia, e portanto aceita o som, naturalmente, como solução desde que não conflite com os demais estímulos ou com o contexto.

\section{Beneficios do Som em Relação a Outros Sentidos}

Uma vantagem do som em conjunto com o sentido da visão é que ele funciona também como auxílio para o canal visual [Ast 92] [Min 95a]. Caso o canal visual esteja carregado, o som é uma altemativa que pode ser usada para ajudar a descongestioná-lo. Nesse caso, o sentido da visão é o "guia" do processo, uma vez que é mais potente.

\section{Desvantagens do Uso do Som}

Algumas dificuldades também são encontradas na utilização do som em sistemas computacionais. Uma delas é que não há padrões para permitir que sistemas sonoros funcionem em plataformas diferentes [Reu 90] [Sca 91] [Min 95a] [Mad 95]. Além disso, usuários geralmente são inseguros e defensivos sobre suas capacidades de percepção sonora. Essa incerteza irá limitar a confiança e aceitação de displays sonoros. Entretanto nota-se que a resistência diminui à medida que o usuário se acostuma com som como ferramenta.

Em exibições de informações quantitativas, a baixa resolução com a qual o usuário percebe muitas variáveis sonoras também é um problema para sistemas que usam som para representar 
essas informações [Reu 90] [Kra 94c]. Algumas variáveis não dão a resolução necessária para determinadas tarefas. Por exemplo, uma sonificação que usa agudeza (brightness) para representar um dado variável pode representar apenas um número limitado de valores.

A falta de valores absolutos é uma dificuldade encontrada na representação de sons. Por exemplo, na representação da entoação de um som muitas vezes só é possível reconhecer se esta entoação é alta ou baixa, ou "mais alta" ou "mais baixa" com relação à entoação de um segundo som, mas não é possível reconhecer exatamente qual valor ela representa. Compare esse exemplo com um gráfico bidimensional simples. Nesse caso, os valores dos eixos em qualquer ponto é facilmente reconhecido.

A falta de ortogonalidade entre parâmetros sonoros que contribui para os problemas de precisão. Muitos os parâmetros sonoros não são perceptualmente independentes o que implica que a mudança de uma determinado parâmetro pode interferir na percepção dos valores de um outro parâmetro sonoro.

Outro problema que pode ocorrer quando o som é usado em sistemas computacionais é a interferência com a comunicação falada. Isso muitas vezes pode criar uma certa resistência às exibições sonoras e limitar seu uso em determinadas aplicações.

O fato de exibições sonoras não produzirem saídas de impressão é outro problema do uso do som. A distribuição dos resultados se torna difícil, embora se observe hoje uma padronização maior, especialmente em aplicações multimídia em redes.

A precisão espacial do som é limitada. Esse é um caso de baixa resolução dos sistemas auditivos e faz com que representações volumétricas sejam pobremente representadas unicamente por som. O som 3D auxilia a sensação de espaço, mas não permite uma localização precisa da fonte do som.

A sobrecarga perceptual é um problema que necessita ser equilibrado. Ao mesmo tempo que é viável usar visão e audição juntas para aumento de desempenho, elas também podem cansar mais 
rápido quando utilizadas simultaneamente. Isso deve ser controlado por períodos de silêncio e pela opção de usuário de silenciar a apresentação sọnora.

\subsection{Paradigmas de Exibições Sonoras}

Esta Seção identifica aspectos em som e percepção sonora que podem ser usados para ajudar a converter informação em som, especialmente em aplicações gráficas. Vários paradigmas serão mostrados aqui, muitos dos quais estão relacionados com linguagem, como exclamação, semelhança, metáfora, deixis e onomatopéia. São paradigmas linguísticos que se adaptam bem a exibições sonoras.

Outros paradigmas aqui apresentados, como cenas sonoras, frames de referência, frames de referência multi-modo, e mensagens indesejadas, estão relacionados com composição musical e percepção. Um relacionamento próximo entre composição e exibições sonoras pode ser encontrado em estruturas para produção sonora e articulação de combinação sonora [Bar 94]. Muitos paradigmas de exibição usados em composição musical são também usados nas exibições sonoras de alguns sistemas.

\section{Exclamação}

Sabe-se que uma função frequente do som é chamar a atenção para algum objeto ou evento especial. Portanto, pode-se dizer que o som serve como uma exclamação e consegue cumprir muito bem esse papel. No entanto, deve-se ter cuidado quando existe um grande número de mensagens exclamatórias. Elas podem apenas causar um grande barulho, sem significar nada exatamente, atrapalhando a solução do problema.

Para se produzir um efeito de exclamação em um som devem ser mudados alguns parâmetros desse som como, por exemplo, pulso e ritmo. No caso de mudança de pulso, se o intervalo entre os pulsos for espaçado e continuado, e mudar para intervalos mais curtos, ele é percebido como se algum evento urgente estivesse acontecendo. 
Embora se tenha pouco entendimento da razão pela qual a mudança desses parâmetros muda a percepção de urgência, isso fornece um método de desenvolver vários níveis de urgência em alertas sonoros.

\section{Semelhança e Metáfora}

Semelhança e Metáfora são a essência da sonificação [Bal 94]. Quando sons estão sendo usados como semelhantes, uma propriedade ou parâmetro do som se torna parecido a alguma propriedade ou parâmetro em outro domímio. A interpretação do som é definida por algo equivalente em legendas num gráfico. Neste caso, a legenda age como o advérbio "parecido" em uma semelhança linguística.

Metáfora é uma extensão da semelhança para um relacionamento identificado. Mais do que dizer que uma coisa é parecida com a outra, a metáfora afirma que uma coisa é a outra. O resultado é um acoplamento justo entre o som e a interpretação pretendida. Muitos sinais sonoros, como sirenes, telefone e campainhas devem ser considerados metáforas, e na maioria das vezes eles são identificados mais rapidamente do que se a palavra equivalente for pronunciada.

\section{Deixis}

Pode-se dizer que o "beep" do computador é equivalente a palavra "este" falada por uma pessoa com a intenção de identificar um determinado objeto que está localizado perto dela.

É importante lembrar que esse paradigma deve levar em consideração a informação contextual; sem ela não é possível entender o som produzido. Devem ser levados em conta a posição do ouvinte e o evento ou objeto referenciado. Por exemplo, uma sala com vários computadores pode confundir o ouvinte, ou seja, talvez ele não saiba de qual dos computadores da sala veio o "beep". Além disso, mesmo se ele tiver esta informação, ele ainda não tem contexto suficiente para entender a mensagem. Pode ser que o ouvinte não saiba a qual evento ou objeto o "beep" está relacionado. 
Não se pode esquecer que existe um número limitado de "beeps" que podem ser usados em um sistema, pois todos eles devem ser de conhecimento do usuário, sendo necessário levar em conta o tempo de aprendizagem do significado dos "beeps". Em um sistema com muitos "beeps" podem ocorrer erros de interpretação.

\section{Onomatopéia}

Na linguística, onomatopéia é a palavra cuja pronúncia imita o som natural do objeto que ela representa. Em casos de sistemas de sonificação, a função desse tipo de som é indicar eventos imitando os sons reais desses eventos no ambiente.

Uma das vantagens desse tipo de som é o reconhecimento rápido do evento sem a necessidade de treinamento extensivo. Entretanto isso não ocorre com todos os sons do dia-a-dia. Existe uma variedade de fatores envolvidos na interpretação desse tipo de som, incluindo propriedades acústicas, interpretações perceptivas e expectativas cognitivas. [Bal 94]. Dois tipos de expectativas cognitivas estão envolvidas: expectativa sobre a causa usual associada com o som (refere-se ao grau de incerteza causal do som), e expectativa sobre o som típico associado com a causa (refere-se ao conceito mental que as pessoas tem de um som).

A identificação de um som também está relacionada com a tipicidade desse som. Sons típicos são mais facilmente identificados do que sons não típicos. Um exemplo de som típico é o som produzido pelo toque de um telefone. Algumas pessoas podem associar esse som com algum outro evento, mas a grande maioria o associa como o som de um telefone tocando.

\section{Cenas Sonoras}

As cenas sonoras descrevem o que se escuta em um ambiente específico. Por exemplo, em uma sala com um ventilador ligado e várias pessoas conversando geralmente pode-se reconhecer o barulho feito pelo ventilador, além das vozes das pessoas. Talvez seja possível até dizer quantas pessoas estão conversando. Mas também existem sons que não se consegue reconhecer. $O$ ambiente citado no exemplo acima é uma cena sonora típica, onde vários sons compartilham um ambiente e alguns podem ser distinguidos, enquanto outros não. 
O conceito de cenas sonoras está ligado à percepção de objetos tri-dimensionais e à localização espacial. Jogos computacionais representam um exemplo típico do uso de cenas sonoras pois empregam sons específicos para movimentos, parecidos com aqueles produzidos na realidade.

A capacidade do usuário de interpretar eventos computacionais usando sons ainda é pouco explorada. A maioria das aplicações usam apenas recursos visuais, em silêncio; quando há som, as mensagens sonoras são eventuais, de curta duração. Esse tipo de meio ambiente descreve um usuário com poucas expectativas para eventos sonoros, sem capacidade de acompanhar transformações sonoras, e com pouca habilidade de atribuir significados às mudanças nos sons. Quando são incluídos eventos sonoros nas aplicações, esses usuários podem ter dificuldades para reconhecê-Ios. Nesse contexto, um certo grau de treinamento é necessário. O hábito permite a introdução de cenas sonoras mais complexas.

\section{Frames de Referência}

Os frames de referência são símbolos usados para medir um ou mais símbolos. O contexto de identificação é hierárquico, ou seja, percepções são referenciadas a símbolos, que por sua vez são referenciados a uma classe superior de símbolos predominantes. Tomando como exemplo a música, existem os sons de referência que são associados a uma camada de fundo, essa camada geralmente muda menos que a música do primeiro plano, e portanto seus sons referenciam vários sons da música do primeiro plano.

Na música, um som que é mais ouvido, ou então mais fácil de ser lembrado numa coleção de sons pode ser tornar um frame de referência para essa coleção de sons. Quando frames de referência são criados ou alterados, deve ser criado um guia para auxiliar o ouvinte a reconhecer os novos símbolos.

Geralmente esses frames devem constituir de símbolos conhecidos pelos ouvintes, como um som que que é relacionado a algum significado específico para o ouvinte ou um som ritimado. 


\section{Frames de Referência Multi-Modo}

Em interfaces computacionais existem três frames de referência que prevalecem sobre as informações sonoras: imagem, texto e ações do usuário [Bar 94]. As exibições sonoras podem acomodar essa situação fazendo referências explícitas a eles como, por exemplo, indicando que a referência sonora está representando a mesma informação que um determinado gráfico. $\mathrm{O}$ uso em conjunto de imagem e som fornece correlações que podem diminuir o aparecimento de mensagens indesejadas.

Para que esses frames de referência multi-modo sejam correlacionados é preciso que seja especificado um relacionamento entre os raios de exibição, ou seja, é preciso que os frames representem os mesmos dados, ou dados relacionados, e que estejam sincronizados.

\section{Mensagens Indesejadas}

Mensagens indesejadas são aquelas mensagens sonoras que têm um significado específico, mas que o ouvinte não compreende corretamente, isto é, o usuário percebe um som emitido pelo sistema com um significado diferente do que o sistema está querendo mostrar, às vezes causado por familiaridade não prevista pelo sistema.

Essas mensagens indesejadas podem também vir do agrupamento de sons que não deveriam ser agrupados, ou seja, de vários sons que deveriam ser percebidos como separados e que foram percebidos como um único som. Esse problema pode ser abordado mostrando os mesmos dados de maneiras diferentes como, por exemplo, por som e por gráfico, ou permitindo ao usuário que mude alguns parâmetros usados na exibição sonora, ou ainda produzindo "reforços de percepção" quando mais de um som é apresentado ao mesmo tempo.

\section{Fidelidade e Ambiguidade}

Fidelidade é o correto mapeamento de dados em um sistema. Quando sons podem ser mapeados e reproduzidos com alta fidelidade, a diferenciação de sons similares podem ser usada com confiança por representações complexas. Quando sons são reproduzidos com baixa fidelidade, a tarefa do ouvinte muda de diferenciação para categorização. Sons com baixa resolução podem ser 
usados quando somente tarefas de reconhecimento são necessárias, como, por exemplo, em uma classe de alarmes.

Um sistema pode ter alta fidelidade e ainda assim pode ocorrer ambiguidade. Ambiguidade ocorre quando sons exibidos simultaneamente se confundem. Por exemplo, dados que devem ser mostrados simultaneamente, quando mapeados apresentam seus timbres tão próximos que o ouvinte não consegue distinguí-los.

A seguir serão apresentados alguns trabalhos prévios de sonificação. A maioria dos trabalhos com uso de som desenvolvidos para representação e interpretação está relacionada com dados multivariados [Min 95c]. Vários sistemas de sonificação já desenvolvidos usaram alguns dos paradigmas citados acima.

\subsection{Trabalhos Prévios de Som como Ferramenta para Aplicações Computacionais}

O uso de som em sistemas computacionais tem atraído um grande número de pesquisadores nos últimos anos. Nota-se um crescimento no número de pesquisas e sistemas nessa área. Várias delas mostram que a adição de sons não falados em interfaces computacionais podem melhorar a performance e aumentar a sua usabilidade [Bre 96]. O caminho para o atual estado da pesquisa em sonificação foi gradual, passando de sistemas dedicados a aplicações específicas, e de apoio a usuários com deficiências visuais, para sistemas de propósito geral com o objetivo de interpretação de dados.

Uma das técnicas que faz uso de som em interfaces computacionais é o Auditory Icons [Gav 94]. Eles são sons do dia-a-dia que transmitem informações sobre eventos no computador ou no meio ambiente de uma aplicação específica, fazendo analogia com os eventos que produzem esses sons no dia-a-dia, ou seja, auditory icons são o mapeamento de eventos em um meio ambiente computacional. Por exemplo, a chegada de um e-mail seria representada pelo ruído de uma caixa de correio. 
Essa técnica é similar a ícones visuais e é aprendida tão facilmente quanto eles. Os Auditory icons refletem categorias de eventos e objetos como fazem os ícones visuais. Eles podem ser parametrizados para refletir suas dimensões relevantes. Por exemplo, ao acessar um arquivo longo, o som produzido também será longo para que essa informação seja refletida.

Extensões do uso de auditory icons para sistemas multi-processamento e multi-usuário também foram efetuadas [Gav 91]. Nesses casos a informação que pode ser mapeada para som identifica o estado do processo que chega e a finalização de atividades, além de outras informações de carga de processos.

Outra técnica que também faz uso de som no contexto de interfaces é o Earcons [Bla 89]. Earcons, da mesma forma que auditory icons, são entidades sonoras que servem para representar eventos computacionais. Nessa técnica, entretanto, são usados sons musicais para representar as informaçōes desejadas. Earcons são constituidos de motifs, que são sequências curtas de notas com um ritmo e entoação específicos, às quais podem ser associados timbre, dinâmica e registro [Sum 86].

Earcons podem ser derivados usando três tipos de operações: combinação, que liga motifs em uma sequência de cadeias iguais; transformação, que altera um motif mudando seu timbre, registro e velocidade para indicar mudança em um objeto; e herança, que foi adicionada pela geração de motifs relacionados, com propriedades diferentes sendo 'herdadas' em níveis diferentes.

$\mathrm{O}$ uso de auditory icons tem se mostrado mais efetivo que o uso do Earcons pelo fato da primeira técnica fazer uso de sons do dia-a-dia [Min 95a]. Os usuários encontram maior facilidade de reconhecimento de sons que ocorrem no seu dia-a-dia do que de sons musicais. Entretanto, os earcons também têm apresentado um resultado razoavelmente eficiente e em geral é mais agradável para os ouvidos.

Um dos trabalhos pioneiros que faz uso de som como forma de representação foi realizado por Yeung [Yeu 80]. Ele descreveu uma apresentação auditiva multidimensional para dados em química analítica. $\mathrm{O}$ objetivo era fazer os estudantes identificarem a qual de quatro conjuntos um 
vetor de seis dimensões pertencia. As dimensões correspondiam à detecção da presença de diferentes metais em cada amostra. Os parâmetros usados foram: frequência, intensidade, direção (direita/esquerda), duração/repetição, entre outros. Mesmo sem outras exibições para comparar os resultados, o acerto da classificação chegou a noventa e oito por cento depois de duas seções de treinamento.

Mezrich e outros [Mez 84] apresentaram um trabalho em sonificação, usado juntamente com uma apresentação gráfica animada simples, para dados multivariados em séries de tempo. Os dados eram apresentados graficamente na tela por linhas horizontais, com uma cor de linha para cada dado apresentado. A evolução das variáveis eram representadas dinamicamente por frames da tela onde cada linha mudava de posição e tamanho de acordo com as mudanças dos dados correspondentes. Os mesmos dados eram gerados em uma apresentação auditiva, onde cada variável era representada por uma melodia diferente. O número de variáveis exibidas simultaneamente era controlado pelo usuário. A animação de som e gráfico ajudoư a reconhecer padrões e suas repetições.

Outro trabalho pioneiro em sonificação é o de Bly [Bly 82]. Ela também trabalhou com mapeamento sonoro de dados multivariados. Pontos de dados de várias dimensões (acima de sete) foram mapeados em parâmetros sonoros de maneira significativa. Um dos estudos realizados foi a habilidade de identificação dos pontos como pertencentes a um ou outro conjunto. A maioria dos ouvintes foi capaz de identificar a classificação dos pontos com um bom índice de acerto.

Smith e outros [Smi 94] apresentaram uma técnica para sonificação de uma iconografia previamente implementada para apresentação de dados multi-paramétricos. A iconografia em questão mapeia parâmetros multivariados em uma representação geométrica bidimensional. Pela percepção de formas se consegue entender valores individuais e pela percepção de textura se percebe tendências e padrões dos dados. Esse modelo foi "sonificado" e o usuário pode controlar os principais parâmetros do som para representar seus ícones. O som é baseado em timbres préprogramados. Algumas dimensões são mapeadas para som, e as demais para ícones de formatos variantes, também chamados glyphs. 
Outra técnica desenvolvida é a integração de som em animações científicas desenvolvida por Evans [Eva 87, 89, 90]. A técnica gera mapeamento sonoro e mapeamento de cores usando o mesmo algoritmo. O mapeamento sonoro deve ser melhor elaborado para que se tenha coerência musical, mas o objetivo era encontrar uma representação única para aspectos gráficos e musicais de uma animação (congruência de algoritmo). Os estudos mapeavam dados matemáticos (processos fractais) para entoação e ritmo.

Blattner e outros [Bla 92b] forneceram uma aplicação de som para representar aspectos de fluxo de fluidos, uma das áreas de liderança em visualização científica [Gal 95]. Eles trabalharam com tipos de som e possíveis atributos do som a serem usados na representação de turbulência em fluidos. No trabalho realizado são dadas sugestões de sonificação para vários aspectos de fluidos como caracterização do fluido, movimento do fluido e dissipação de energia. Por exemplo, registro é usado para representar viscosidade do material, timbre para representar temperatura, tempo para representar velocidade de injeção, e outros. Embora nenhuma estrutura de implementação tenha sido proposta, o trabalho é valioso por identificar a associação natural feita pelo ouvinte com propriedades do som em audição musical de fenômenos análogos aos da dinâmica de fluidos.

McCabe e Rangwalla [McC 94] também apresentaram um mapeamento de som para dados de dinâmica de fluidos computacional. Um caso estudado, utilizando essa técnica, foi o mapeamento da funcionalidade de uma bomba cardíaca, e a utilidade da apresentação sonora foi confirmada para esse caso. Eles identificaram quatro categorias para mapear esse tipo de aplicação:

1 - simulação direta, onde os dados são traduzidos para o som;

2 - reação à realidade virtual, para facilitar a sensação de presença para o usuário;

3 - anotações de cenas e animações, para acompanhamento de apresentação das imagens;

4 - validação, para confirmar que os cálculos do processo gráfico estão corretos. 
Bargar [Bar 92] apresentou vários esforços em relacionar som a aplicações de imagens. Ele incluiu som para vídeo-produção e exibições em tempo real. No segundo caso, foi mencionado um sistema para apresentação de funções e topologias matemáticas acompanhadas de som.

Foi desenvolvido também o Magic Mikes, um método para sonificação espacial [Gro 95] que apresentou a idéia dos microfones virtuais, os quais podem ser usados para sonificar dados espaciais. Esse é um método em três estágios, como mostra a figura 3.1, e serve para sonificar conjuntos de dados espacialmente localizados para que pontos ou grandes áreas possam ser exploradas. O primeiro dos três passos é delimitar a região de interesse no conjunto de dados. $O$ segundo passo é mapear o valor escolhido para parâmetros de som nas localizações correspondentes (gravados como sondas visuais). No terceiro e último passo, o som é "espacializado", de acordo com a distância e localização da fonte relativa às sondas. Espacialização significa adicionar acústica para sensação de direção e distância. Com os microfones virtuais é possível rastrear um conjunto de dados efetivamente, obter uma visão geral do conjunto, além de detectar pontos de interesse.

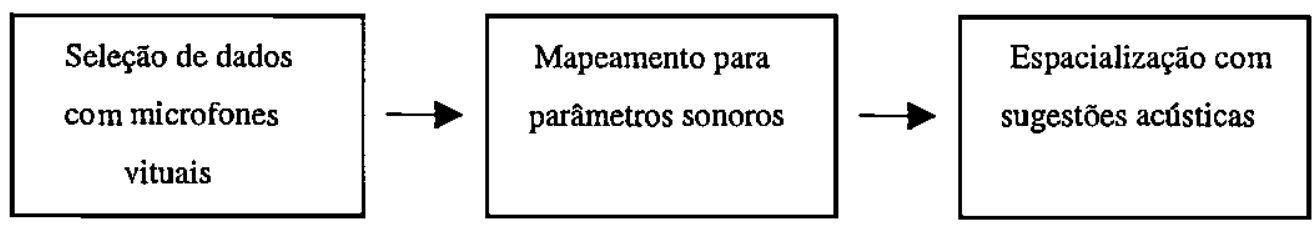

Figura 3.1 - Estágios da sonificação espacial [Gro 95].

Testes realizados com o Magic Mikes indicaram que em um ambiente com poucos dados pode ser fácil a localização de fontes sonoras usando apenas uma espacialização simples. Também se concluiu que o método é mais apropriado para conjunto de dados com extremidades bem definidas para cada canal.

Scaletti [Sca 91] também usou som para extrair significado de dados complexos. O objetivo inicial era adicionar som a vídeos de visualização científica gerado em NCSA (National Center for Supercomputer Applications). Ela desenvolveu protótipos para várias ferramentas de sonificação de alto-nível que podem ser aplicadas a uma grande variedade de dados. $\mathrm{Na}$ ferramenta protótipo foram incluídos o mapeador, que mapeia dados para vários parâmetros sonoros; o comparador, que faz o mapeamento diferente para cada canal; o histograma sonoro, 
que mapeia a magnitude de cada categoria na amplitude do som; o shifter, que muda sinais para intervalos audíveis; e o marcador, que é um alarme sonoro que marca uma condição específica. Para desenvolver o conjunto de ferramentas foi usado uma linguagem sonora chamada Kyma desenvolvida pela Symbolic Sound Corporation. Essa ferramenta foi testada na geração de trilhas sonoras de dados para animações geradas por esses mesmos dados. O resultado forneceu um crescimento do senso de realidade virtual do usuário.

Outro trabalho foi desenvolvido por Kramer e Ellison no Instituto Santa Fe [Kra 91]. Eles usaram o conceito de parâmetros aninhados para aumentar o número de dimensð̋es das apresentações. Parâmetros aninhados é o uso simultâneo de variáveis sonoras básicas em diferentes escalas de tempo. Trabalhando com cientistas do Instituto Santa Fé, onde se estuda a "Ciência da Complexidade", a sonificação foi aplicada a um conjunto de nove equações de Lorenz. Foi aplicada a sonificação nessas equações para auxiliar a investigação de fenômenos caóticos, que são frequentemente representados por elas. As equações foram mapeadas para alguns parâmetros sonoros (velocidade, tempo de ataque, duração, entoação, amplitude) e depois mostradas em gráficos. Como os gráficos usualmente apresentados nessa applicação são considerados complexos, a nova ferramenta incluída como auxílio é bem vinda para analisá-los.

Wilson e Lodha [Wil 96] desenvolveram o Listen, um toolkit para sonificação de dados. O objetivo primordial no desenvolvimento do Listen foi fomecer um sistema que fosse barato, flexível, interativo, adaptável e portátil, além de ser um toolkit que pode mapear qualquer tipo de dado. O sistema em questão usou no seu desenvolvimento um sintetizador Yamaha PSR-320 que foi conectado via MIDI. Foi implementado em uma plataforma Silicon Graphics, e é um sistema modular. Listen é formado por quatro programas básicos: Listen1 que aceita argumentos em linhas de comando e usa o chip de audio interno da máquina; Listen2, que usa o chip de audio interno e tem uma interface gráfica com o usuário que permite mapeamentos mais complexos que o Listen1. O artigo alega que esses dois módulos permitem que o usuário comece a realizar sonificações com um mínimo de dificuldades. Listen 3 usa um dispositivo MIDI e tem uma interface gráfica; e o Listen 4 que é uma versão módulo de Listen 3 e é designada para ser incorporada a programas de visualização já existentes. Como uma unidade, esses módulos fornecem um ponto de partida estruturado para experimentos com sonificação. Esse sistema foi 
incorporado pelos autores em um sistema para visualização geométrica para superfícies interpolantes e um sistema para visualização de algoritmos de fluxo de fluidos.

Axen e Choi [Axe 96] pesquisaram a descoberta de novos métodos para visualizar estruturas grandes e multi-dimensionais, dados que são difíceis ou impossíveis de 'renderizar' com métodos padrões. Primeiramente, pesquisaram a representação da estrutura topológica ou a conectividade dos dados. Alguns detalhes da geometria foram mapeados sonoramente. Ou seja, eles usaram a composição de mapas para produzir um som para os dados.

Martins, Rangayyan, Portela, Amaro e Ruschione [Mar 96] apresentaram um novo método para exibições sonoras e sonificação de texturas, em particular para Imagens de Ressonância Magnética (MRD), como adjunto a exames visuais da imagem. Foram considerados dois modelos para texturas: textura ordenada, ou textura periódica, onde elementos básicos da textura são repetidos no campo da imagem, e textura randômica, onde não existe uma ordem. $O$ procedimento de sonificação consiste em mapear projeções de pequenos ângulos da imagem para sinais auditivos e apresentá-los em sequência.

Barrass [Bar 96] apresentou o TaDa, método para apresentação de informação sonora. O método TaDa integra análise de tarefas, uma base de dados de exemplos sonoros, um método de auxílio baseado em regras e ferramentas de som interativo. $\mathrm{O}$ TaDa segue a seguinte sequência: primeiro realiza-se a descrição de um cenário, que é um breve histórico sobre as informações a serem processadas, depois realiza-se uma análise das tarefas necessárias para o processamento das informações, posteriormente é escolhido o método de representação das informações e por último é feita a utilização dos métodos sonoros necessários. Esse método foi demonstrado em cenários de exploração de minas, planejamento de recursos e climatologia.

Brewster [Bre 96] apresentou um conjunto de ferramentas de som para eventos em interfaces. Os sons não falados utilizados nesse conjunto de ferramentas foi baseado nos Earcons [Bla 89] já citados neste Capítulo. Cada elemento da interface, como botões, barras de ferramentas e ícones, pertence a uma classe (exemplo: classe dos botões, classe dos ícones, etc.) a eles são atribuídos sons específicos. Cada aplicação presente na área de trabalho da interface possui seu próprio timbre e localização espacial. Todos os elementos pertencentes à aplicação herdarão o timbre e 
localização espacial dela, modificando apenas ritmo, entoação ou outra propriedade do som, dependendo da classe a que cada elemento pertence. Por exemplo, quando uma barra de ferramentas em uma determinada aplicação é acessada, o som produzido terá timbre e localização espacial caracterizados pela aplicação, e ritmo e entoação padrões do elemento 'barra de ferramentas'.

Finalmente, Minghim e Forrest [Min 95c] projetaram e implementaram um sistema de som para dados de superfície, chamado SSound. O SSound [Min 95a] implementa um número de funções sonoras para suportar apresentação e análise de dados para visualização baseada em superfície. Esse sistema é a base para o trabalho em questão e será melhor detalhado no próximo Capítulo.

A tabela 3.1 apresenta um resumo dos principais trabalhos citados neste Capítulo.

\begin{tabular}{|c|c|c|}
\hline Trabalho & Propriedades & Comentário \\
\hline Earcons & $\begin{array}{l}\text { Entoação, sequência de } \\
\text { entoações, ritmo, timbre, } \\
\text { volume, registro. }\end{array}$ & $\begin{array}{l}\text { Motivos podem ser associados com estruturas de } \\
\text { linguagem definindo uma linguagem universal, } \\
\text { independentes de idiomas. }\end{array}$ \\
\hline $\begin{array}{l}\text { Yeung [Yeu 80] } \\
\text { Dados Químicos }\end{array}$ & $\begin{array}{l}\text { Frequência, intensidade, } \\
\text { direção, Duração/Repeti- } \\
\text { ção. }\end{array}$ & $\begin{array}{l}\text { Boa hierarquia de propriedades sonoras para tarefas de } \\
\text { classificação. }\end{array}$ \\
\hline $\begin{array}{l}\text { Bly [Bly 82] } \\
\text { Dados multivariados }\end{array}$ & $\begin{array}{l}\text { Frequência, intensidade, } \\
\text { duração, forma de onda } \\
\text { fundamental, investida } \\
\text { (envelope), quinta har- } \\
\text { mônica, nona harmônica. }\end{array}$ & $\begin{array}{l}\text { Os efeitos mais significantes para discriminação são } \\
\text { dados pelo timbre. Resolução do som não é boa. Som } \\
\text { estéreo apresenta uma boa ferramenta para codificar } \\
\text { informação. }\end{array}$ \\
\hline $\begin{array}{l}\text { Mezrich e outros } \\
\text { [Mez 84] } \\
\text { Dados multivariados } \\
\text { em séries de tempo }\end{array}$ & Notas, melodia & $\begin{array}{l}\text { Mapeamento melódico promove identificação de } \\
\text { sequências similares de notas, para representar sequências } \\
\text { similares de dados. }\end{array}$ \\
\hline $\begin{array}{l}\text { Evans }\left[\begin{array}{lll}\text { Eva } & 87 & 89 \\
90\end{array}\right]\end{array}$ & Entoação, ritmo. & $\begin{array}{l}\text { Para criar expressões corretas sintaticamente, ritmos } \\
\text { periódicos devem ser usados com entoações consonantes }\end{array}$ \\
\hline
\end{tabular}




\begin{tabular}{|c|c|c|}
\hline $\begin{array}{l}\text { Fractais, algoritmos } \\
\text { congruentes }\end{array}$ & & e ritmos aperibdicos com domínio de entoação atonal. \\
\hline $\begin{array}{l}\text { Gaver [Gav 91] } \\
\text { Auditory Icons }\end{array}$ & Sons do dia a dia. & $\begin{array}{l}\text { Para a percepção de eventos, sons do dia a dia apresentam } \\
\text { uma solução intuitiva para expressar resultados. }\end{array}$ \\
\hline $\begin{array}{l}\text { Scaletti [Sca 91] } \\
\text { Dados complexos }\end{array}$ & $\begin{array}{l}\text { Frequência, canal } \\
\text { estéreo, timbre }\end{array}$ & \\
\hline $\begin{array}{l}\text { Kramer [Kra 91] } \\
\text { Parâmetros } \\
\text { aninhados }\end{array}$ & $\begin{array}{l}\text { Frequência, amplitude, } \\
\text { velocidade, tempo de } \\
\text { investida, duração, } \\
\text { entoação. }\end{array}$ & $\begin{array}{l}\text { Usa o conceito de parâmetros aninhados para aumentar o } \\
\text { número de dimensões das apresentações. }\end{array}$ \\
\hline $\begin{array}{l}\text { Smith e outros [Smi } \\
\text { 94] } \\
\text { Glyphs }\end{array}$ & Timbre, campo estéreo. & \\
\hline $\begin{array}{l}\text { Mc Cabe } \\
\text { Rangwalla [McC 94] } \\
\text { Dados dinâmicos de } \\
\text { fluidos computacio- } \\
\text { nais }\end{array}$ & $\begin{array}{l}\text { Frequência, ritmo, } \\
\text { amostra direta. }\end{array}$ & \\
\hline $\begin{array}{l}\text { Grohn [Gro 95] } \\
\text { Magic Mikes }\end{array}$ & $\begin{array}{l}\text { Timbre, entoação, } \\
\text { volume do som, duração. }\end{array}$ & $\begin{array}{l}\text { Usa três estágios para sonificar conjuntos de dados } \\
\text { espacialmente: delimitar a região, mapear os valores e } \\
\text { espacializar o som. Apresentou a idéia de microfones } \\
\text { virtuais. }\end{array}$ \\
\hline $\begin{array}{l}\text { Wilson [Wil 96] } \\
\text { Listen }\end{array}$ & $\begin{array}{l}\text { Entoação, duração, } \\
\text { volume e localização }\end{array}$ & $\begin{array}{l}\text { Na implementação MIDI, um timbre pode ser usado para } \\
\text { cada linha de dados. }\end{array}$ \\
\hline $\begin{array}{l}\text { Axen e Choi [Axe } \\
\text { 96] }\end{array}$ & & $\begin{array}{l}\text { Métodos para visualizar estruturas grandes e multi- } \\
\text { dimensionais. }\end{array}$ \\
\hline $\begin{array}{l}\text { Martins, Rangayyan, } \\
\text { Portela, Amaro e } \\
\text { Ruschione [Mar 96] }\end{array}$ & Frequência. & Método para sonificação de texturas. \\
\hline Barrass [Bar 96] & & TaDa, método para apresentação de informação sonora. \\
\hline
\end{tabular}




\begin{tabular}{|l|l|l|}
\hline Brewster [Bre 96] & $\begin{array}{l}\text { Frequência, timbre, } \\
\text { localização espacial, } \\
\text { ritmo, entoação. }\end{array}$ & Conjunto de ferramentas para interfaces que realçam o \\
som.
\end{tabular}

Tabela 3.1 - Tabela de sistemas com uso de som e seus resultados.

De acordo com o panorama apresentado acima, é possível perceber que a área de sonificação, inicialmente, teve problemas de aceitação, ou seja, a confiança dos usuários em display sonoro era limitada.

No entanto, nota-se que a resistência ao uso de som diminuiu à medida que o usuário se acostuma com o uso do som como ferramenta. Além disso, resultados demonstram que o uso de som como ferramenta para auxiliar aplicações gráficas ou para representar dados é realmente útil na grande maioria dos casos.

Existem ainda alguns problemas que precisam ser solucionados no entendimento da percepção de algumas propriedades sonoras e no teste das técnicas desenvolvidas.

As ferramentas sonoras para apoio a aplicações gráficas evoluíram de aplicações específicas e dependentes da imagem, para a concentração em desenvolvimento de estratégias para o mapeamento de dados para som. A área de sonificação tende a crescer em associação com sistemas gráficos. É preciso uma maior divulgação desses sistemas para que um número maior de usuários tenha conhecimento de sua utilidade. Além disso, é necessária a realização de testes extensivos para que esses usuários se acostumem com o som como ferramenta para apoio a aplicações gráficas, e possam apontar inconsistências e melhorias.

Essa visão geral de trabalhos que usam som em aplicações computacionais e sonificação mostra o progresso que vem ocorrendo na área. Alguns aspectos das pesquisas mostradas acima tem interesse e influenciaram o presente projeto de mestrado.

O próximo Capítulo apresenta a área de visualização e as bases gráficas para esta dissertação, além da estrutura usada para o desenvolvimento prático deste trabalho. 


\section{Visualização e Som}

O mapeamento sonoro de dados numéricos com a intenção de exibir informações é chamado de sonificação. Nesse contexto, a sonificação de dados científicos é uma sub-área da Visualização Científica.

Este Capítulo apresenta uma visão geral sobre visualização e sobre o uso de som no contexto da visualização. Na Seção 4.1 são apresentadas as técnicas de visualização e o papel da percepção no contexto da visualização. A Seção 4.2 apresenta um estudo sobre o VTK (Visualization Toolkit), um conjunto de ferramentas para visualização usado no desenvolvimento de SVol (módulo multimodal para visualização volumétrica). A Seção 4.3 apresenta um exemplo do uso de som em visualização. A Seção 4.4 mostra o sistema SSound apresentando sua estrutura e sonificações. A Seção 4.5 discute as sonificações passiva e interativa, usadas no desenvolvimento de SVol. A última Seção deste Capítulo apresenta um especificação do sistema desenvolvido, SVol.

\subsection{Visualização e Percepção}

Como visto em Capítulos anteriores, a Visualização é uma área de pesquisa que estuda estratégias e algoritmos para traduzir dados e informações em representações gráficas. Com isso, é possível um melhor entendimento do conteúdo de grandes conjuntos de dados e dos fenômenos que os geram.

A Visualização Computacional é uma área que atualmente conta com um grande número de pesquisadores em todo o mundo. A razão pela qual essa área está se destacando é a grande 
quantidade de informações disponíveis para serem interpretadas em um tempo hábil insuficiente. Há necessidade de se alcançar melhor desempenho em muitas tarefas que exigem interpretação de dados numéricos. Essa grande quantidade de dados é devido ao aumento da capacidade de medição e processamento alcançados com o avanço da tecnologia.

Existem inúmeras áreas de atividade humana que têm se beneficiado dos produtos da visualização. Exemplos na área científica são a mecânica dos fluidos, aplicações envolvendo imagens médicas, biologia molecular, meteorologia, microscopia, odontologia, física nuclear, geologia, astronomia, engenharia aeronáutica e automotiva, entre outras.

Os dados em visualização computacional podem ser definidos sobre domínios bidimensionais (2D), tridimensionais (3D) e, genericamente, multi-dimensionais. Geralmente, os dados estão dispostos em uma malha (regular ou irregular), mas também podem ser encontrados como um conjunto de pontos esparsos. As informações associadas a cada ponto da malha podem envolver um ou mais campos escalares, vetoriais ou tensoriais [Min 97b].

Os dados definidos em um domínio tridimensional são geralmente representados em uma malha volumétrica, como a ilustrada na figura 4.1. Essas malhas volumétricas podem ser representadas como conjuntos de voxels ou células.

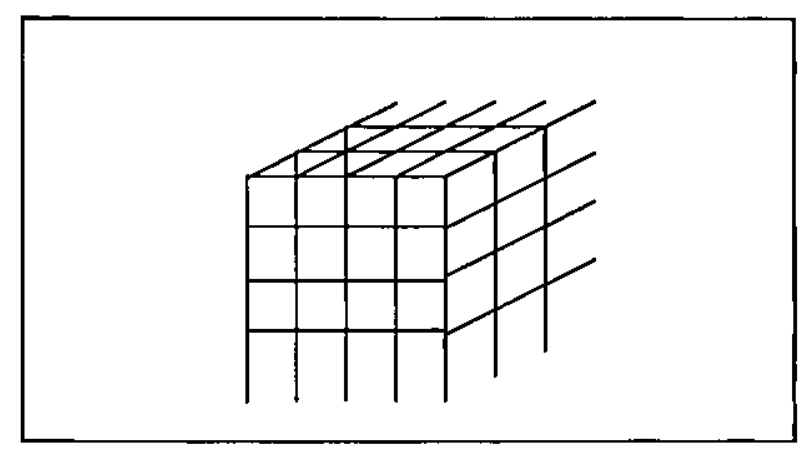

Figura 4.1 - Malha volumétrica.

O voxel é um elemento de volume unitário, correspondente 3D do pixel. Um único dado é armazenado no interior do voxel. A célula também é um elemento de volume unitário, porém os dados estão posicionados nos seus vértices, e valores no interior das células podem ser obtidos 
por interpolação. As representações de voxel e célula são equivalentes, porém algoritmos de visualização são baseados em uma ou outra forma.

$\mathrm{Na}$ área da Visualização $3 \mathrm{D}$ as técnicas de apresentação podem geralmente ser classificadas como baseadas em superfícies ou em renderização volumétrica direta (Direct Volume Rendering) [Elv 92] [Min 97].

As técnicas baseadas em superfícies geram isosuperfícies (superfícies de nível) de valor constante dentro do volume. Uma vantagem das isosuperfícies é a possibilidade de identificação de estruturas nas medições ou simulações. Elas também permitem análise em tempo real pois, apesar do processo de extração das superfícies ser lento, a renderização das superfícies resultantes pode ser muito rápida, principalmente se feita por hardware. Uma desvantagem da técnica é a perda de informação relativa ao interior do conjunto de dados fora dos valores selecionados para o traçado.

Uma técnica baseada em superfície é a conexão de contornos [Shi 97], que identifica os contornos para um determinado valor de interesse em cada fatia do volume de dados e em seguida as curvas em fatias adjacentes, determinadas pelo valor escolhido, são conectadas através de triangulação ou tecelagem (patching). A interseç̧ão de voxels é outra técnica de superfície e é baseada em algum critério de intersecção entre a superfície sendo construída e as células ou voxels do volume. Uma triangulação é realizada nos voxels interceptados. Nessa categoria se encontra o algoritmo marching cubes que será descrito no item 4.1.1.

As técnicas de renderização volumétrica direta permitem a renderização direta de conjuntos de dados tridimensionais, sem a geração de primitivas geométricas intermediárias, pois trabalham com os valores armazenados nos voxels do volume. As técnicas de renderização volumétrica direta têm por objetivo visualizar a estrutura interna do volume de dados. Essas técnicas podem ser agrupadas em duas categorias: as que operam no espaço do objeto, ou seja, os voxels são projetados diretamente no plano de imagem, e as que operam no espaço da imagem, isto é, pixel a pixel. Ambas contam com a transparência dos objetos como ferramenta de visualização do interior do volume. 
Uma técnica de renderização volumétrica direta que opera no espaço do objeto é o splatting onde a contribuição de cada voxel é calculada e combinada com as contribuições dos outros voxels que projetam no mesmo pixel. Uma técnica de renderização volumétrica direta que opera no espaço da imagem é o ray casting. No ray casting, raios são traçados a partir da câmera, passando por um pixel e continuando no volume em linha reta até que a opacidade acumulada no caminho de cada raio atinja o máximo, ou seja, valor 1 .

As técnicas mencionadas acima se relacionam à apresentação de valores escalares, que é o objetivo desse trabalho. Dados vetoriais e tensores [Mar 97] são apresentados por técnicas alternativas às mencionadas neste texto.

Dentre as técnicas mencionadas acima, o marching cubes, descrito a seguir, se relaciona diretamente com alguns dos procedimentos referentes ao presente projeto.

\subsubsection{Marching Cubes}

Uma técnica para extração de superfícies estudada para o desenvolvimento de funçōes do SVol é o algoritmo marching cubes desenvolvido por Lorensen e Cline [Lor 87]. O processo de deteç̧ão da superfície é iniciado pela seleção do valor escalar de interesse. O marching cubes trata as células independentemente. Algumas células estão completamente dentro ou completamente fora da isosuperfície definida pelo valor de interesse, enquanto que outras são interceptadas por ela.

Inicialmente, identifica-se as células que são interceptadas pela superfície. Uma tabela de casos é construída, enumerando todas as possíveis situações de intersecção de uma célula pela superfície. Os casos possíveis dependem do número de vértices da célula, e do número de relacionamentos do tipo "dentro/fora" que um vértice pode assumir com relação ao valor de interesse. Um vértice é considerado "dentro" da isosuperfície se o seu valor escalar associado é maior ou igual ao o valor da isosuperfície, e fora caso o seu valor seja menor. No caso de células, tem-se 8 vértices, e $2^{8}=256$ situações possíveis (cada vértice pode estar dentro ou fora). Por simetria, pode-se reduzir esse número para 15 casos realmente distintos, ilustrados na figura 4.2, que são mantidos em uma tabela. Pode-se calcular um índice para a tabela de casos codificando o estado de cada vértice como um dígito binário (definindo um código de 8 bits para o caso 3D). 


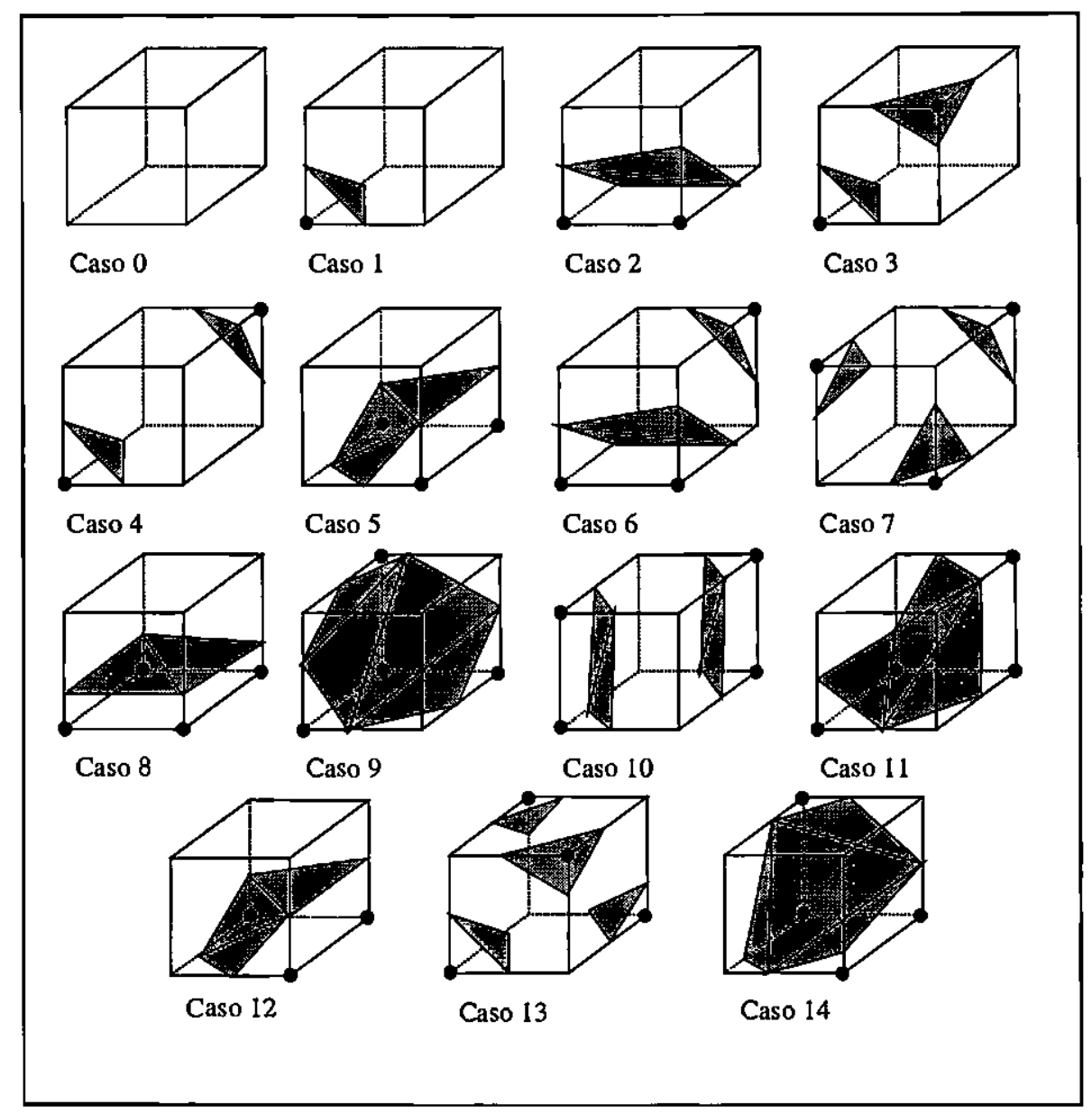

Figura 4.2 - Tabela de casos de triangulaçöes para o marching cubes [Min 97b].

Em um segundo passo, um conjunto de um ou mais polígonos é gerado para essa célula, dependendo do caso identificado. Em seguida, o algoritmo é aplicado na próxima célula. Depois que todas as células foram visitadas, a isosuperfície, definida em termos de uma malha poligonal, está pronta para ser renderizada. Exemplos de superfícies serão dadas no Capítulo 5.

O item 4.1.2 abaixo apresenta alguns aspectos importantes da percepção humana na visualização, estudados no desenvolvimento deste trabalho. 


\subsubsection{Percepção em Visualização}

Quando dados científicos ou estatísticos são apresentados em algum dispositivo gráfico, o usuário é forçado a usar sua percepção visual para fazer julgamentos quantitativos sobre a apresentação para comparar tamanhos, localizações, orientações, cores, densidades, texturas e outras propriedades de elementos da apresentação [Reu 90]. Por causa disso, quando uma apresentação computacional complexa está sendo desenvolvida, devem ser considerados alguns aspectos, como mecanismos fisiológicos e psicofísicos do olho humano, e diferenças culturais na percepção.

Existem dois níveis da percepção do usuário que devem ser considerados. O primeiro é relacionado com a maneiras com que o usuário interpreta e entende o próprio conjunto de dados e sua natureza, ou seja, o usuário forma uma imagem mental do que o objeto é. O segundo nível está relacionado com as propriedades da imagem (cor, forma, posição, etc) que facilitam a interpretação. Considerando aspectos da percepção humana de objetos visuais e suas propriedades é possível gerar boas representações e evitar ambiguidades e confusões [Min 95a].

Rogowitz e Treinish [Rog 93b] apresentaram uma análise de uma arquitetura previamente publicada [Rog 93a] para incorporar regras de percepção nos processos de visualização. Essa arquitetura introduziu a noção de um conjunto de regras que mapeiam dados usando operações de visualização que são invocadas pelo usuário e são baseadas nos princípios da percepção visual (como escala de cores).

Ainda assim, existem muitos desafios associados à percepção na área de visualização. Na sonificação, os aspectos perceptivos apresentados acima são fundamentais, uma vez que existe menos informação sobre o uso de som do que atributos visuais. Além disso, a capacidade auditiva humana é menor do que a capacidade visual, o que torna essencial considerar características de percepção no projeto sonoro. Um dos objetivos a médio prazo do projeto Svol é o de propor um conjunto de regras para sonificação, seguindo a arquitetura mencionada acima [Rog 93a] e estendida por Minghim e Oliveira [Min 97b]. 
Essa arquitetura está sendo implementada para atributos visuais (como cores e formas), no contexto do toolkit de visualização VTK. O VTK é apresentado na próxima Seção.

\subsection{A Biblioteca VTK}

O projeto SVol foi implementado como extensão de um software específico para visualização e computação gráfica tridimensional, o VTK. Acompanha um livro texto intitulado "The Visualization Toolkit, An Object-Oriented Approach to 3D Graphics" [Sch 97], uma biblioteca $\mathrm{C}++$, e uma implementação Tcl/Tk baseada na biblioteca. A implementação dessa biblioteca foi fortemente influenciada por princípios de orientação a objetos. A documentação ${ }^{6}$ e código fonte ${ }^{7}$ encontram-se disponíveis pelos serviços da Internet.

\subsubsection{Descrição Geral}

O modelo gráfico do VTK possui alto nível de abstração, o que permite rendering através de bibliotecas como openGL ou PEX. Isso significa que é relativamente fácil programar aplicações gráficas e visualizações a partir do VTK. As aplicações do VTK podem ser escritas diretamente em C++ ou em Tcl/Tk, uma linguagem interpretada desenvolvida por John Ousterhout [Ous 94]. O software VTK suporta uma grande variedade de algoritmos de visualização incluindo visualização escalar, vetorial e tensorial, além de alguns recursos de modelagem.

Esta Seção fornece os conceitos básicos de VTK relacionados ao desenvolvimento do projeto. No item 4.2.2 serão descritos os tipos de dados utilizados pelo VTK. No item 4.2 .3 será explicado o pipeline de visualização. $\mathrm{O}$ item 4.2 .4 descreve a geração de isosuperfícies no sistema VTK. O item 4.2.5 fornece diretrizes de implementação do VTK, extraídas durante o projeto.

\footnotetext{
${ }^{6}$ Web http:/www.cs.rpi.edu/ -martink

${ }^{7}$ FTP ftp://prenhall.com/pub/utk
} 


\subsubsection{Tipos de Dados}

Um tipo de dados em VTK especifica uma malha (grid) de dados através do relacionamento que as células e pontos possuem entre si. Assim, um tipo de dados é caracterizado de acordo com sua regularidade ou irregularidade.

Um tipo de dados é regular se existe um relacionamento matemático regendo a disposição de pontos e células. Desse modo, se um tipo de dados apresenta regularidade, a sua natureza sugere um sistema cartesiano, onde pontos e células podem ser indexados facilmente. Um tipo de dados completamente regular pode ser implicitamente representado, com grande economia de memória.

Já um tipo de dados irregular deve ser representado explicitamente pois ele não possui um padrão que possa descrevê-lo resumidamente. Tipos de dados irregulares tendem a ser mais genéricos, mas exigem muitos recursos computacionais e memória. Abaixo serão mostrados os tipos de dados implementados no VTK. A figura 4.3 ilustra esses tipos de dados.

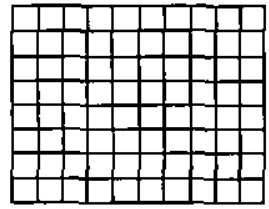

(a) Grid cartesiano.

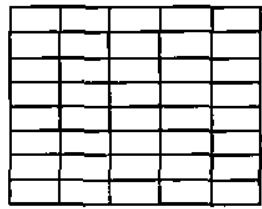

(b) Grid regular.

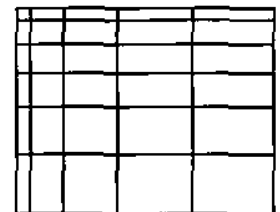

(c) Grid retilíneo.

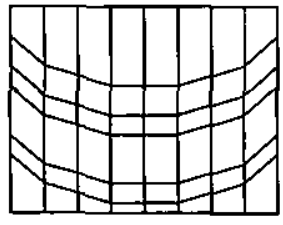

(d) Grid estruturado.

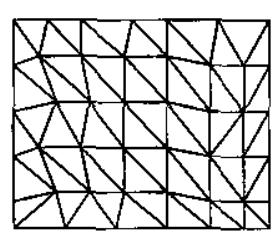

(e) Grid desestruturado.

Figura 4.3 - Diferentes tipos de grids [Min 97b]- 


\section{Dados Poligonais}

Uma estrutura de dados poligonal consiste de vértices, poli-vértices, linhas, poli-linhas, e polígonos. A topologia e a geometria de dados poligonais são irregulares (desestruturadas), e as células que compõem esse tipo de dados variam em dimensão topológica, devendo ser explicitamente representada.

O objeto $v t k$ PolyData implementa estruturas poligonais em VTK. Ele usa a classe $v t k$ Points para armazenar os vértices das células e usa a classe vtkCellArray para representar a topologia da célula. Essa classe é uma lista de conectividade de células. Para cada célula, o primeiro número é o total de pontos presentes na célula seguido de uma série de números que representa a conectividade da célula (cada número é um índice para um ponto da lista de vértices). Essa sequência de contagem seguida por uma lista de conectividade é repetida até que todas as células sejam enumeradas. Informações adicionais tais como o número de células na lista e a posição corrente são mantidas pela classe vtkCellArray.

\section{Grid Retilíneo}

Outro tipo de dados implementado no VTK é o grid retilíneo (Rectilinear Grid). Essa estrutura é uma coleção de células arranjadas em uma malha de topologia regular. As linhas, colunas e planos da malha são paralelos às coordenadas globais do sistema cartesiano (x, y, z). Mas, enquanto a topologia do tipo de dados é regular, a geometria é parcialmente regular. Ou seja, os vértices são alinhados aos eixos das coordenadas mas o espaçamento entre eles pode variar.

Essa estrutura é implementada no VTK por duas classes separadas, apresentadas a seguir.

\section{Grid Estruturado}

O tipo de dados grid estruturado (vtkStructuredGrid) possui topologia regular e geometria irregular. A topologia desse tipo de dados é definida especificando as dimensões num sistema topológico de coordenadas i-j-k. Entretanto, a geometria da estrutura é realizada especificando 
individualmente as coordenadas de todos os pontos no sistema de coordenadas global x-y-z, uma vez que o espaçamento entre "linhas" consecutivas da malha é variável.

A topologia do grid estruturado é representada implicitamente especificando um vetor $3 D\left(n_{x}, n_{y}, n_{z}\right)$, sendo composta por quadriláteros (2D) ou hexaedros (3D). A geometria é representada explicitamente mantendo um array com as coordenadas de vértices da malha.

O tipo grid estruturado é comumente utilizado em análise de diferenças finitas, que é uma técnica de análise numérica para aproximação da solução de equações diferenciais parciais. Aplicações típicas incluem fluxo de fluídos, transferência de calor, e combustão.

\section{Pontos Estruturados}

Um tipo de dados de pontos estruturados (vtkStructuredPoints) é uma coleção de vértices e células arranjados numa malha de forma regular, e retangular. As linhas, as colunas, e os planos da malha são paralelos para o eixo global do sistema cartesiano, além de serem igualmente espaçados. Se os pontos e células estão arranjados num plano (isto é, são bidimensionais), o tipo de dados é referido como pixmap, bitmap, ou imagem. Se os pontos e células são arranjados como planos empilhados (isto é, tridimensional), o tipo de dados é denominado volume. Utilizase, no contexto do VTK, o termo mais geral Structured Points para referir a imagens, volumes, ou um array unidimensional de pontos coletivamente.

O vtkStructuredPoints consiste de elementos de linha (1D), pixels (2D), ou voxels (3D). Os pontos da estrutura de pontos estruturados são regulares e tanto a sua geometria como sua topologia podem ser representadas implicitamente. $O$ esquema representacional requer somente as dimensões de dados, um ponto de origem, e uma razão de aspecto. A dimensão do dado é dada por um vetor $3 D\left(n_{x}, n_{y}, n_{z}\right)$, especificando o número de pontos nas direções $x, y, e$ z. O ponto de origem é a posição no espaço tridimensional do mínimo vértice $\mathrm{x}, \mathrm{y}, \mathrm{e} \mathrm{z}$. Cada pixel (2D) ou voxel (3D) na estrutura é idêntico em forma, e a razão de aspecto especifica a escala nas direções em $x$, ye $z$. 
A natureza regular da topologia e da geometria do conjunto Structured Points sugere um sistema de coordenadas i-j-k natural. O número de pontos na estrutura de dados é $n_{x} n_{y} n_{z}$ enquanto que o número de células é $\left(\mathrm{n}_{\mathrm{x}}-1\right) *\left(\mathrm{n}_{\mathrm{y}}-1\right) *\left(\mathrm{n}_{\mathrm{z}}-1\right)$. Um vértice particular ou célula pode ser selecionado especificando os três índices $\mathrm{i}-\mathrm{j}-\mathrm{k}$. Tanto as células quanto os pontos são numerados na direção em ordem crescente de $x, y$ e depois $z$.

A simplicidade e a representação compacta são características desejáveis dessa estrutura de dados. É uma estrutura eficiente computacionalmente, porém possui uma grande desvantagem: para se obter maior resolução deve-se aumentar as dimensões do tipo de dados. Aumentando as dimensões de uma imagem resulta em um aumento de requerimento de memória da ordem de $\mathrm{n}^{2}$, enquanto volumes requerem um aumento de $\mathrm{O}\left(\mathrm{n}^{3}\right)$.

A estrutura de pontos estruturados é freqüentemente utilizada em imagens, medições e simulações. Volumes são freqüientemente gerados a partir de imagens médicas como Tomografia Computadorizada (CT) e Imagens de Ressonância Magnética (MRI). Algumas vezes volumes são utilizados para amostragem de funções matemáticas e soluções numéricas.

\section{Grid Desestruturado}

A forma mais flexível de tipo de dados é o grid desestruturado (vtkUnstructuredGrid). Ambas topologia e geometria são completamente livres. Qualquer tipo de célula pode ser combinado de forma arbitrária nesse tipo de dados. A topologia das células varia de $0 \mathrm{D}$ (vertex, poly-vertex) a 3D (tetraedro, hexaedro, voxel). Tanto os pontos como as células são explicitamente representados utilizando classes derivadas de $v$ tkPoints e $v t k C$ CllArray.

No VTK, qualquer tipo de dados pode ser representado na forma de grid desestruturado. Entretanto, utiliza-se esta forma apenas quando ela é necessária, porque esse tipo de dados requer muito recurso computacional para ser representado e operado.

Grids desestruturados são encontrados em campos como análise de elemento finitos, geometria computacional, e modelamento geométrico. 
Um componente importante da maioria dos sistemas de visualização de arquitetura do tipo data flow, como o VTK, é o "pipeline". Tal componente é discutido a seguir.

\subsubsection{Pipeline de Visualização}

Um sistema de visualização transforma dados em uma representação visual para que a informação a respeito dos dados possa ser eficientemente interpretada. Isso indica que a visualização envolve um processo de transformação, que é a conversão dos dados de sua forma original para primitivas gráficas seguida de rendering.

Pode-se esquematizar essas etapas de transformação e representação num pipeline de visualização. O pipeline, ou a rede de visualização, pode ser descrito através de um modelo funcional, mostrando como os dados fluem através do sistema, e as interdependências entre cada etapa de transformação. Um exemplo é apresentado na figura 4.4, onde os blocos ovais indicam operações (processos) realizados sobre os dados, e os blocos retangulares abertos representam um meio de armazenamento. Setas indicam a direção do movimento dos dados: setas que apontam para os blocos são entradas, e setas que deixam os blocos são as saídas. 


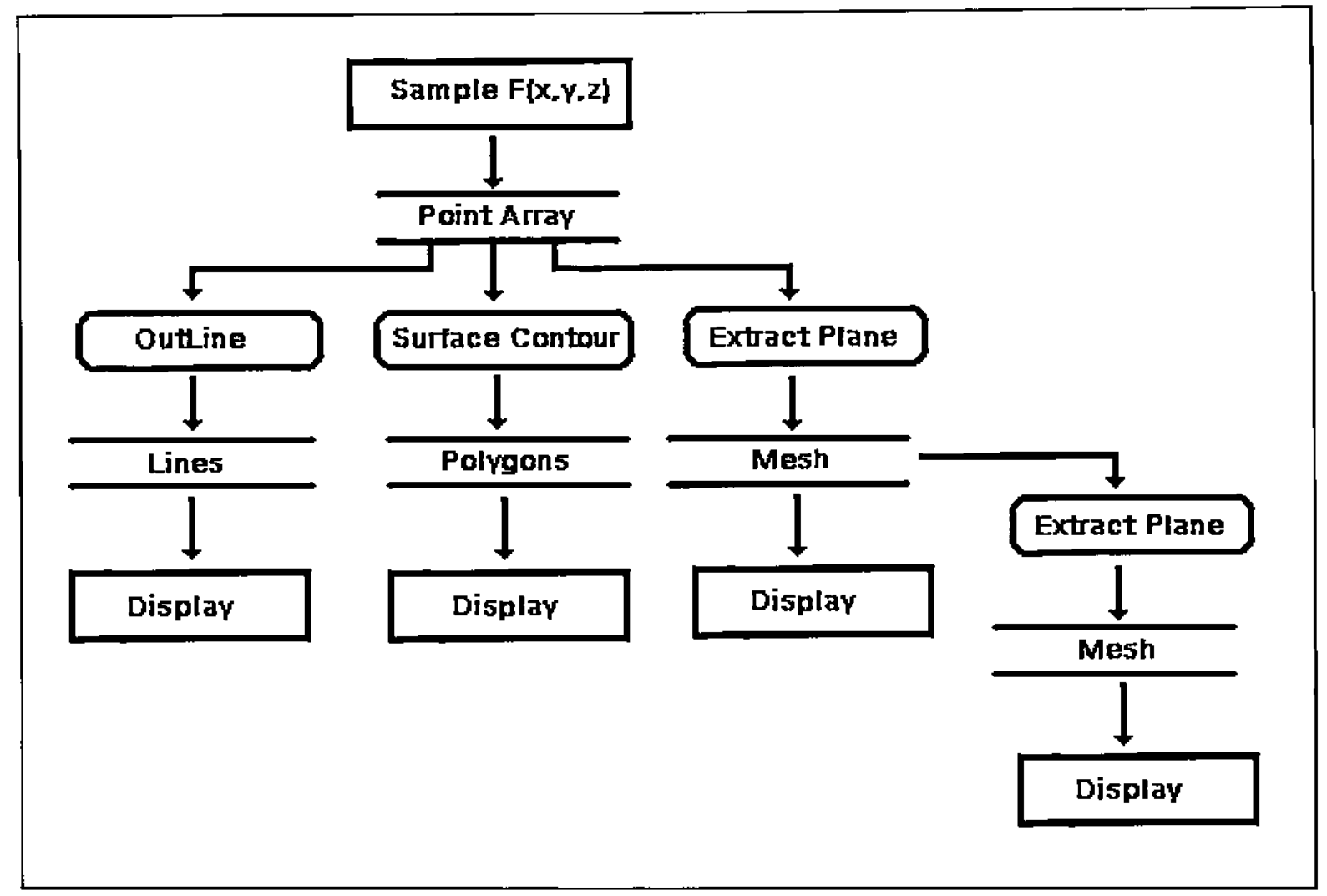

Figura 4.4 - Pipeline de Visualização

De acordo com a presença de canais de entrada e saída podemos classificar os processos em três formas :

- Processos com apenas saídas (fontes): As fontes são objetos que fazem interface com fontes externas de dados, ou geram dados a partir de parâmetros locais. Fontes que geram dados a partir de parâmetros locais são chamados de objetos procedurais. Um exemplo típico seria uma função implícita que gera pontos sobre uma esfera (vtkSphereSource). Fontes que fazem interface com dados externos são chamadas de readers, uma vez que um arquivo externo deve ser lido e convertido para uma forma interna.

- Processos com entradas e saídas (filtros): Os filtros são objetos que processam um ou mais dados de entrada, gerando um ou mais dados de saída. Os conversores são filtros especiais responsáveis por transformar uma forma de representação de dados em uma outra. Além disso, existem filtros que apenas operam transformações geométricas (rotação, escala, translação) e filtros que operam funções booleanas (por ex: união) entre duas entradas. 
- Processos com apenas entradas (mapeadores): Os mapeadores são objetos responsáveis pelo término do fluxo de dados do pipeline de visualização. Usualmente eles são utilizados para converter dados em primitivas gráficas, mas eles também podem arquivar os dados externamente, através de um arquivo, ou interfacear com outros sistemas de software ou dispositivos. Tais tipos de mapeadores são chamados de writers.

\subsubsection{Geração de Isosuperfícies em VTK}

O VTK permite a renderização de objetos a partir dos dois métodos de apresentação da visualização 3D mostrados na Seção 4.1 deste Capítulo: técnicas de superfícies e renderização volumétrica direta.

Para a re-implementação do SSound foram utilizados filtros do VTK que geram isosuperfícies. Esses filtros utilizam rendering de superfícies como método de apresentação. Genericamente falando, quando um objeto é renderizado usando uma técnica de superfícies, o interior do objeto não é descrito. Ele é implicitamente representado por uma representação de superfície . Abaixo serão mostrados dois filtros do VTK que utilizam esse método de apresentação.

O vtkCountourFilter é um filtro que tem como entrada qualquer conjunto de dados e gera como saída isosuperfícies ou isolinhas. A forma exata da saída depende da dimensionalidade dos dados de entrada, ou seja, dados de entrada tridimensionais geram isosuperfícies e dados de entrada bidimensionais geram isolinhas. O vtkContourFilter usa variações do algoritmo marching cubes, apresentado na Seção 4.1, para gerar as primitivas de saída.

O vtkMarchingCubes é um filtro que tem como entrada um conjunto de pontos estruturados e gera como saída uma ou mais isosuperfícies. Esse filtro é usado exclusivamente para dados escalares em malhas tridimensionais. Um ou mais valores devem ser especificados para que as isosuperfícies sejam geradas, através da função SetValue, pertencente ao filtro. Alternativamente, pode ser especificado um intervalo de escalares (mínimo/máximo) e o número de contornos para gerar uma série de contornos igualmente espaçados, através da função GenerateValues. A figura 4.5 mostra um exemplo de acesso ao filtro vtkMarchingCubes. 
O SVol foi desenvolvido com base na versão 1.3 do VTK. Para o desenvolvimento de algumas funções do projeto SVol, como, por exemplo, a função de sonificação de coordenadas, foi necessária a criação de novos filtros para o VTK.

A chave para a criação de um novo filtro é identificar os dados de entrada e saída. Os filtros mais gerais são aqueles que conseguem processar um maior número de estruturas de dados. Depois de identificadas as entradas e saídas do novo filtro, deve-se criar uma nova classe, derivada de um dos filtros abstratos do VTK. Esses filtros abstratos existentes no VTK identificam as entradas e saídas do novo filtro. A nova classe deve ser derivada do filtro abstrato mais adequado aos seus tipos de dados de entrada e saída. Por exemplo, um novo filtro que transforma dados do tipo vtkStructuredPoints para dados do tipo vtkPolyData, deve ser implementado como uma classe derivada de vtkStructuredPointsToPolyDataFilter.

Posteriormente, deve-se implementar o algoritmo do novo filtro no seu método de nome Execute. O método Execute consiste de cinco partes principais:

- Declaração : As variáveis locais são declaradas.

- Inicialização : Verifica a validade e consistência dos dados de entrada.

- Alocação : As variáveis de visualização são instanciadas.

- Corpo : O algoritmo propriamente dito.

- Saída : A saída é especificada.

Depois de criado o novo filtro, ele deve ser compilado segundo algumas regras básicas, apresentadas no Apêndice $\mathrm{B}$, essas regras descrevem os procedimentos referentes à compilação no Visual $\mathrm{C}++5.0$. 
A seguir é apresentada a Sonda Sonora, uma ferramenta de investigação do conteúdo do volume através de estímulos sonoros, implementado no contexto do SSound, e re-implementado no SVol.

\subsection{Exemplo do Uso de Som (Sonda Sonora)}

Por causa da organização volumétrica de muitos conjuntos de dados, a "busca" volumétrica é uma ferramenta útil para explorar e interagir com os dados. A sonda sonora é utilizada para sonificar um determinado trecho do volume em análise, geralmente aquele de difícil visualização, para auxiliar a seleção de um sub-volume de interesse e a detecção de elementos selecionados no volume [Min 95a, b, c].

No processo da sonda sonora, toda a superfície que está sendo analisada é cercada por uma borda (caixa), e uma segunda borda (caixa da sonda sonora) pode ser movimentada dentro do volume (figura 4.6c). A sonda sonora permite uma série de operações de deslocamento, captura e extração no volume em estudo. No SSound, o acesso a uma função específica é alcançado por toques em teclas chaves do teclado ou pelo "clique" do mouse em janelas de ferramentas e diálogo (figuras 4.6a e 4.6b). 


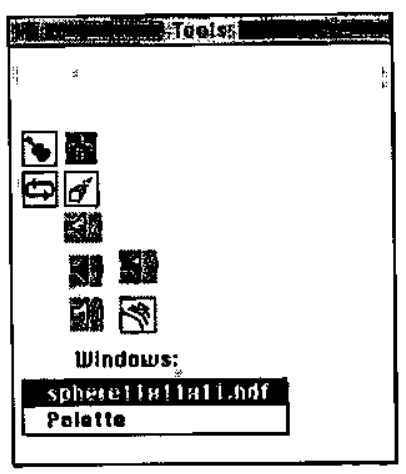

(a)

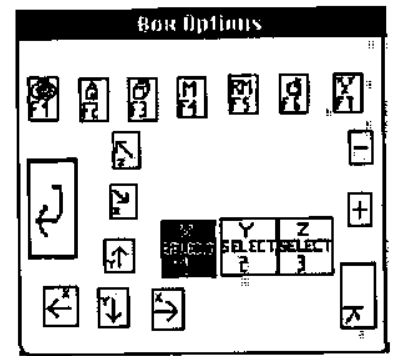

(b)

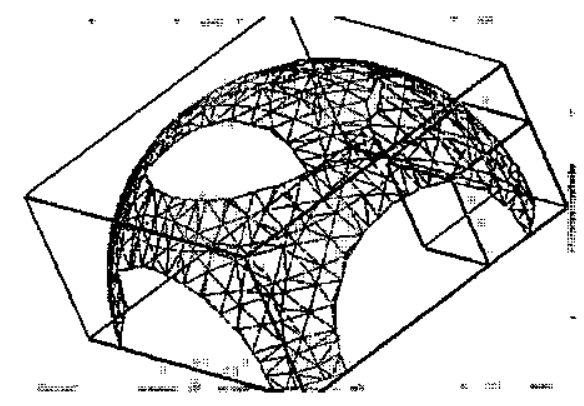

(c)

Figura 4.6 - Sonda sonora implementada em SSound [Min 95a].

(a) Janela de ferramentas.

(b) Caixa de opçōes da sonda sonora.

(c) Superfície com borda e borda da sonda sonora.

A janela apresentada na figura 4.6a apresenta as várias funções de sonificação que serão explicadas na Seção 4.4, e uma delas é a sonda sonora. A janela apresentada na figura 4.6b apresenta as opções de operação da função sonda sonora como, por exemplo, tipos de sonificação disponíveis, o aumento e diminuição do tamanho da sonda, o movimento em $\mathrm{x}, \mathrm{y}, \mathrm{z}$ da sonda, e a seleção da direção de movimento da sonda. A Figura 4.6c apresenta o volume renderizado com a sonda sonora.

A figura 4.7 mostra uma sequência de passos na função da sonda sonora implementada em SSound. 


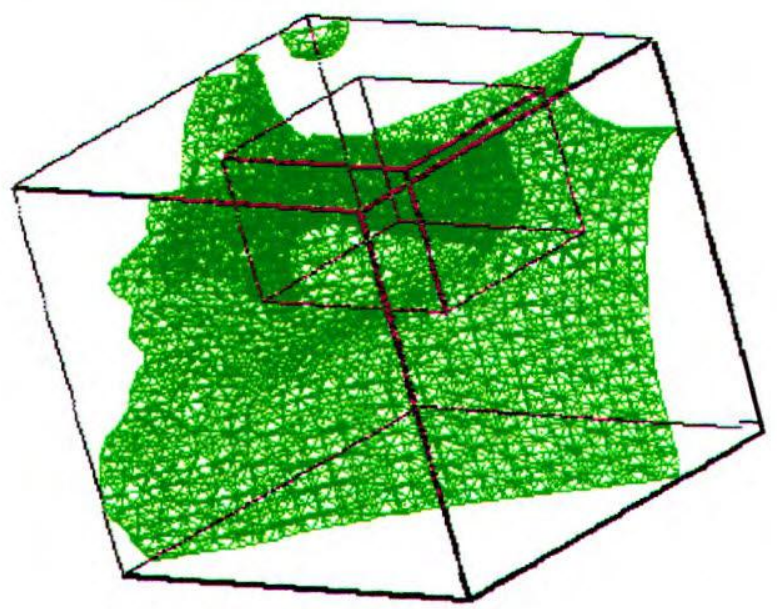

(a)

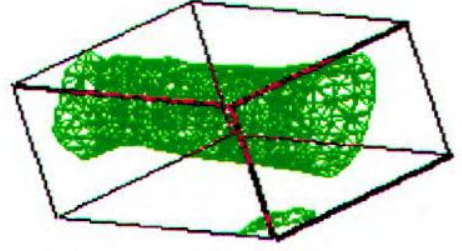

(b)

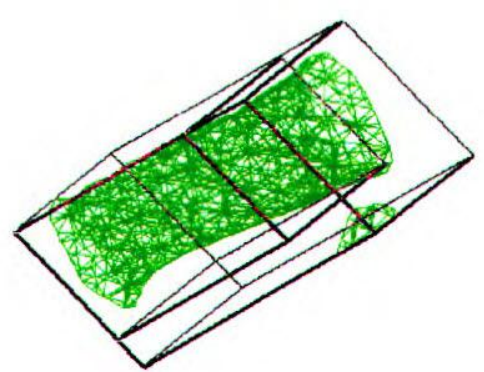

(c)

Figura 4.7 - Sequência de passos da função da sonda sonora no SSound [Min 95a].

(a) Superficie original e com a borda.

(b) Renderização da seleção.

(c) Sonda posicionada na nova seleção, realizada em (b).

A próxima Seção apresenta o sistema SSound desenvolvido por Minghim e Forrest [Min 95 a, b, c], e que é a base do sistema SVol.

\subsection{SSound}

Como já foi dito anteriormente, o sistema desenvolvido, SVol, compreende a implementação, em um sistema de ampla utilização (VTK), de funções de som para visualização volumétrica baseada em superficies desenvolvidas anteriormente em SSound [Min 95 a, b, c] 
As sonificações projetadas e implementadas para o SSound foram baseadas primeiramente em princípios de audição musical e audição do dia-a-dia, e em reconhecimento de timbre. Tais diretivas serão mantidas no desenvolvimento de SVol. A decisão de que som usar em cada situação depende:

- da estrutura particular e combinações de som que podem ser detectadas e interpretadas pelo ouvido humano.

- do significado atribuído naturalmente a um determinado som, ou propriedade do som.

- de qual novo significado pode ser atribuído a um som ou estrutura sonora por aprendizado, que não seja conflitante com idéias pré-condicionadas.

- de qual som e significado devem ser usados em conjunto para representar um evento, ação, ou objeto sob análise.

A maioria dos elementos usados no SSound são metafóricos ${ }^{8}$, embora algumas sejam relações simbólicas 9 .

As sonificações são baseadas em múltiplos estímulos de som (de l a 4) criados e controlados independentemente ou em combinação, dependendo do gráfico ou propriedade do dado, objeto, ou evento sob análise. O controle do som é transparente ao usuário. Através de mudanças no som, o usuário detecta mudanças no dado ou propriedade do dado, e através do tipo de mudança no som ele detecta o tipo de mudança no dado.

Para usar som em visualização tri-dimensional existem problemas de interação e sincronização com objetos complexos. Três tipos de sincronização são usadas em SSound: uma é controlada pela mudança em uma das possíveis dimensões (geralmente $x, y$ ou $z$ ) ou em todas as direções simultaneamente; outra é controlada pela ação do usuário, causando cálculos de propriedades que

\footnotetext{
'Embora não fisicamente relacionada com a informação que eles representam, seus mapeamentos não são totalmente simbólicos, mas consideram peso representativo da informação, por usar similaridades entre diferentes experiências. ${ }^{\ominus}$ Existe um símbolo do qual o dado ou evento está relacionado.
} 
geram uma sequência de tons; e a última é associada com propriedades de objetos que geram uma série de sons simultâneos automaticamente, em conjunto com a apresentação gráfica.

O SSound é baseado no software NCSA Image. O Image constrói superfícies de nível (isosurfaces) usando uma extensão do algoritmo Marching Cubes [Lor 87], aplicado aos dados escalares definidos em uma malha volumétrica regular. No presente trabalho, SSound foi transposto para o contexto do VTK, uma vez que o Image possui uma estrutura ultrapassada, com funções muito limitadas.

\subsubsection{Estrutura do SSound}

SSound foi desenvolvido em um Macintosh Quadra 950. O som é produzido por um sintetizador Korg Wavestation SR, conectado via MIDI ao computador. O software foi desenvolvido usando MPW C. Todas as funções gráficas e sonoras foram implementadas como extensões do NCSA Image.

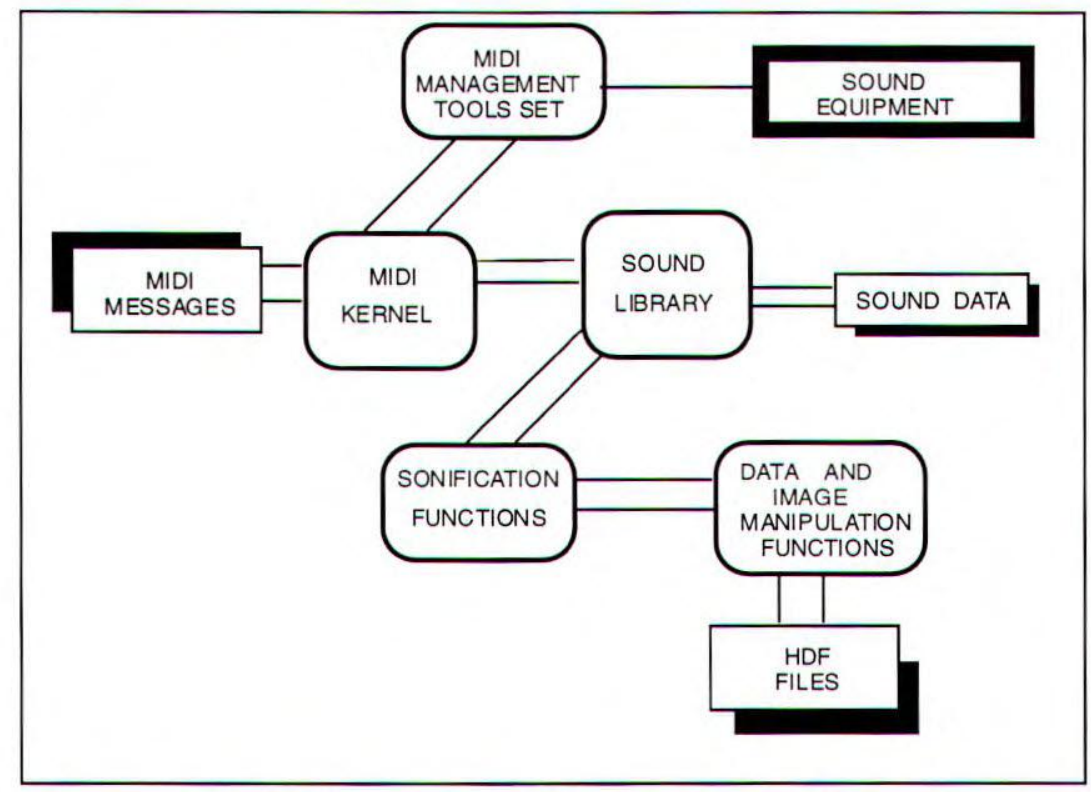

Figura 4.8 - Organização do SSound. Retirado de [Min 95a].

Os módulos que compreendem o SSound, mostrados na figura 4.8, são especificados a seguir. O "MIDI Manager" é uma biblioteca fornecida pela Apple para controlar as comunicações via MIDI 
entre drivers e programas ou entre módulos ou programas diferentes. O "MWI Messages" armazena uma tabela de possíveis mensagens implementadas pelo sintetizador. O "MWI Kernel" controla a composição das mensagens MIDI requeridas pela biblioteca sonora e a formatação das mensagens no formato MIDI Manager. O "Sound Tools Library" é um conjunto de funções de geração e playback de som implementado para fornecer as ferramentas para o programa de visualização. "Sound Data" armazena o estado corrente de diferentes trilhas sonoras. O "Data and Image Manipulation Functions" é o módulo responsável pela criação e interação da imagem, parte do NCSA Image e parte desenvolvido pelos autores do SSound para estender apresentaçōes gráficas, cálculos e interações no Image. O "Sonification Functions" é o módulo responsável pelas interfaces entre usuários, gráficos, dados e som, implementando o mapeamento sonoro. “HDF Files" são arquivos de dados formatados em Hierarchical Data Format, um formato para dados cientificos definidos pela NCSA. Uma descrição mais completa do SSound é dada em [Min 95a].

\subsubsection{Sonificações do SSound}

Alguns dos mapeamentos sonoros implementados em SSound são baseados diretamente no conjunto de dados original e outros nas propriedades geométricas de isosuperfícies.

A sonificação da malha é obtida através dos valores dos dados. A malha tridimensional original é projetada na janela onde as isosuperfícies estão sendo apresentadas. Conforme o usuário movimenta o mouse sobre a janela, os valores existentes na célula corrente são mapeados em propriedades do som, principalmente freqüência. A posição interna da célula é reforçada pela distribuição do canal estéreo ou por som quadrafônico. Valores altos são mapeados em altas frequiências e valores baixos em baixas freqüências. Essa sonificação admite selecionar os valores a serem sonificados.

Outra sonificação implementada em SSound é a sonda sonora (ver Seção 4.3). O processo cria uma borda (caixa) em volta do volume a ser analisado e uma outra borda (a sonda sonora) pode ser movida no volume coletando informações sobre $a(s)$ superfície(s) renderizada(s). Uma função de apoio, a função Score, estima o número de triângulos da superfície contida em um volume qualquer. Essa função será melhor explicada no Capítulo 5 desta dissertação. 
$\mathrm{Na}$ sonificação mapeamento de coordenadas, também implementada em SSound, as coordenadas de pontos selecionados são mapeadas em freqüência. Três trilhas de som são apresentadas continuamente, representando variações nas coordenadas $x, y$ e $z$ da superfície. Quando ocorre variação em alguma direção o valor correspondente àquela trilha de som muda. $O$ objetivo dessa sonificação é representar progressão nos valores das coordenadas. Variações na forma geram variações no som, o que pode ser detectado sonoramente. Quando um dos eixos codifica uma variável significativa, a sonificação de coordenadas na sua direção auxilia o entendimento da relação entre essa variável e as demais.

Outra sonificação implementada em SSound é a sonificação de propriedades de superficie. Várias propriedades geométricas diferentes da superfície analisada são mapeadas sonoramente, para identificação de forma e investigação dessa superfície. Quando a superfície é exibida, o valor da propriedade escolhida é apresentada sonoramente. Isso ajuda a analisar não somente a evolução da propriedade na superfície, mas também identificar características não vistas ou clarear informações visuais ambíguas.

A tabela abaixo apresenta as principais sonificações implementadas em SSound.

\begin{tabular}{|c|c|c|}
\hline Sonificação & Função & Propriedades \\
\hline Sonificação da malha & $\begin{array}{l}\text { Mapeia valores de dados } \\
\text { escalares. }\end{array}$ & Frequência, volume. \\
\hline Sonda sonora & $\begin{array}{l}\text { Mapeia a quantidade da sonda } \\
\text { ocupada e quanto do total da } \\
\text { superfície o volume da sonda } \\
\text { contém. }\end{array}$ & Frequência, estéreo, volume. \\
\hline Mapeamento de coordenadas & $\begin{array}{l}\text { Mapeia as variações nas } \\
\text { coordenadas } x, y, z \text {. Representa } \\
\text { a progressão nos valores das } \\
\text { coordenadas. }\end{array}$ & Frequência, timbre, volume. \\
\hline $\begin{array}{l}\text { Propriedades de Superfície } \\
\text { Normal } \\
\text { Sinal do Gradiente }\end{array}$ & $\begin{array}{lrr}\text { Campo } & \text { estéreo ajuda } & \text { a } \\
\text { identificar } & \text { mudanças } & \text { em } \\
\text { direçōes } & \text { não identificadas }\end{array}$ & $\begin{array}{l}\text { Frequência, campo estéreo, } \\
\text { intensidade, ritmo, tempo, timbre. }\end{array}$ \\
\hline
\end{tabular}




\begin{tabular}{|l|l|l|}
\hline Curvatura Média & visualmente. \\
Curvatura Gaussiana & Mostra alterações na posição & \\
Curvatura Geodésica & que podem não ser identificadas & \\
Geodésicas & visualmente. \\
& Auxilia a percepção de variação \\
& da forma e de identidade da \\
& forma. & \\
\hline
\end{tabular}

Tabela 4.1 - Sonificaçōes implementadas pelo SSound, funcões exercidas por elas e propriedades utilizadas.

Das sonificações apresentadas acima, muitas foram mapeadas em SVol. A sonificação de propriedades não foi abordada neste trabalho. As demais foram implementadas e melhoradas, juntamente com os processos gráficos associados a elas. Os procedimentos visuais associados à execução das sonificações são apresentadas a seguir.

\subsection{Sonificações Passiva e Interativa}

As sonificações em SSound e SVol podem ser classificadas como: sonificações interativas e sonificações passivas.

As sonificações interativas são aquelas funções em que os dados são apresentados na tela de uma só vez, ou seja, primeiramente os dados são mostrados na tela e então o usuário pode interagir com o sistema escolhendo as funções sonoras disponíveis. Os sons são apresentados de acordo com a ação do usuário pela utilização do mouse. Exemplos de sonificações interativas são a sonda sonora e a sonificação da malha do SSound.

Para que se possa implementar as funções interativas no VTK, deve-se utilizar a classe $v t k R e n d e r W i n d o w I n t e r a c t o r$. Essa classe permite que o usuário tenha acesso a alguns eventos especiais, como rotação dos objetos, através do mouse ou de teclas específicas. Para que o usuário possa interagir com o volume renderizado de uma maneira específica, ou seja, não prédefinida pelo VTK, é preciso programar essa interação através de uma função específica, e então utilizar a operação SetUserMethod, pertencente à classe vtkRenderWindowInteractor, para 
indicar a função que cuidará da interação. A função interativa é então acionada, clicando a tecla "u”, após a renderização do objeto na janela do VTK.

Já as sonificações passivas dependem da apresentação progressiva dos dados. Isto é, conforme os dados estão sendo apresentados na tela, a sonificação já está sendo aplicada. Não existe intervenção do usuário durante a apresentação. Um exemplo de sonificação passiva é o mapeamento de coordenadas implementado em SSound.

Em SVol, foi desenvolvido um novo filtro no VTK que possibilita a apresentação dos dados progressivamente para que as sonificações passivas possam ser implementadas no SVol, uma vez que a apresentação no VTK não admite esse tipo de apresentação. Esse novo filtro será explicado no próximo Capítulo desta dissertação.

\subsection{Especificação do SVol}

O projeto SVol (Som Volumétrico), desenvolvido no âmbito do ICMC-USP, visa criar uma biblioteca sonora completa para apoio a técnicas volumétricas de visualização. Esse sistema tem sido desenvolvido como uma extensão de SSound [Min 95a, b, c] apresentado acima. Juntos, SVol e SSound, formarão um conjunto compacto de funções de sonificação para sistemas de visualização de propósito geral e suas funções de interação. O resultado esperado é um conjunto de rotinas que possa ser incorporado a sistemas de visualização, capacitando o usuário a trabalhar com sinais sonoros de apoio às técnicas gráficas.

Com relação à estrutura de SSound, apresentada na figura 4.8, ela é a base também para SVol, de forma que modificações podem ser paulatinamente adicionadas aos níveis mais baixos da estrutura conforme novas técnicas volumétricas e de interação são implementadas.

Com relação à estrutura de sistemas de visualização, a maioria deles admite a utilização de diferentes técnicas visuais independentemente para o mesmo conjunto de dados, e via de regra a interface é do tipo DataFlow [Gal 95], ou seja, módulos de tratamento de dados, geração de imagens e interação são 'conectados' em sequência, e uma rede é formada por vários módulos para uma específica visualização de dados. Essa estrutura está sendo incorporada ao SVol. 
Com relação à interface, a especificação de SVol prevê três tipos de funções sonoras:

1. Módulos específicos de som que podem ser 'conectados' diretamente a dados e imagens (para os casos de funções de identidade de objetos);

2. Funções de interação que devem ser incorporadas aos módulos visuais;

3. Funções de geração sonora em paralelo com a geração gráfica que devem ser incorporadas aos módulos de geração de imagens do sistema de visualização.

A figura 4.9 apresenta o detalhamento dos mapeamentos sonoros de SVol. Essa figura apresenta a distinção entre a sonificação de dados, eventos e operações, e também os tipos diferentes de mapeamentos gráficos. Pode-se também observar a necessidade do sistema de sonificação cuidar de mapeamentos diretamente retirados do processo gráfico e de sonificação de propriedades calculadas a partir da imagem formada. 


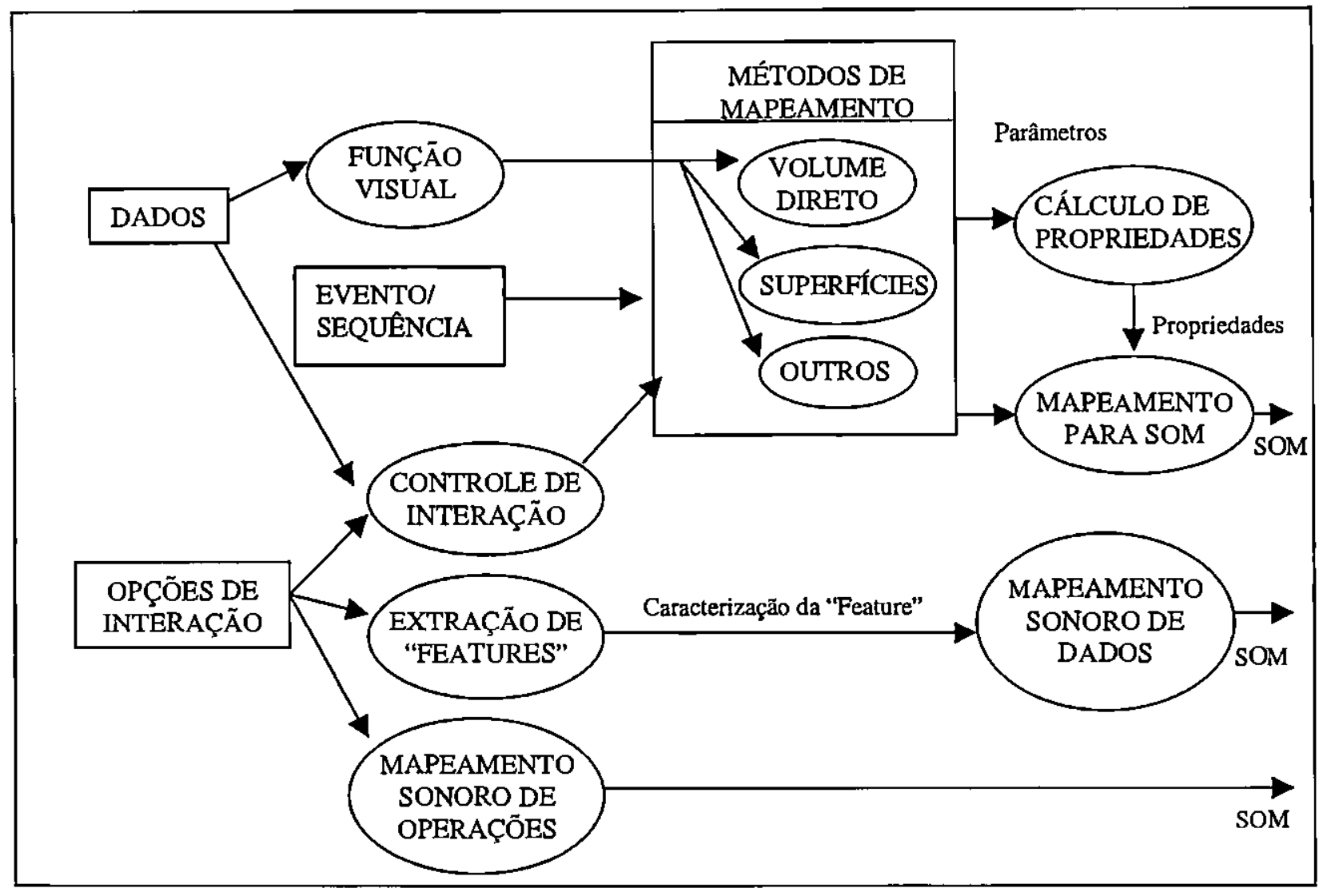

Figura 4.9 - Detalhamento dos mapeamentos no SVol.

SVol e SSound convergem para uma estrutura comum, cuja organização física é apresentada na figura 4.10 .

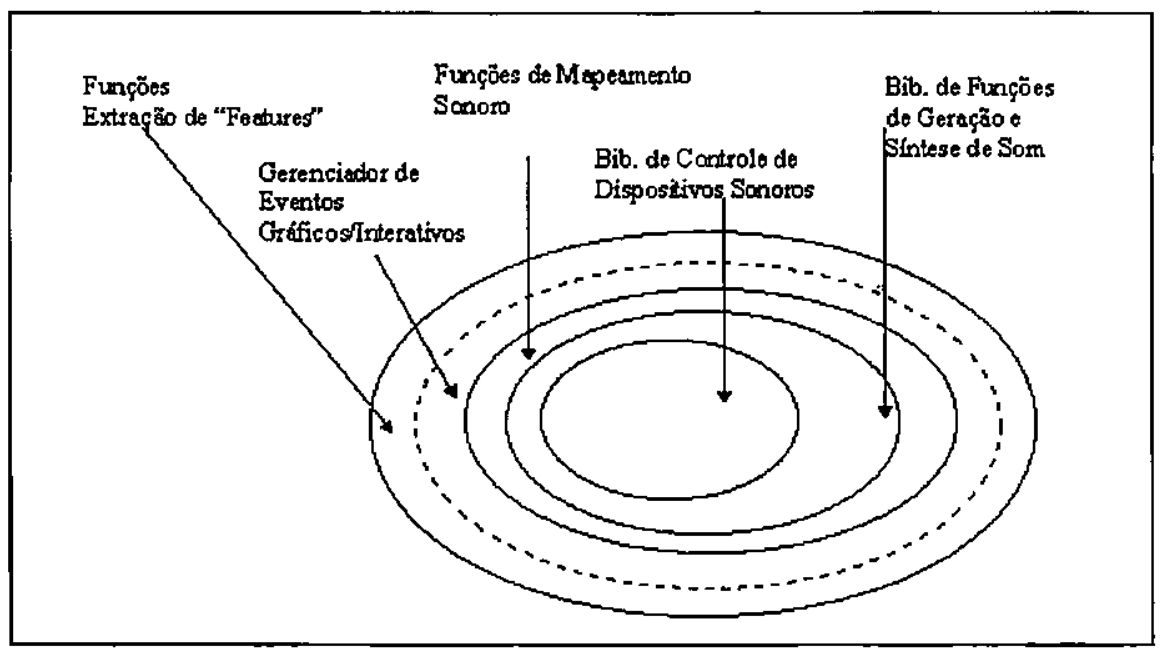

Figura 4.10 - Organização física do sistema de sonificação 
No nível inferior, uma biblioteca de Controle de Dispositivos é responsável por traduzir a 'linguagem' sonora do nível superior em comandos que possam ser entendidos por um dispositivo ou protocolo específico (MDI, funçōes específicas do equipamento ou placa de som utilizada). Para um dispositivo MDI, essas funções foram desenvolvidas para SSound e apenas 'portadas' para o novo ambiente (ver Capítulo 5). As Funções de Geração de Som levam em conta aspectos de temporização e sincronização de eventos nos moldes do método de sonificação desenvolvido anteriormente em SSound. As Funções de Mapeamento Sonoro são responsáveis por traduzir para componentes da linguagem sonora informações numéricas, qualitativas, gráficas, geométricas, e de eventos (os tipos de informações mapeadas para som no sistema de visualização). As informações qualitativas são representadas por 'assinaturas sonoras' de informações específicas dos conjuntos de dados e que não são propriamente numéricas, como identificações de objetos ou características. O Gerenciador de Efeitos Gráficos e Interativos é responsável por detecção de fatores que alteram 'representações em andamento', isto é, tanto ações do usuário quanto algum evento geométrico que causam alterações em displays já em andamento. As funções de Extração de Features dizem respeito aos cálculos e procedimentos que identificam elementos a serem representados "sonoramente", seja por detecção de informações que se está procurando (efeito sonda) ou por cálculo de propriedades selecionadas pelo usuário explicitamentes para sonificação.

Os módulos implementados neste trabalho correspondem à espinha dorsal das camadas de mapeamento sonoro e efeitos gráficos e interativos acima, fazendo uso de bibliotecas anteriormente desenvolvidas para as camadas inferiores. A camada de extração de "features" não foi implementada até o momento.

A atividade básica deste trabalho de mestrado foi reproduzir a parte central do SSound no novo ambiente de programação (VTK no Windows95/NT), preparando o caminho para as futuras pesquisas em sonificação para visualização. Com relação a interface de SVol, foram implementadas funções dos tipos 2 e 3 citados acima.

O próximo Capítulo descreve a implementação de SVol, no contexto colocado aqui. 


\section{SVol - Módulo Multimodal para Visualização Volumétrica}

Ainda não existe um padrão para a geração de sistemas de sonificação. Para que isso aconteça, é preciso muito estudo e pesquisa na definição de alguns aspectos de estímulos auditivos associados a sistemas para análise de dados, além de testes rigorosos dos sistmas de sonificação existentes.

Conforme mencionado no Capítulo 4, o sistema desenvolvido para implementar as idéias apresentadas nessa dissertação é chamado SVol. Ele implementa as funções sonoras para visualização volumétrica baseada em superfícies desenvolvidas anteriormente em SSound [Min 95 a], em uma nova plataforma, e seguindo a abordagem orientada a objetos, além de adicionar algumas sonificações que não estavam presentes em SSound.

Este Capítulo será dividido em duas partes. Na primeira parte do Capítulo, que compreende as seções 5.1 ate 5.4, são apresentados o ambiente computacional, a estrutura e as ferramentas utilizadas para o desenvolvimento do projeto SVol. A Seção 5.1 apresenta o ambiente computacional no qual SVol foi desenvolvido. A Seção 5.2 apresenta o OMT (Object Modeling Technique) [Rum 91], a ferramenta de modelagem orientada a objetos utilizada no desenvolvimento do sistema. A Seção 5.3 apresenta a MIDI Kernel e a Sound Library, que são as camadas de comunicação sonora utilizadas no SVol, e que foram implementadas no contexto do VTK, em um projeto de Iniciação Científica. Na Seção 5.4 é mostrado um panorama geral do sistema SVol, isto é, os processos gráficos gráficos principais que representam o "esqueleto" do sistema sonoro, em cima do qual as sonificações são implementadas. 
A segunda parte deste Capítulo, composta pelas seções 5.5 a 5.8, apresenta o projeto SVol, detalhando sua implementação. A Seção 5.5 apresenta o display progressivo, um processo gráfico desenvolvido que está sendo utilizado nas sonificações passivas de SVol, e o desenvolvimento de um filtro necessário para a criação desse processo. A Seção 5.6 apresenta a sonda sonora desenvolvida para o projeto SVol, mostrando a função de apoio score, utilizada para os cálculos necessários às sonificações. A Seção 5.7 apresenta a sonificação da malha, o último processo gráfico desenvolvido para o sistema SVol. A Seção 5.8 apresenta os casos de testes de SVol. Cada sonificação desenvolvida é associada a pelo menos um dos processos gráficos acima. Em cada Seção as sonificações associadas aos processos gráficos são apresentadas.

\subsection{Equipamento e Software}

Os equipamentos utilizados no desenvolvimento deste projeto de mestrado compreendem de:

1. Um microcomputador Pentium MMX $200 \mathrm{MHZ}$, executando sob Windows NT 4.0;

2. Um Sintetizador Alesis S4 QuadraSynth . O módulo de som S4 é equipado com uma memória ROM expandida de $20 \mathrm{MB}$ otimizada com composição multitimbral e aplicações MIDI. O módulo possui memória que fornece 128 programas e 128 "mixes". Ele permite uma grande variedade de controles via MIDI;

3. Um amplificador FR752 DOLBY SURROUND PRO LOGIC. O sistema possui potência de 400 Watts RMS (4X100 W RMS), modo Dolby 3 Stereo e modo Hall de reprodução sonora, entradas de áudio e vídeo, saídas Pre Rear e Pre Center, além de vários controles de som. Com esse equipamento é possível fazer apresentação das sonificações no ambiente. Com utilização de som surround, a percepção sonora é melhorada.

4. Um Kit Multimídia com placa de som Sound Blaster 64 Pro, também sob controle via MIDI.

5. Compilador Microsoft Visual C++. 
6. Bblioteca de visualização VTK (Visualization Toolkit).

A idéia primordial do SVol é implementar a estrutura e as principais funções do SSound em um novo ambiente, que permita futuros testes controlados, bem como futuro desenvolvimento de novas funções sonoras. Adicionalmente, algumas extensões das sonificações foram implementadas.

A próxima Seção apresenta a técnica de programação orientada a objetos utilizada no desenvolvimento do SVol, a OMT.

\subsection{OMT (Object Modeling Technique)}

Para o desenvolvimento do projeto SVol foi adotada a técnica de programação orientada a objetos e os padrões de desenvolvimento do software usado como base para o desenvolvimento, o VTK [Sch 97]. Para isso foi estudada a técnica OMT, para modelagem orientada a objetos [Rum 91].

\subsubsection{Conceitos de Orientação a Objetos}

Objeto é o principal conceito em sistemas orientados a objetos. Um objeto é uma abstração que engloba as propriedades e operações sobre entidades existentes no sistema em desenvolvimento. Cada objeto tem uma identidade que o distingue de outros objetos do sistema. Os estados de um objeto são denominados atributos (ou variáveis de instância), e seus procedimentos são as operações aplicadas a ele. Juntos, atributos e operações formam as propriedades de um objeto.

Os objetos que compartilham as mesmas propriedades podem ser agrupados em uma mesma classe de objetos. Uma classe de objetos, usualmente chamada apenas de classe, especifica as propriedades que todos os objetos pertencentes àquela classe possuem. Diferentes classes podem conter propriedades com mesmo nome. Quando uma operação com o mesmo nome é aplicada a objetos de diferentes classes ela é denominada polimorfica. 
Herança é um mecanismo de programação que simplifica a adição de novas classes a um sistema quando a diferença entre a nova classe e uma classe existente é pequena. A noção de herança é adaptada da observação de que a maioria dos sistemas pode ser especificada usando um esquema de classificação hierárquica. Organizar objetos em uma hierarquia fornece muitos benefícios. Por exemplo, propriedades de uma classe são utilizadas pelas suas subclasses. Operaçסes são herdadas por classes derivadas, que podem compartilhar operações com as classes definidas em níveis superiores da hierarquia enquanto podem definir as proprias operações, ou mesmo redefinir uma operação herdada.

A herança pode ser derivada de cima para baixo usando um processo chamado especialização ou pode ser criada de baixo para cima através de um processo chamado generalização.

\subsubsection{Modelagem Orientada a Objetos}

A técnica OMT usa três modelos para especificar um sistema orientado a objetos: um modelo de objetos, um modelo dinâmico, e um modelo funcional. Cada modelo descreve um aspecto diferente do sistema e cada um tem uma técnica com diagramas próprios que ajuda na análise e na implementação de sistemas.

O modelo de objetos identifica cada classe do sistema, suas propriedades, e seus relacionamentos com outras classes. A técnica gráfica do OMT para esse modelo usa retângulos para descrever classes de objetos, e uma variedade de conectores para descrever herança e relacionamentos com outros objetos (ver figura 5.1). O retângulo da classe é dividido em três seções separadas por linhas: a primeira contém o nome da classe, a segunda seção contém os atributos e a terceira possui a descrição dos métodos. Os relacionamentos são chamados de associações e possuem vários tipos de cardinalidade: um para um, um para vários, e vários para vários. A herança é representada por um triângulo com a superclasse ligada no topo e as subclasses na base do triângulo. A figura 5.1 mostra um exemplo de modelo de objetos parcial para locação de dispositivos para uma interface gráfica. 


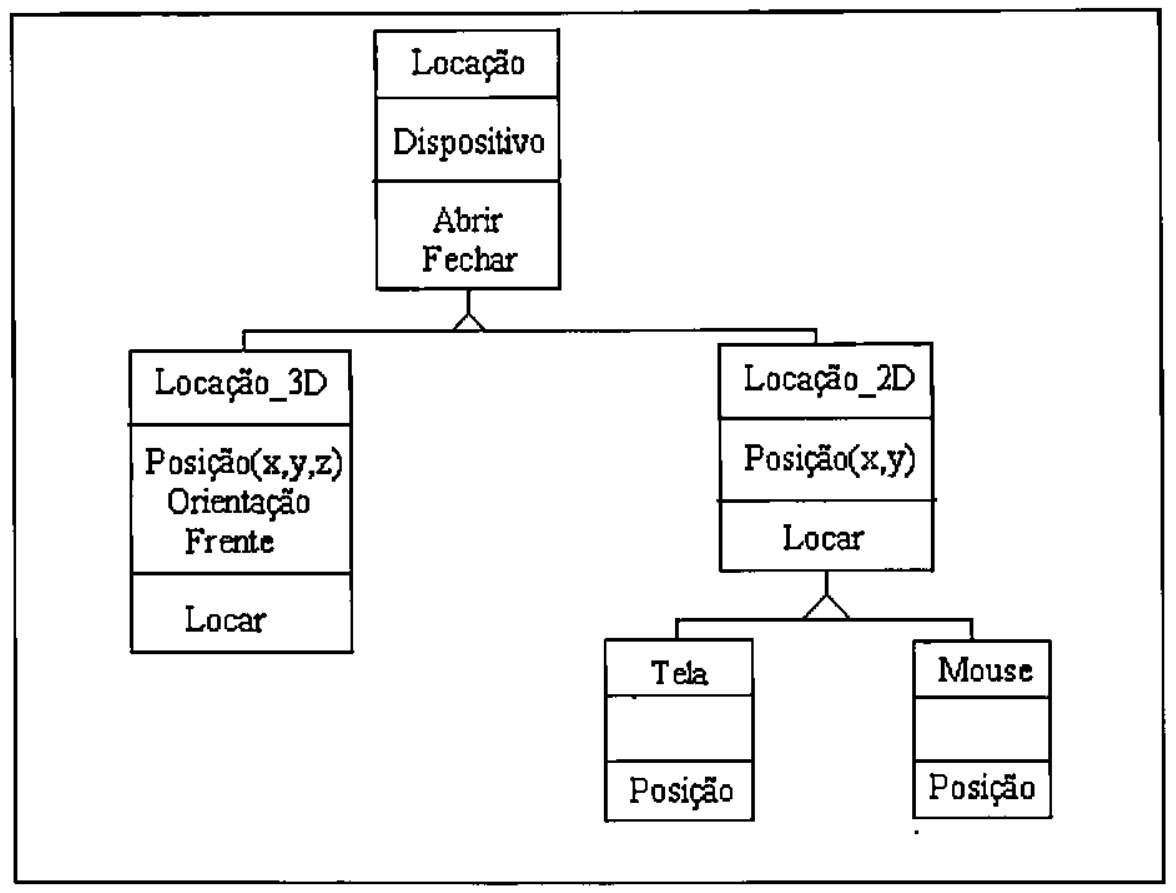

Figura 5.1 - Modelo de Objetos para locação de dispositivos [Sch 97].

O modelo de objetos descreve a porção estática do sistema enquanto o modelo dinâmico detalha a sequência de eventos e dependências temporais do sistema. A técnica OMT usa um diagrama de estados para modelar a parte dinâmica dos sistemas.

O modelo funcional mostra o fluxo de dados pelo sistema, a forma como os processos e algoritmos transformam esses dados, e as dependências funcionais entre os processos. Os DFDs (diagramas de fluxo de dados) são utilizados para descrever o fluxo total de um sistema modelado por OMT.

No desenvolvimento de SVol, algumas das técnicas estão sendo incorporadas no modelo de objetos do VTK. Essas são derivadas de classes existentes no módulo do próprio VTK. Além disso, algumas técnicas interativas são procedurais e adicionadas diretamente à interface. $\mathrm{O}$ modelo funcional e o modelo dinâmico do VTK não existem por se tratar de uma biblioteca. As alterações ocasionadas pela implementação do SVol mantém intacta a arquitetura dataflow, e de 
fato toda a biblioteca original. A próxima Seção apresenta dois módulos do SSound que foram implementados no contexto do VTK e utilizados em SVol.

\subsection{MIDI Kernel e Sound Tools Library}

Esta Seção apresenta duas camadas do sistema SSound que foram traduzidas e melhoradas a partir do SSound para o sistema VTK, e que foram empregadas no sistema SVol: a MIDI Kernel e a Sound Tools Library (vide figura 4.8 desta dissertação). Essa implementação foi realizada em um projeto de Iniciação Científica [Pac 97]. Essas classes são a implementação das camadas "Biblioteca de Controle de Dispositivos Externos" e "Biblioteca de Funções de Geração e Síntese de Som", do esquema apresentado na figura 4.10, e geram mensagens MIDI de acordo com as requisições dos módulos de sonificação.

O uso de MDI (Musical Instrument Digital Interface) para controlar equipamentos de síntese sonora fornece um bom grau de generalização do que os algoritmos de síntese sonora com a garantia de boa qualidade de produção de sons a um custo razoável [Min 95a]. A maioria dos equipamentos sonoros implementa um subconjunto de mensagens MIDI, o que torna a adaptação fácil. Um conjunto de procedimentos, chamado de $M I D I$ Kernel, foi criado para fazer o gerenciamento do empacotamento de mensagens.

\subsubsection{MIDI Kernel}

A MIDI Kernel é responsável pela construção de pacotes de mensagens MIDI e seus parâmetros, que sejam aceitos pelo módulo sonoro. Nele é implementado um conjunto de possíveis comandos e construídas mensagens para comandos específicos dos programas "clientes".

Esse objeto implementa operações que realizam a inicialização e finalização da comunicação com o dispositivo MDI, a definição de um pacote com mensagens MIDI, a inclusão de mensagens em um pacote já inicializado, a definição de um canal inicial e o envio de mensagens. A descrição dessa classe é mostrada no apêndice A desta dissertação. 


\subsubsection{Sound Tools Library}

Um sistema sonoro foi desenvolvido para fornecer um número de objetos com operações sonoras básicas além de estruturas sonoras para apoiar os processos de sonificação. Esse sistema gerencia a comunicação entre os processos de sonificação e a MIDI Kernel, além do timbre e do status dos componentes sonoros e das suas temporizações. Com o uso desses objetos consegue-se fazer mapeamento de valores para frequências; calcular correspondência de acordes; gerar distribuição do canal estéreo; mapear valores numéricos para propriedades do som como distorção de entoação; 'tocar' uma nota por um curto período; iniciar ou finalizar uma nota; e "tocar" várias notas de várias formas; além de controle de canais, volume, timbre e silêncio. As principais funções implementadas na Sound Library são apresentadas no apêndice A dessa dissertação.

A próxima Seção apresenta um panorama geral dos componentes do sistema desenvolvido.

\subsection{Panorama Geral do Projeto SVol}

Todos os processos gráficos e sonoros do SVol foram implementados para dados escalares armazenados em malhas estruturadas, ou grid estruturado, conforme apresentado na Seção 4.2 dessa dissertação. Entretanto, a maioria das sonificações fazem o mesmo sentido se aplicados a outras organizações de dados, e deverão no futuro acomodar essa possibilidade.

O projeto SVol manteve a estrutura adotada pelo sistema SSound [Min 95 a b c], conforme mencionado na Seção 4.6. Os processos gráficos associados aos objetos de sonificação pode ser divididos em três componentes distintos que identificam a espinha dorsal do sistema SSound. Esses componentes são apresentados na figura 5.2. No contexto do presente projeto, eles representam a base para o desenvolvimento da maioria das funções sonoras do SVol, uma vez que os processos gráficos direcionam as apresentações sonoras e são responsáveis pela maioria dos cálculos necessários para as sonificações. Todas esses processos utilizam as classes MIDI Kernel e o Sound Functions mencionadas na Seção 5.3. 


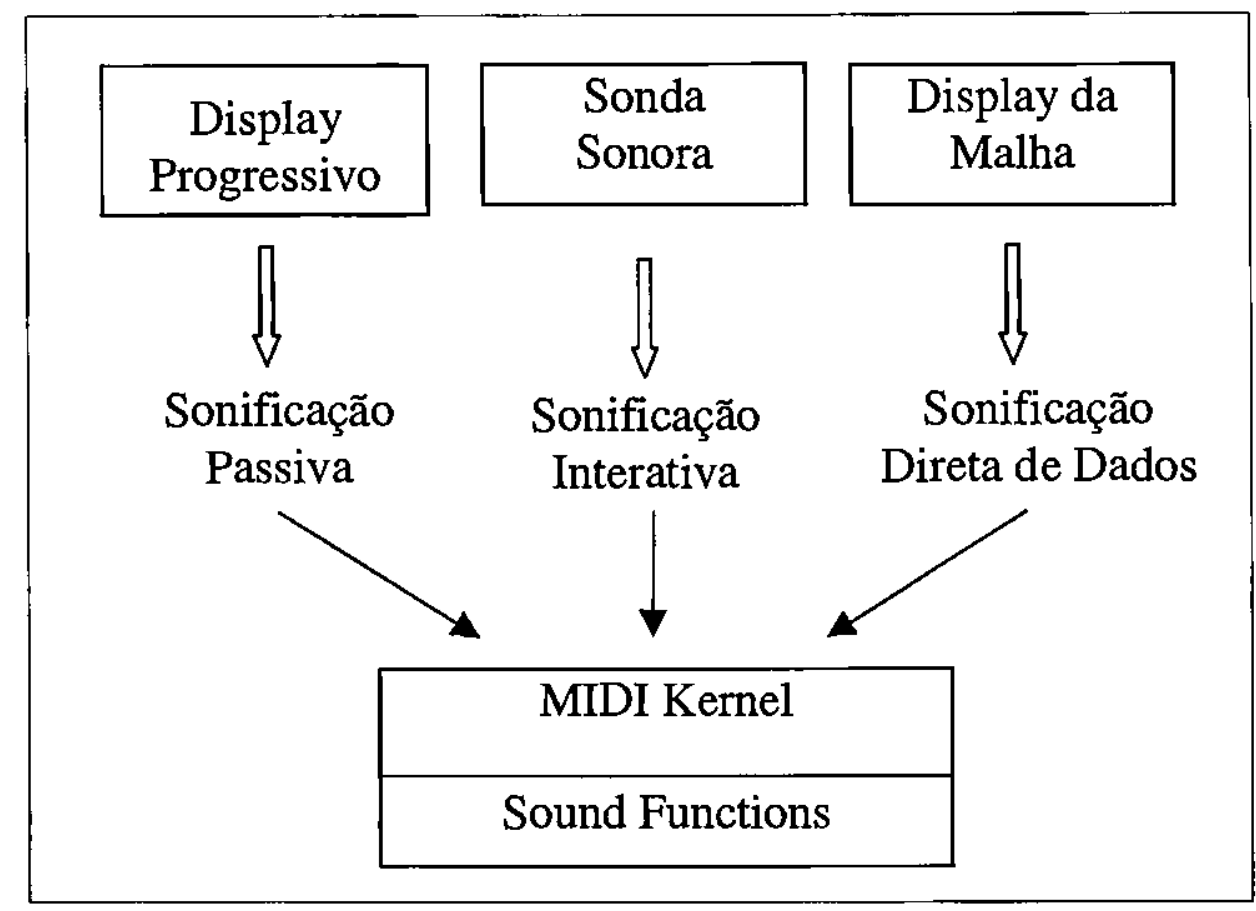

Figura 5.2 - Espinha dorsal do sistema SVol.

No VTK, como em muitos outros sistemas gráficos, objetos são "renderizados" totalmente e apresentados de uma só vez, ou seja, quando um objeto é apresentado na tela, todos os cálculos necessários para sua apresentação já foram realizados. Entretanto, para uma parte das sonificações isso não é satisfatório, uma vez que o processo de mapeamento de dados para gráficos carrega consigo informações úteis. Assim, foi necessário elaborar um esquema para apresentação sucessiva de partes do objeto sob análise, conforme eles são criados. Esse esquema foi chamado de Display Progressivo.

O Display Progressivo é a apresentação dos objetos gráficos conforme eles são gerados, ou seja, a representação gráfica dos dados do volume é apresentada fatia a fatia ao invés de apresentada de uma única vez. Com base na parte gráfica do Display Progressivo, pode-se controlar a sonificação de propriedades de fatias do volume, de superfícies, e propriedades estatísticas dos dados. Essa parte gráfica do SVol foi implementada com o auxílio de um novo filtro criado para o VTK, que separa subvolumes a partir de um volume inicial. Esse novo filtro é apresentado na Seção 5.5 deste Capítulo. 
A Sonda Sonora, apresentada na Seção 5.6, é representada por uma entidade gráfica que caminha dentro do volume sob análise detectando informações. Com base na Sonda Sonora, várias sonificações podem ser implementadas, como a sonificação de propriedades volumétricas e a detecção de características. A parte gráfica da sonda sonora também foi implementada para o SVol. Além disso, foram implementadas algumas das sonificações utilizadas na sonda, como a sonificação da densidade local da sonda sonora e da "população" da sonda sonora em relação ao volume total.

O terceiro e último processo gráfico do projeto é o Display de Malha, que molda a parte visual da sonificação direta de dados. O Display de malha consiste de um mapeamento ortogonal simples das linhas da malha sobre a janela, com sonificação controlada pelo movimento do mouse sobre essa projeção. Como apoio ao componente gráfico foi utilizado um novo filtro que faz a projeção de dados, e foi implementada uma função sonora para o mapeamento de escalares. Esse processo é apresentado na Seção 5.7.

\subsection{Display Progressivo}

O display progressivo foi implementado para possibilitar o desenvolvimento de sonificaçб̋es passivas no projeto SVol, como a sonificação das coordenadas de um volume que transforma em sons as coordenadas $\mathrm{x}, \mathrm{y}$ ou $\mathrm{z}$.

O que as sonificações passivas têm em comum é a necessidade de que os sons apresentados sejam associados a alguma modificação no objeto na tela. A modificação provocada pela própria criação do objeto em tela é, em visualização, a mais significativa delas.

Para que fosse possível o desenvolvimento de funções desse tipo foi necessária a implementação de um novo filtro, no sistema VTK, que separasse do volume original (tipo vtkStructuredPoints) um subvolume qualquer, relativo às coordenadas $\mathrm{x}, \mathrm{y} \mathrm{e} \mathrm{z}$ (também vtkStructuredPoints). Assim, foi desenvolvido um novo filtro chamado vtkStructuredPointsSubVolume, derivado das classes de filtros do VTK. 
O filtro vtkStructuredPointsSubVolume recebe como entrada uma estrutura de dados do tipo pontos estruturados (vtkStructuredPoints), que representa o volume total dos dados sob análise. Em seguida é definido o subvolume a ser extraído do volume total, especificando as suas coordenadas mínimas e máximas em cada direção, através do método SetExtent $\left(\mathrm{x}_{\text {mínimo, }} \mathrm{x}_{\text {máximo, }}\right.$, $\mathrm{y}_{\text {mínimo }}, \mathrm{y}_{\text {máximo }}, \mathrm{z}_{\text {mínimo }}, \mathrm{z}_{\text {máximo }}$ ). Com isso, é possível obter, como saída do filtro, um subvolume que mantém a organização de pontos estruturados. As linhas de código na figura 5.3 mostram como o filtro vtkStructuredPointsSubVolume deve ser adicionado a um pipeline de visualização qualquer.

vtkStructuredPointsSubVolume *subVolume;

subVolume $=$ new $v$ tkStructuredPointsSubVolume;

subVolume->SetInput(Objeto1->GetOutput());

subVolume->SetExtent $(0,1,0,18,0,29)$;

Objeto2->SetInput (subVolume->GetOutput());

(a)

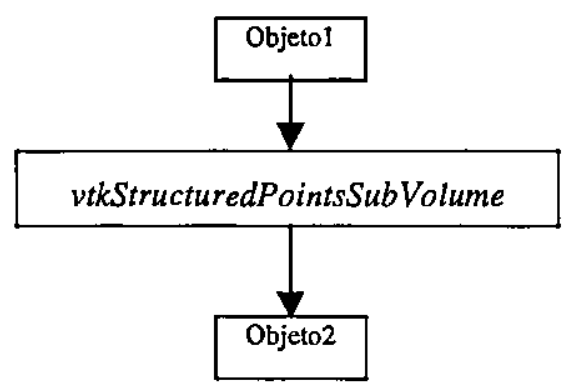

(b)

Figura 5.3- Filtro vtkStructuredPointsSubVolume.

(a) - Exemplo de utilização do filtro.

(b) - Pipeline de visualização incluindo o vtkStructuredPointsSubVolume.

Como mostra a figura 5.3(a), primeiramente deve ser criado um objeto da classe, o subvolume. Em seguida, deve-se definir a entrada do filtro, nesse caso, a saída do objeto Objetol. Por último devem ser especificadas as coordenadas mínimas e máximas do subvolume. A saída do filtro pode ser utilizada por qualquer outro objeto do VTK que aceite dados do tipo vtkStructuredPoints, através do método GetOutput().

Os valores default para a extensão do subvolume são 0 para o valor mínimo das coordenadas, e 1 para o valor máximo das coordenadas. A página de manual para $o$ filtro vtkStructuredPointsSubVolume, seguindo o modelo estabelecido pelo próprio manual do VTK, é apresentada no apêndice $\mathrm{B}$ desta dissertação. 
A figura 5.4 mostra a colocação do vtkStructuredPointSubVolume na hierarquia de classes do VTK.

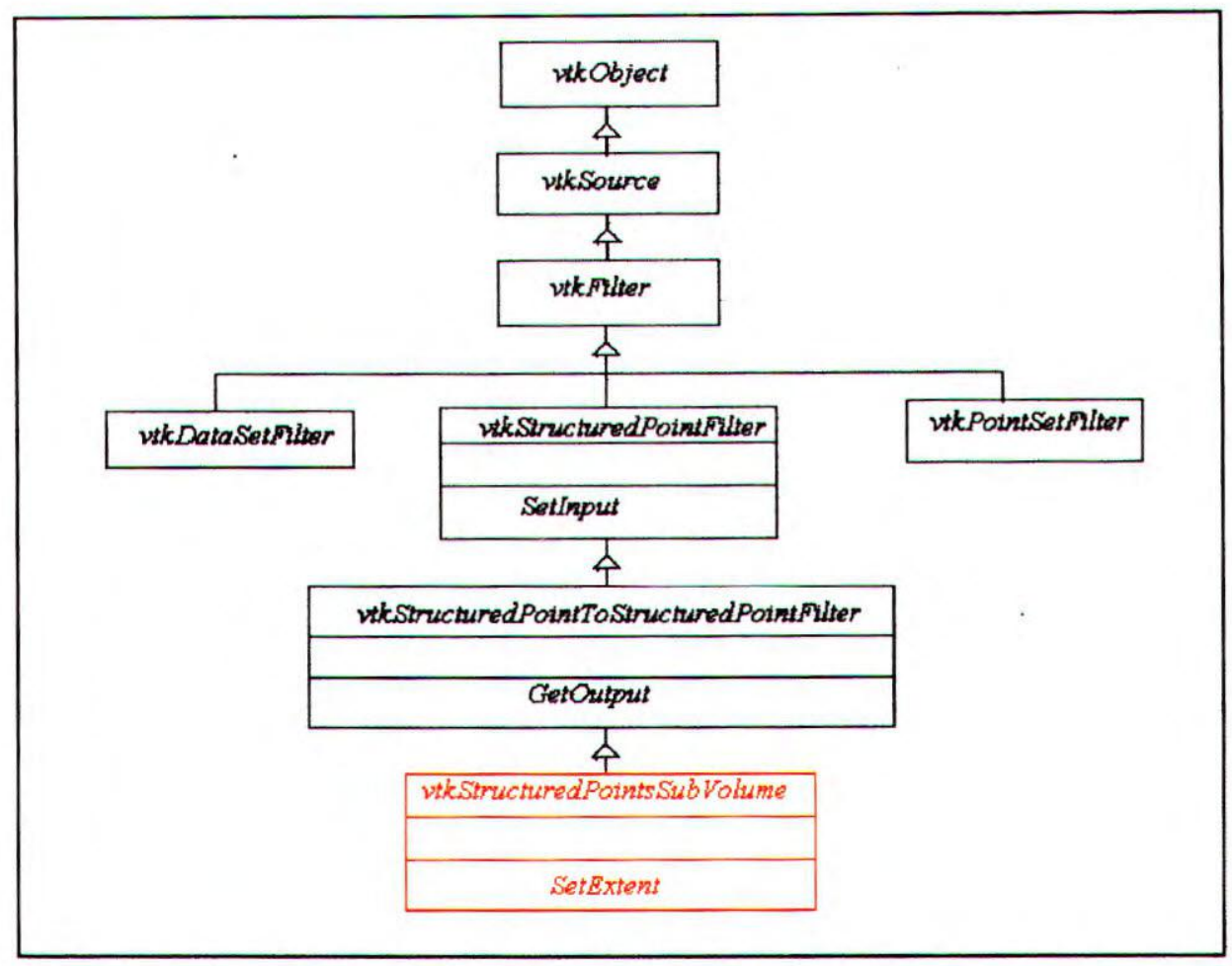

Figura 5.4 Diagrama de objetos do VTK incluindo o novo filtro.

O objeto no fim da hierarquia é o novo filtro adicionado à hierarquia do VTK. Os demais são objetos pré-definidos.

A codificação desse filtro seguiu os padrões estabelecidos pelo sistema VTK.

Para a apresentação do Display Progressivo ocorrer, o usuário precisa acionar a função de interação das sonificações, pressionando a tecla "u" (conforme especificado na Seção 4.5), após a apresentação da tela gráfica. Nesse momento, o filtro vtkStructuredPointsSubVolume é repetido várias vezes, dependendo da dimensão das coordenadas escolhidas pelo usuário, aumentando em uma fatia a cada repetição. Esses passos são mostrados nas linhas de código apresentadas na figura 5.5, que inclui o acionamento de duas das sonificações associadas ao Display Progressivo. Essas sonificações são apresentadas na próxima Seção. 


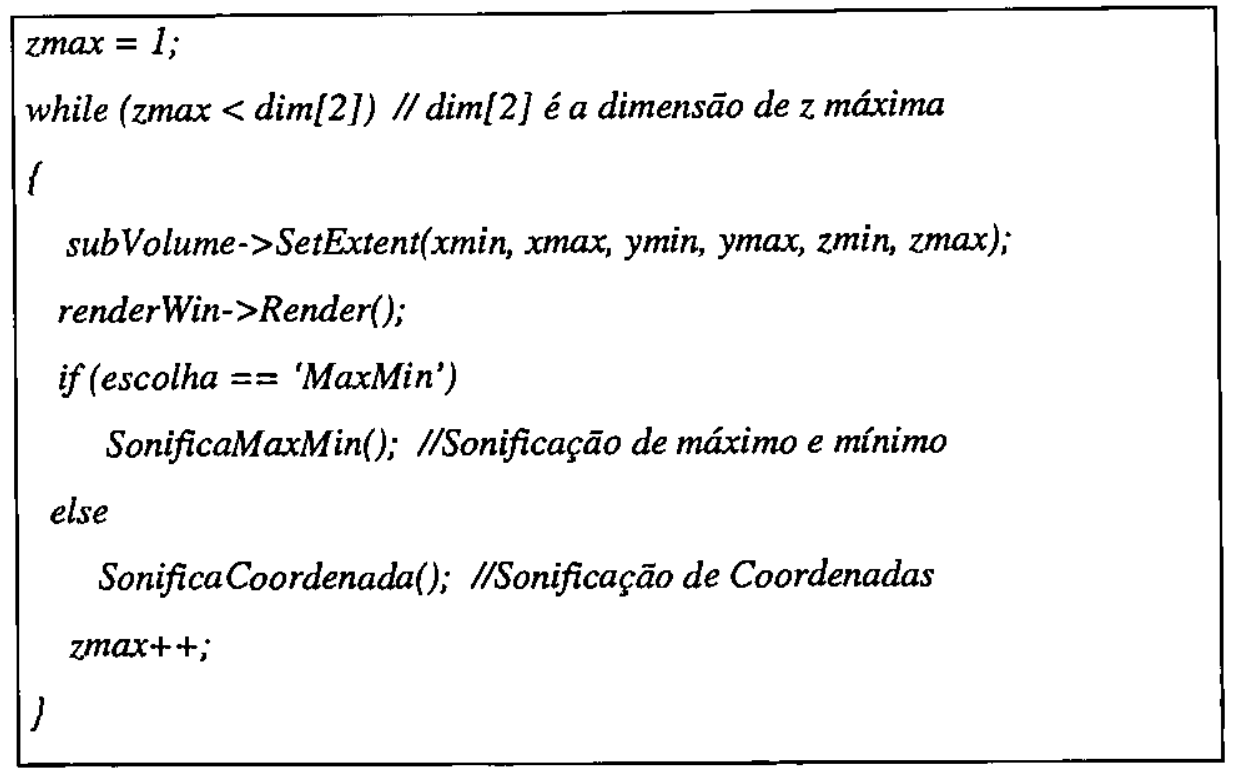

Figura 5.5 -Linhas de código do Display Progressivo, apresentando a coordenada z. A variável $\operatorname{dim}[2]$ é a dimensão da coordenada escolhida pelo usuário (nesse caso z). 0 laço If seleciona a escolha do tipo de sonificação feita pelo usuário.

\subsubsection{Sonificações do Display Progressivo}

Dentre os tipos de sonificação implementados para o Diplay Progressivo está a sonificação dos valores máximo e mínimo da coordenada a ser mostrada. Conforme as fatias do volume vão sendo apresentadas em sequência, os valores máximo e mínimo de coordenadas da fatia em questão são mapeados para frequência, e para timbres diferentes (valor máximo em um determinado timbre e valor mínimo em outro timbre). Essa sonificação permite ao usuário observar os valores máximo e mínimo de cada fatia de uma coordenada escolhida, o que não é possível observar visualmente.

No caso de sonificação de máximos e mínimos, dois novos sons são ouvidos em sequência a cada fatia apresentada (cada som é representado por um timbre diferente para que o usuário possa distinguí-los). Frequências próximas equivalem a um intervalo de dados curto, ou seja, os valores máximo e mínimo da coordenada se encontram próximos. Frequências distantes equivalem a um intervalo de dados maior. A frequência em si (sons agudos ou graves) mostra o posicionamento do intervalo de dados na escala daquela coordenada.

O outro tipo de sonificação implementada para o Display Progressivo foi a sonificação da própria coordenada que está sendo mostrada. Ou seja, conforme a apresentação está ocorrendo a 
coordenada está sendo sonificada, em mapeamento para frequência. Nesse caso, o som apenas "marca"o momento em que a nova fatia vai ser adicionada à figura. Com isso o usuário se fixa na progressão das demais variáveis, com relação ao aumento da variável apresentada por som. Isso auxilia a verificação de dependências entre variáveis.

O funcionamento do display progressivo em SVol ocorre da seguinte maneira: primeiramente o usuário deve escolher qual coordenada ele deseja que o sistema sonifique, além de escolher quais contornos ele deseja visualizar e que tipo de sonificação ele deseja ouvir, como mostra a figura 5.6. Depois da escolha feita, o sistema renderiza o volume fatia por fatia, de acordo com a coordenada e contornos escolhidos, e sonifica essa coordenada simultaneamente, de acordo com o tipo de sonificação escolhido.

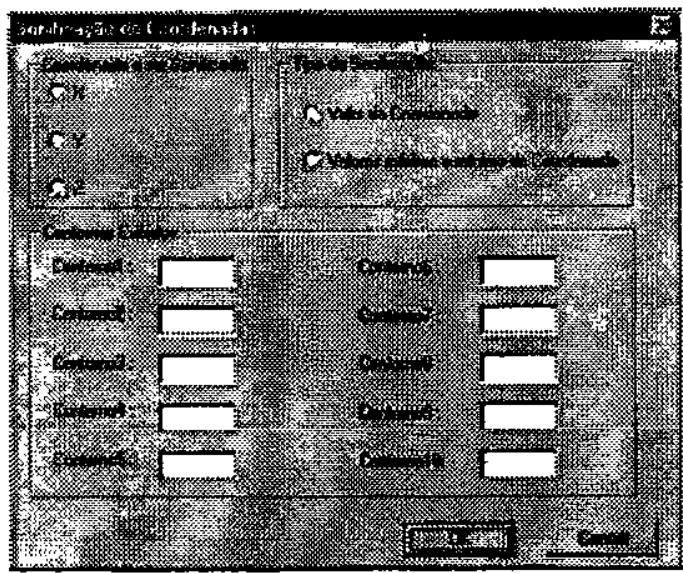

Figura 5.6 - Interface da sonificação das coordenadas de um volume do sistema SVol.

A figura 5.7 mostra uma sequência das fatias apresentadas no display progressivo implementado em SVol. A cada nova fatia, um som é ouvido, que representa a escolha de sonificação feita pelo usuário.

Os dados utilizados no exemplo são valores de substâncias medidas no Mar do Norte [Day 97], que variam ao longo do ano (eixo $\mathrm{z}$ ). $\mathrm{O}$ eixo $\mathrm{x}$ representa latitude $\mathrm{e} O \mathrm{o}$ eixo y representa longitude. Esses dados são resultados de coletas de fluxos e produção das substâncias DMS, DMSp e Clorofila no Mar do Norte, entre fevereiro e outubro de 1989. Essa pesquisa foi realizada na Universidade East Anglia, Reino Unido. 


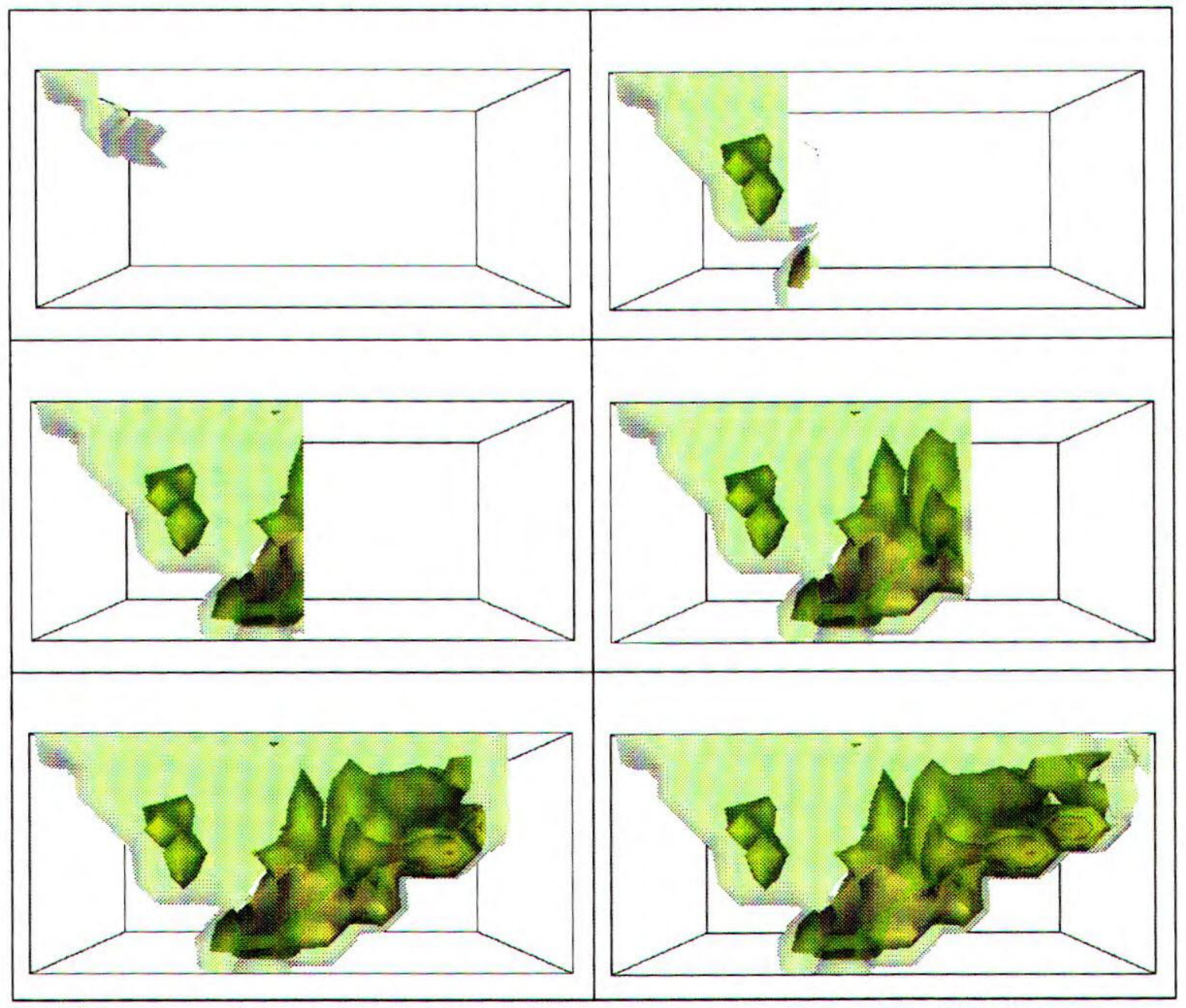

Figura 5.7 - Sequência de passos do Display Progressivo.

Assim como essas sonificações foram implementadas em SVol, outras sonificações podem ser facilmente adicionadas utilizando os recursos do display progressivo como, por exemplo, a apresentação sonora dos escalares armazenados em cada fatia apresentada, a sonificação de um contorno específico enquanto outros estão sendo apresentados visualmente, e a sonificação dos vetores armazenados nas fatias, além de muitas outras.

\subsection{Sonda Sonora}

A sonda sonora, presente em SSound, foi re-projetada e implementada para o projeto SVol. Essa função gráfica é utilizada para separar um determinado trecho do volume em análise, e investigar o conteúdo volumétrico num objeto estático utilizando sons. 
A nova sonda sonora, implementada no contexto do VTK, recebe como entrada um volume de pontos estruturados (vtkStructuredPoints) e apresenta na tela o volume total envolto em uma borda, além de uma segunda borda (a sonda), dimensionada de acordo com a escolha do usuário. $\mathrm{O}$ sonda pode ser movimentada pelo usuário para que ele possa investigar o conteúdo do volume limitado pela sonda, selecionando partes de interesse. Os sons fornecem informações sobre o conteúdo da sonda.

Para que todos os movimentos sejam realizados, a tela gráfica, onde o volume é apresentado, foi dividida em nove quadrantes imaginários como mostra a figura 5.8. Para que o usuário consiga movimentar a sonda, ele deve seguir o esquema apresentado na figura 5.8.

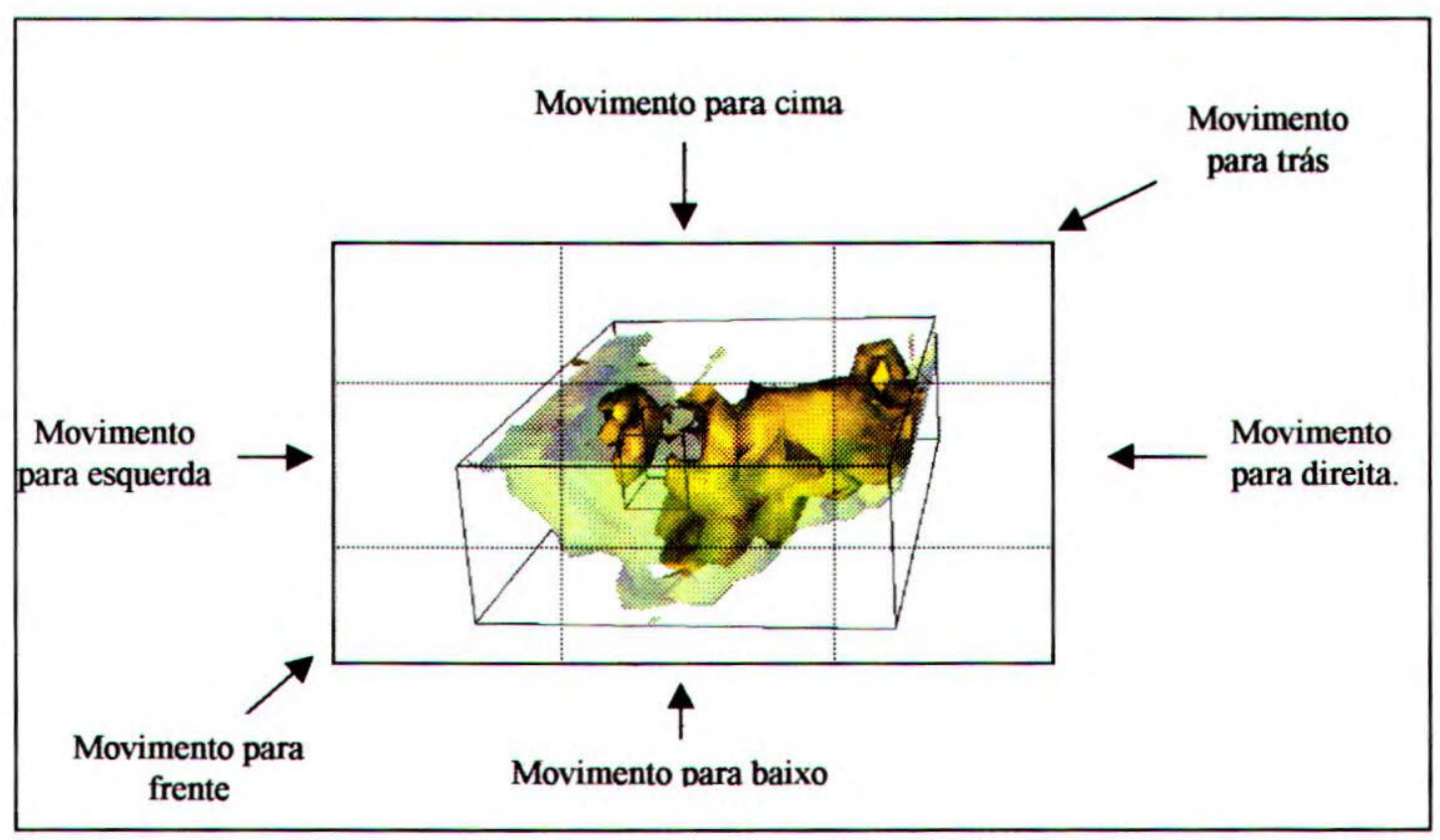

Figura 5.8 - Esquema para o movimento da sonda sonora.

Quando o usuário desejar que a sonda se movimente para alguma direção ele deve pressionar o botão esquerdo do mouse em algum ponto dos quadrantes específicos mostrados na figura 5.8. 0 movimento pode ser realizado quantas vezes forem necessárias.

Movimentando a sonda é possível investigar o subvolume específico contido dentro dela, e para que isso aconteça é preciso coletar informações sobre esse subvolume, como, por exemplo, a quantidade de valores de interesse que está contida dentro da sonda ou a quantidade de triângulos 
formados pelo algoritmo de contorno. Para obter essa informação, foi implementada a função score explicada na próxima Seção.

\subsubsection{Função Score}

A função score estabelece um esquema de pontuação para um voxel. Um ponto é associado a cada triângulo formado no voxel, determinado pelo algoritmo de contorno marching cubes, definido na Seção 4.1 desta dissertação.

Em cada voxel existem 16 possíveis casos de triangulação, de acordo com o algoritmo mencionado. Uma vez que o caso de um voxel específico é encontrado, é possível conhecer quantos triângulos serão gerados naquele voxel. Esses valores são fixos, como pode ser observado na tabela 5.1, exceto quando o número de valores encontrados é 4 . Nesse caso, podem ser gerados 2 ou 4 triângulos, dependendo da configuração do voxel.

\begin{tabular}{|c|c|}
\hline Numero de Valores $>=$ isovalor & $\begin{array}{c}\text { Número de triângulos formados } \\
\text { (pontuação) }\end{array}$ \\
\hline 0 & 0 \\
\hline 1 & 1 \\
\hline 2 & 2 \\
\hline 3 & 3 \\
\hline 4 & 2 ou 4 \\
\hline 5 & 3 \\
\hline 6 & 2 \\
\hline 7 & 1 \\
\hline 8 & 0 \\
\hline
\end{tabular}

Tabela 5.1 - Pontos encontrados pela função score. Isovalor é o valor de interesse, responsável pela geraçāo da isosuperficie dentro do volume.

A decisão entre 2 ou 4 triângulos para o caso 4 acima é feita conferindo-se a configuração do voxel. Se todos os pontos encontrados no voxel ocorrem em vértices da mesma face, serão formados 2 triângulos, caso contrário serão formados 4 triângulos. Todos os voxels do volume incluídos na sonda são testados com relação a cada valor de interesse, e o resultado é somado. 
O número de triângulos é a base para o cálculo do número de pontos (score) de cada subvolume da sonda e para o cálculo da função de sonificação. O número de pontos do subvolume é a soma dos triângulos formados em cada voxel do subvolume, e é usado para os cálculos de opupação e densidade da sonda, mencionados acima e especificados no próximo item.

\subsubsection{Sonificações da Sonda Sonora}

Quando o movimento da sonda é realizado, existe uma série de respostas sonoras que podem ser fornecidas, dependendo de uma escolha feita pelo usuário. A primeira função sonora implementada em SVol é a densidade local, isto é, a ocupação da sonda sonora, que calcula o conteúdo ocupado pela sonda sonora dividido pelo conteúdo máximo possível para a própria sonda sonora, indicando quão "cheia" ou "vazia" ela está.

\section{Quantidade ocupada da sonda sonora \\ Densidade Local $=$ \\ Quantidade máxima que a sonda sonora poderia conter}

A cada movimento da sonda, sua densidade local é calculada, mapeada para frequência e sonificada. Frequências baixas, ou seja, sons graves, representam alta ocupação da sonda. Altas frequências (sons agudos) representam baixa ocupação da sonda. Nessa sonificação o usuário consegue distinguir quão "cheia" ou "vazia" a sonda está a cada movimento realizado. A frequência mínima é correspondente a sonda "totalmente cheia", isto é, existe na sonda o número máximo de triângulos que ela poderia conter. A frequência máxima corresponde a sonda vazia.

Essa escolha para o mapeamento é devida ao fato de que associamos baixas frequênicas a objetos ou eventos "pesados", "lentos" e "cheios", enquanto sons agudos são mais naturalmente associados a leveza, rapidez e espaços vazios.

A segunda função sonora implementada é a população da sonda sonora, isto é, a relação entre o conteúdo da sonda sonora e o volume total analisado. Esse valor (número de triângulos no 
volume) é dado pelo conteúdo ocupado pela sonda sonora dividido pelo conteúdo máximo do volume total.

Quantidade do objeto ocupada pela sonda sonora

População da Sonda Sonora $=$

Quantidade máxima do volume

Para essa sonificação, a cada movimento da sonda é calculada a quantidade do volume contido na sonda em relação ao volume total. Essa quantidade é então mapeada para frequência e sonificada em seguida. Frequências altas representam pouca quantidade de valores de interesse na sonda em relação ao volume total. Baixas frequências representam grande quantidade de valores de interesse encontrados na sonda em relação ao volume total.

No caso da sonificação da população da sonda, o usuário consegue identificar, no volume total, os locais de maior ou menor concentração de valores de interesse, e pode utilizar esse resultado para refinar sua análise do volume.

As funçōes sonoras que utilizam o processo gráfico da sonda sonora auxiliam o usuário a "navegar" o volume sem refazer a renderização ou recorrer a complexos e lentos processos de "mergulhar" no interior do volume. Além das funções implementadas em SVol, outras também podem ser implementadas utilizando esse processo como a presença e quantidade de um valor específico dentro da sonda, número de valores de interesse dentro da sonda, existência de valores especificados pelo usuário, densidade "visual" (incluindo transparência), detalhes de forma , e densidade de vetores.

O funcionamento da sonda sonora em SVol ocorre da seguinte maneira: inicialmente o usuário deve escolher os contornos a serem visualizados, que função sonora deve ser realizada, e também a dimensão inicial da sonda sonora. A dimensão default da sonda é de uma unidade em todas as coordenadas $(\mathrm{x}, \mathrm{y}, \mathrm{z})$, isto é, o tamanho de um voxel. Esse tamanho pode ser alterado pelo usuário A figura 5.9 mostra a tela inicial do processo. 


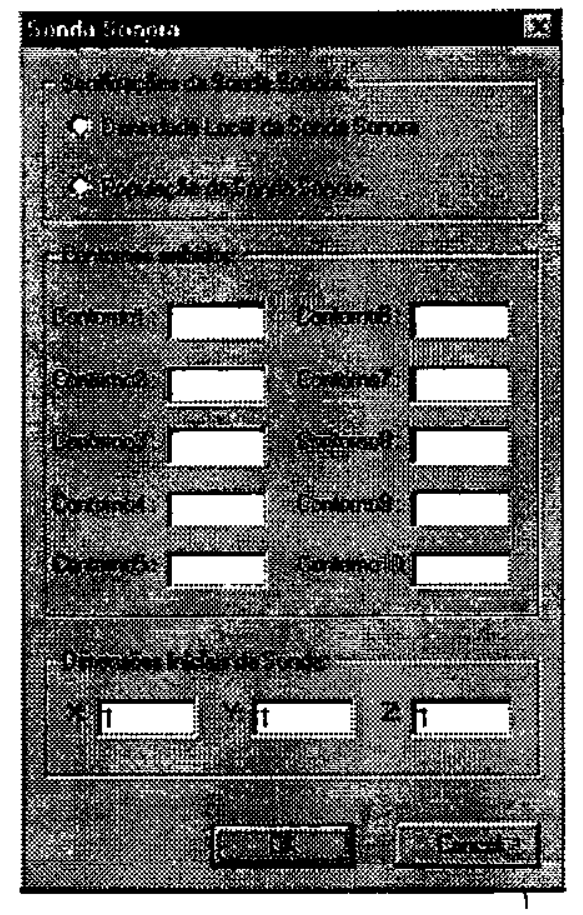

Figura 5.9 - Interface de escolha da parte grafica Sonda Sonora desenvolvida em SVol.

Assim que as escolhas são feitas deve ser acionado o botão "OK" (mostrado na figura 5.9) e então o volume é apresentado juntamente com a sonda sonora, inicialmente no canto "superior esquerdo" do volume.

Para que as sonificações interativas da sonda sejam ativadas, deve-se acionar a função de interação da sonificação, selecionando a tecla "u" (conforme especificado na Seção 4.5 desta dissertação), após a apresentação da tela gráfica. Essa opção desvia o controle da interação para um procedimento do programador; nesse caso, a própria sonda sonora Assim, é possível movimentar a sonda em todas as direç̃es do volume, clicando o botão esquerdo do mouse em determinadas posições na tela gráfica, como apresentado anteriormente.

A próxima Seção apresenta o Display da malha, último processo gráfico desenvolvido em SVol, e suas sonificações. 


\subsection{Display da Malha}

A forma mais imediata de mapeamento sonoro é mapear os dados diretamente da malha para parâmetros sonoros. Como foi visto no Capítulo 3 desta dissertação, em Visualização Científica existem vários tipos de dados existentes. $O$ tipo utilizado neste projeto é o grid volumétrico com espaçamento uniforme, contendo valores escalares. No entanto, mapeamentos semelhantes podem ser realizados para outros tipos de malhas, contendo dados de natureza não escalar.

Algumas vezes uma grande quantidade de informação pode ser obtida observando o dado no grid original. O display da malha, implementado em SVol, dá ao usuário a opção de verificar valores, padrões e estruturas que não são possíveis de serem visualizados, através do som. Nessa sonificação, o grid 3D é mapeado em um grid 2D através de um filtro implementado em um projeto de iniciação científica, o vtkProjectionFilter [Lic 98] deste Capítulo. Com o grid 2D, o usuário tem uma estrutura para interpretar a posição do dado no espaço, conforme ilustrado na figura 5.10 abaixo.

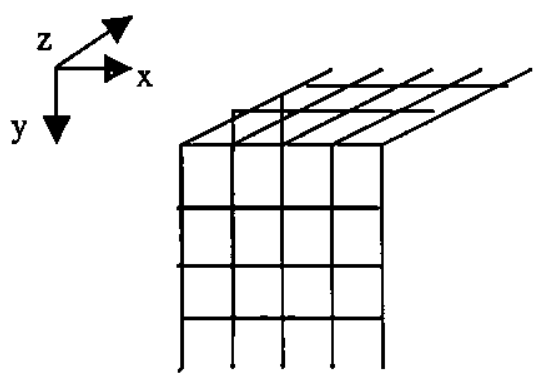

(a)

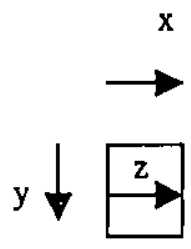

(b)

Figura 5.10 - Display da Malha. O Grid 3D é representado em tela por um grid 2D.

(a) - Grid 3D e suas direçōes e sentidos.

(b) - Grid 2D e suas direçōes e sentidos.

Como mostra a figura 5.10, os dados das coordenadas $\mathrm{x}$ e y são mapeados diretamente no plano $\mathrm{x}$-y da tela. Os dados da coordenada $\mathrm{z}$ são mapeados horizontalmente em cada "retângulo" do plano $x-y$ da tela. Conforme o usuário "move" o cursor sobre a projeção da malha, sons são ouvidos, correspondentes aos valores armazenados na malha. Para que esse mapeamento fosse realizado, foi utilizado o filtro vtkProjectionFilter apresentado na próxima Seção. 


\subsubsection{Filtro vtkProjectionFilter}

O filtro vtkProjectionFilter, derivado das classes de filtros do VTK, aceita como entrada dados poligonais ( $v t k P o l y D a t a)$ tridimensionais, e fornece como resultado dados poligonais bidimensionais, que são a projeção ortogonal dos dados de entrada. O eixo de projeção (x-y, y-z ou $\mathrm{x}-\mathrm{z}$ ) é definido pelo usuário do filtro através do médoto SetPlane(), conforme ilustrado na figura 5.11.

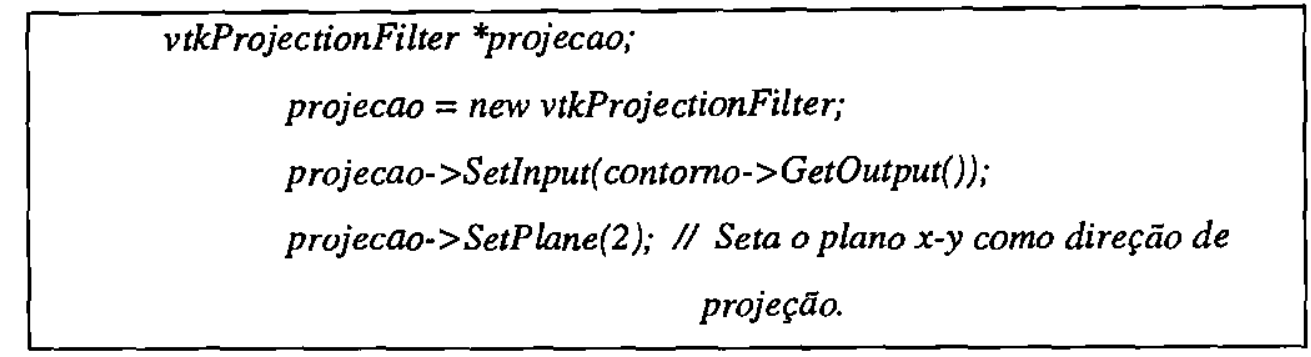

Figura 5.11 - Linhas de código do display da malha.

O objeto projeçäo é do tipo vtkProjectionFilter (filtro que faz a projeção ortogonal dos dados iniciais). Esse objeto recebe como entrada um objeto poligonal e realiza sua projeçāo.

A figura 5.11 mostra uma parte das linhas de código do display da malha do SVol. Depois de lido o arquivo de dados e passados os contornos desejados, é feita a projeção dos dados. No caso do exemplo, os dados foram projetados no plano x-y (projeção-> SetPlane(2)). O filtro também dá as opções de projeção no plano y-z (projeção-> SetPlane(0)) e projeção no plano y-z (projeção-> SetPlane(1)). A figura 5.12 exemplifica o filtro de projeção ortogonal, mostrando dois contornos do volume de dados marítimos e sua projeção no plano x-y. 

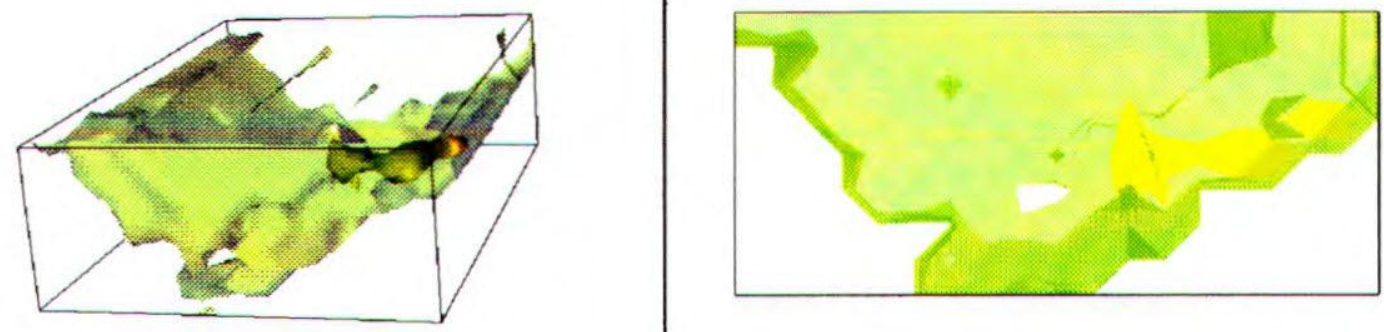

(a)

(b)

Figura 5.12 - Exemplo do uso do vkProjectionFilter.

(a) Dois contornos do volume de dados marítimos.

(b) Projeção no plano x-y de (a).

\subsubsection{Sonificação do Display da Malha}

A única sonificação implementada para o Display da malha é a sonificação dos valores da malha, isto é, sonificação direta dos valores obtidos do volume.

$\mathrm{Na}$ sonificação da malha, a interação é oferecida movimentando o mouse sobre o grid 2D. Quando o mouse se movimenta, a sua posição 2D é extraída e então a posição 3D correspondente é calculada. $\mathrm{O}$ valor escalar exato atribuído àquela posição no grid 3D é então mapeado para frequência e sonificado. $\mathrm{O}$ som produzido significa que para cada valor diferente da frequência existe um valor diferente de dado. Nessa sonificação, altos valores de dados são representados por altas frequências e valores baixos dos dados são representados por baixas frequências, devido à associação natural de valores para frequências realizadas por seres humanos.

Essa sonificação permite que o usuário tenha um reforço dos dados apresentados visualmente, isto é, os mesmos valores representados graficamente são representados sonoramente. Adicionalmente, ele consegue uma precisão maior de valores da malha.

Essa sonificação tem utilidade na análise detalhada de trechos pequenos da malha, em caso de precisão de valores, e na análise global de trechos maiores da malha, para reconhecimento de padrões globais de dados. 
O processo gráfico display da malha funciona da seguinte maneira: primeiramente deve-se escolher os contornos a serem visualizados, e também se deseja a sonificação de todos os valores ou apenas dos contornos escolhidos. Então o botão "OK" deve ser acionado. A janela gráfica é apresentada contendo na sua metade esquerda o grid bidimensional e na sua metade direita o grid tridimensional, como apresentado na figura 5.13(b).

Para que a sonificação aconteça, o usuário precisa acionar a função de interação da sonificação, selecionando a tecla "u" (conforme especificado na Seção 4.5) e então arrastar o mouse, posicionando o cursor sobre o grid 2D apresentado na tela gráfica.
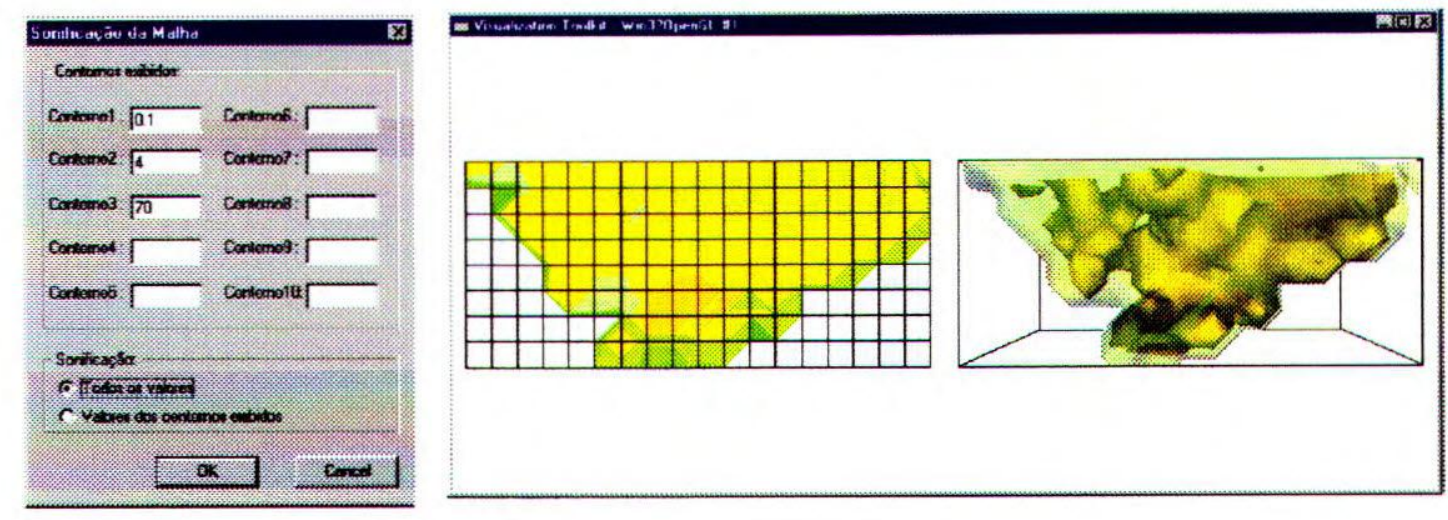

Figura 5.13 - Display da malha do projeto Svol.

(a) - Interface inicial para escolha dos contornos a serem visualizados.

(b) - Tela gráfica com o grid 3D e o grid 2D.

A tabela 5.2 abaixo apresenta um resumo das sonificações implementadas em SVol, mostrando, além das sonificações, os processos gráficos aos quais elas estão associadas, e sua utilidade. A tabela apresenta também algumas extensões imediatas que o sistema admite.

\begin{tabular}{|l|l|l|}
\hline \multicolumn{1}{|c|}{ Sonificações } & \multicolumn{1}{|c|}{ Processo Gráfico } & \multicolumn{1}{c|}{ Utilidade } \\
\hline $\begin{array}{l}\text { Sonificação de Valores Máximo e } \\
\text { Mínimo. }\end{array}$ & Diplay Progressivo & $\begin{array}{l}\text { Percepção de intervalos entre valores } \\
\text { máximo e mínimo de uma coordenada. }\end{array}$ \\
\hline Sonificação da Coordenada & Display Progressivo & $\begin{array}{l}\text { Informação de progressão de uma variável, } \\
\text { ou seja, no momento em que a fatia é } \\
\text { desenhada. }\end{array}$ \\
\hline Densidade Local & Sonda Sonora &
\end{tabular}




\begin{tabular}{|c|c|c|}
\hline & & sonda está. \\
\hline População da Sonda & Sonda Sonora & $\begin{array}{l}\text { Percepção da Quantidade de valores de } \\
\text { interesse em uma região do volume. }\end{array}$ \\
\hline $\begin{array}{l}\text { Sonificação dos Valores da } \\
\text { Malha. }\end{array}$ & Display da Malha & Percepção direta dos valores do volume. \\
\hline \multicolumn{3}{|c|}{ Extensōes para SVol } \\
\hline $\begin{array}{lll}\text { Apresentação Sonora dos } \\
\text { Escalares }\end{array}$ & Display Progressivo & $\begin{array}{l}\text { Observação dos valores escalares da malha } \\
\text { por fatias. }\end{array}$ \\
\hline $\begin{array}{l}\text { Sonificação de Contornos } \\
\text { Específicos }\end{array}$ & Display Progressivo & $\begin{array}{l}\text { Observação dos valores de um contorno } \\
\text { específico em cada fatia enquanto outros } \\
\text { estão sendo visualizados. Até três valores de } \\
\text { contornos podem ser apresentados } \\
\text { simultaneamente. }\end{array}$ \\
\hline Sonificação de Vetores & Display da Malha & Observação dos vetores na malha. \\
\hline $\begin{array}{l}\text { Presença e Quantidade de Valores } \\
\text { Específicos no Volume }\end{array}$ & Sonda Sonora & $\begin{array}{l}\text { Observação e localização de valores espúrios } \\
\text { dentro do volume. }\end{array}$ \\
\hline $\begin{array}{l}\text { Sonificação da Média, Mediana e } \\
\text { Correlação }\end{array}$ & $\begin{array}{l}\text { Sonda Sonora e Display } \\
\text { Progressivo }\end{array}$ & Observação da tendências dos dados. \\
\hline
\end{tabular}

Tabela 5.2 - Sonificações do SVol e extensōes planejadas.

\subsection{Casos de Teste}

O primeiro conjunto de dados utilizado nos testes foram os dados marítimos, obtidos no Mar do Norte, que representam longitude na coordenada $\mathrm{x}$, latitude na coordenada y e progressão do tempo na coordenada $z$. As figuras mostradas como exemplo do SVol neste Capítulo foram geradas com esse conjunto de dados.

As figuras 5.14 e 5.15 representam, respectivamente, um exemplo da sonda sonora e um exemplo do display progressivo de SVol, utilizando um segundo conjunto de dados. Esse conjunto apresenta imagens dentárias, visualizando a coroa, o nervo e a raiz de um dente. $O$ dente foi reconstruído a partir de contornos editados em fatias consecutivas do volume, no contexto de um outro projeto de mestrado [Shi 97]. 
No display progressivo, as sonificações chamam a atenção para detalhes da forma.

A tabela 5.3 apresenta um resumo das sonificações testadas em dois conjuntos de dados, mostrando também sua utilidade.

\begin{tabular}{|c|c|}
\hline \multicolumn{2}{|c|}{ Dados Marítimos } \\
\hline Sonificação Utilizada & Utilidade \\
\hline Sonificação de valores máximo e mínimo & $\begin{array}{l}\text { Observação do intervalo de valores das coordenadas, } \\
\text { implicando em variações de latitude ou longitude. }\end{array}$ \\
\hline Sonificação da coordenada & Observação da progressão do tempo, latitude ou longitude. \\
\hline Densidade local & $\begin{array}{l}\text { Observação da concentração de substâncias em porçōes do } \\
\text { volume. }\end{array}$ \\
\hline População da sonda & $\begin{array}{l}\text { Observação da quantidade de valores específicos } \mathrm{cm} \text { locais } \\
\text { do volume. }\end{array}$ \\
\hline Sonificação dos valores da malha & $\begin{array}{l}\text { Observação direta dos valores de concentração de substâncias } \\
\text { em partes específicas do mapa. }\end{array}$ \\
\hline \multicolumn{2}{|c|}{ Dados Dentários } \\
\hline Sonificação Utilizada & Utilidade \\
\hline Densidade local & $\begin{array}{l}\text { Observaçāo da densidade de uma superfície específico no } \\
\text { dente. }\end{array}$ \\
\hline População da sonda & Observação de espaços e densidades relativas. \\
\hline Sonificação de valores máximo e mínimo. & $\begin{array}{l}\text { Observação do intervalo de valores específicos do dente, } \\
\text { implicando na presença ou ausência de superfícies. }\end{array}$ \\
\hline Sonificação da coordenada & Observação das fatias individuais. \\
\hline
\end{tabular}

Tabela 5.3 - Exemplos de conjuntos de dados aplicados a SVol com sonificações aplicadas e suas utilidades.

O próximo Capítulo apresenta as conclusões obtidas com o estudo e desenvolvimento do sistema de sonificação SVol. 


\section{Conclusões}

Durante o desenvolvimento deste trabalho de mestrado, observou-se que, inicialmente, o som como ferramenta de apoio foi utilizado em sistemas computacionais dedicados a aplicações gráficas específicas, ou seja, o som era adaptado a sistemas gráficos já existentes e era dependente da imagem. Hoje em dia, estratégias estão sendo desenvolvidas para o mapeamento de dados para som, isto é, o som está sendo visto como parte importante dos sistemas computacionais. A maioria das técnicas se preocupa, em primeira instância, com o poder dos estímulos sonoros para representar informações.

A utilização do som como ferramenta em sistemas computacionais tende a crescer a cada dia. $\mathrm{Na}$ maioria das aplicações, exibições sonoras serão apresentadas em conjunto com exibições gráficas, pois a visão do ser humano é mais poderosa do que a audição. Contudo, é possível perceber que a utilização do som em sistemas computacionais é muito útil tanto como reforço para imagens como para representação de dados independentemente da visão.

O principal objetivo prático deste projeto, que foi a re-implementação de SSound num novo contexto (o SVol), foi alcançada com as vantagens previstas. SSound foi desenvolvido no software Image, que hoje é ultrapassado, além de ser estritamente procedural. Com a reimplementação, SVol foi desenvolvido como uma extensão de VTK, que é um software de uso geral e de ampla utilização, e tem como base o desenvolvimento orientado a objetos. Além disso, VTK possui programação DataFlow, que permite a conexão de seus módulos, nos moldes da maioria dos sistemas disponíveis comercialmente. Com isso, conseguiu-se, ao mesmo tempo, 
uma plataforma extensível e de fácil reutilização, para futuros testes da sonificação, e para o restante do desenvolvimento do projeto Svol.

Nesta etapa do SVol, foram implementadas as sonificações centrais de SSound. Contudo, todas as outras funçðes sonoras mencionadas como possíveis extensões no Capítulo 5 desta dissertação, são imediatas, já que todas as partes gráficas se encontram concluídas e, sem elas, o SSound não poderia ser estendido.

Os mapeamentos sonoros realizados em SVol se basearam em aspectos de percepção essenciais para o entendimento do som. Foram utilizados para os mapeamentos a frequência, para a representação de valores de dados, e o timbre, para permitir a distinção entre sons diferentes.

O poder representativo das propriedades sonoras empregadas neste projeto podem ser resumidas nos dois aspectos a seguir:

- A frequência é a mais poderosa das propriedades sonoras e é usada para associações, representações de sequências, e identificações de mudanças. Pode também representar quantidades, embora não com muita precisão, e sempre necessitando de comparação para permitir a identificação de valores.

- O timbre é excelente para representar eventos e para associaçöes em geral, e é essencial para segregação.

Uma das extensठes possíveis para SVol envolve incorporar outras propriedades sonoras no esquema de sonificação tanto para aumentar o poder de representação quanto para reforçar a percepção das propriedades centrais (frequência e timbre). O projeto SVol continua, a partir da realização das seguintes tarefas:

- implementação das extensðes das sonificaçðes. Além das extensões sugeridas no Capítulo 5 existe uma série de possibilidades de sonificação que pode ser explorada. 
- generalização dos processos visuais implementados e a realização de testes nesses processos. Até o momento, os processos visuais são específicos dos programas-exemplo, mas podem ser generalizados para se transformar num "plug-in" do software VTK, com facilidade.

- extensão do sistema SVol para outros tipos de dados, como malhas não cartesianas (malhas retangulares não regulares e malhas não estruturadas), e dados não escalares (vetoriais $\mathrm{e}$ tensores);

- realização de testes de melhoria de performance do usuário, com a utilização de som e sem a utilização de som. Comparação com os resultados obtidos anteriormente.

Com relação à área de sonificação de dados, a criação de novos paradigmas necessita ser considerada. Até o momento, a maioria dos trabalhos trabalha com o mapeamento de escalares e eventos para propriedades do som, como frequência, timbre, e ritmo; é preciso buscar recursos sonoros que representem melhor a natureza do fenômeno que gerou os dados. Um exemplo seria estudar recursos da música para representação sonora, uma vez que sua organização tem natureza matemática, análoga a processos numéricos de geração de dados.

A experiência no desenvolvimento de SVol mostrou a dificuldade de entendimento das pessoas em um primeiro contato com a sonificação. Contudo, foi notado durante o desenvolvimento deste projeto que o ponto crucial na aceitação de som como ferramenta é a consciência de nossa capacidade de interpretar sinais sonoros.

A implementação de técnicas de sonificação como as apresentadas neste trabalho, em sistemas de visualização de baixo custo, vem colaborar para a disseminação desta atividade, o que é um elemento essencial para o desenvolvimento da representação sonora de informações numéricas e gráficas em sistemas computacionais. 


\section{Bibliografia}

[Ast 92] Astheimer, P. - "Sonification in Scientific Visualization and Virtual Reality Applications", comunicação pessoal.

[Axe 96] Axen, U.; Choi, I. - "Investigating Geometric Data with Sound", Proceeding of ICAD'96, http://www.santafe.edu/ icad/ICAD96/proc96/axen.htm, 1996, 16/04/98.

[Bae 87] Baecker, R. M.; Buxton, W. A. S. - Readings in Human Computer Interaction: A Multidisciplinary Approach, Morgan Kauffmann Publishers, Inc. 1987.

[Bal 94] Ballas, J. A. - "Delivery of Information Through Sound", em Kramer, G. (ed.) Auditory Display: Sonification, Audification and Auditory Interfaces - The Proceedings of ICAD'92, the First International Conference on Auditory Display, Addison-Wesley, 1994, pp.79-94.

[Bar 94] Bargar, R. - "Pattern and Reference in Auditory Display", em Kramer, G (ed.) Auditory Display - Sonification, Audification and Auditory Interfaces - The Proceedings of ICAD'92, the First International Conference on Auditory Display, Addison-Wesley, 1994, pp. 151-166.

[Bar 96] Barrass, S. - "TaDa! Demonstrations of Auditory Information Design", Proceeding of ICAD'96, 1996.

[Ber 95] Bergman, L. D.; Rogowitz, B. E.; Treinish, L. A. - "A Rule-based Tool for Assisting Colomap Selection" - Proceedings of IEEE Visualization'95, Atlanta, E.U.A, OutubroNovembro, 1995, pp. 118-125.

[Bly 82] Bly, S. - "Presenting Information in Sound", Proceedings of ACM CHI'82, pp. 371" 375.

[Bre 96] Brewster, S. A. - "A Sonicallt Enhanced Interface Toolkit”, Proceeding of ICAD'96, http://www.santafe.edu/ icad//CAD96/proc96/brewster.htm 1996.

[Bre 97] Brewer, D. - "A Brief Survey of Speech Recognition Tchnology", http::// www. linfield.edu/ dbrewer/speech.html, 1997, 04/04/1997. 
[Bux 90] Buxton, W.; Gaver, W.; Bly, S.; Empowering People - The Use of Non-Speech Audio at the Interface, ACM Conference on Human Factors in Computing Systems, Tutorial 4 Notes, Abril 1990.

[CG 87] ACM SIGGRAPH Computer Graphics, Special issue on Visualization in Scientific Computing, vol. 21, n.6, Novembro 1987.

[Dav 89] David,G.; Jones,R; Sound Reinforcement Handbook, 2a edição, Hal Leonard Publishing Corporation, 1989, pp. 1-4.

[Day 97] Day, A. M.; Minghim, R.; Turner, S. M.; Arnold, D. B. - "Visualization and Sonification of Marine Survey Data", Earnshaw et. al. (eds.), Visualization \& Modeling, Academic Press, 1997, pp. 87-97.

[Elv 92] Elvins, T. T. - "A Survey of Algorithms for Volume Visualization", ACM SIGGRAPH Computer Graphics, vol. 26, n. 3, Agosto 1992, pp. 194-201.

[Eva 87] Evans, B. - "Integration of Music and Graphics through Algorithm Congruence", Proceedings of International Computer Music Conference, 1987, pp. 17-24.

[Eva 89] Evans, B. - "Enhancing Scientific Animations with Sonic Maps", Proceedings of International Computer Music Conference, 1989, pp.105-108.

[Eva 90] Evans, B. - "Correlating Sonic and Graphic Materials in Scientific Visualization", Proceedings SPIE - Extracting Meaning from Complex Data, v. 1259, 1990, pp.154162.

[Gal 95] Gallagher, R. S. (ed.) - Computer Visualization: Graphics Techniques for Scientific and Engineering Analysis, CRC Press, 1995.

[Gav 86] Gaver, W. W. - "Auditory Icons: Using Sound in Computer Interfaces", HumanComputer Interaction, vol.2, pp.167-177,1986.

[Gav 89] Gaver, W. - "The SonicFinder: An Interface that uses Auditory Icons", HumanComputer Interaction, vol. 4, n. 1, 1989, pp. 67-94.

[Gav 90] Gaver,W.; Smith, R. - "Auditory Icons in Large-scale Collaborative Environments", em Buxton, W.; Gaver, W.; Bly, S.; Empowering People - The Use of Non-Speech Audio at the Interface, ACM Conference on Human Factors in Computing Systems, Tutorial 4 Notes, Seattle, Abril 1990.

[Gav 91] Gaver, W. W. ; Smith, R. B.; O'Shea, T. - "Effective Sounds in Complex Systems: The ARKOLA Simulation”, Proceedings of ACM CHI'91, 1991, pp.85-90.

[Gav 94] Gaver, W. W. - "Using and Creating Auditory Icons", em Kramer, G - Auditory Display - Sonification, Audification and Auditory Interfaces - The Proceedings of ICAD'92, the First International Conference on Auditory Display, Addison-Wesley , 1994, pp.417-446. 
[Gro 95] Grohn, M. - Magic Mikes - Method for Spatial Sonification - Proceedings of SPIE, vol. 2410, 1995, pp. 294 - 301.

[Kra 91] Kramer, G; Ellison, S. Audification: The Use of Sound to Display Mutivariate Data Proceedings of International Computer Music Conference, 1991, pp. 214-221.

[Kra 94] Kramer, G. (ed.) - Auditory Display: Sonification, Audification and Auditory Interfaces - The Proceedings of ICAD'92, the First International Conference on Auditory Display, Addison-Wesley, 1994.

[Kra 94b] Kramer, G. - "Some Organizing Principles for Representing Data With Sound" - em Kramer, G - Auditory Display - Sonification, Audification and Auditory Interfaces The Proceedings of ICAD'92, the First International Conference on Auditory Display, Addison-Wesley, 1994, pp.185-222.

[Kra 94c] Kramer, G. - "An Introduction to Auditory Display", em Kramer, G - Auditory Display - Sonification, Audification and Auditory Interfaces - The Proceedings of ICAD'92, the First International Conference on Auditory Display, Addison-Wesley, 1994,pp. 1-78.

[Kra 96] Kramer, G. - "Mapping Single Data Stream to Multiple Auditory Variables: A Subjective Approach to Creating a Compelling Design", Proceeding of ICAD’96, 1996.

[Lic 98] Licciardi, P. R. - "Funções de apoio à Visualização em Odontologia" - Relatório parcial de Iniciação Científica PIBIC - CNPq/ICMC, Janeiro, 1998.

[Lor 87] Lorensen, W. E.; Cline, H. E. - "Marching Cubes: A high resolution 3D surface construction algorithm", ACM SIGGRAPH Computer Graphics, vol. 21, 1987, pp.163-169.

[Mad 95] Madhyastha, T. M.; Reed, D. A.. - "Data Sonification: Do you See what I hear?", IEEE Software, Março 1995, pp. 45-56.

[Mar 97] Martins, A. C. G. - "Apresentação Sonora e Sonificação de Imagens com Texturas", Tese de Doutorado, Escola Politécnica da Universidade de São Paulo, Agosto 1997.

[Mas 87] Massey, H.; Noyes, A.; Shklair, D. - A Synthesist's Guide to Acoustic Instruments, Amsco Publications, 1987.

[McC 83] McCleary Jr., G. F. - "An Effective Graphic 'Vocabulary", IEEE Computer Graphics and Applications, Março/Abril 1983, pp.46-53.

[McC 94] McCabe,K.; Rangwalla, A. - "Auditory Display of Computational Fluid Dynamics Data", em Kramer, G - Auditory Display - Sonification, Audification and Auditory Interfaces - The Proceedings of ICAD'92, the First International Conference on Auditory Display, Addison-Wesley, 1994, pp.327-340.

[Mez 84] Mezrich, J. J.; Frysinger, S.; Slivjanovski, R. - "Dynamic Representation of Multivariate Time Series Data", Journal of The American Statistical Association, vol. 79, n.385, pp. 34-40, Março 1994. 
[Min 95a] Minghim, R. - On Sound Support for Visualisation, PhD thesis, School of Information Systems, University of East Anglia, UK, Março 1995.

[Min 95b] Minghim, R.; Forrest, A. R. - "Sound Mappings for Surface Visualisation", em Proceedings of WSCG'95, The Third International Conference in Central Europe on Computer Graphics and Visualisation 95, vol. II, pp. 210-220.

[Min 95c] Minghim, R.; Forrest, A. R. - "An Illustrated Analysis of Sonification for Scientific Visualisation”, em Proceedings of IEEE Visualization' 95, pp. 110-117.

[Min 97a] Minghim, R.; Oliveira, M. C. F. - "PowerVis: Empowering the User with a Multi-Modal Visualization System", II IEEE Workshop on Cybernetic Vision, São Carlos, Dezembro 1996, publicado pela IEEE CS Press, 1997, pp. 106-111.

[Min 97b] Oliveira, M. C. F.; Minghim R. - "Uma Introdução à Visualização Computacional", JAI'97 - Jornadas de Atualização em Informática, XVII Congresso da SBC, Brasília, 2 a 8 de Agosto de 1997, 45p.

[Ous 94] Ousterhout, J. K. - Tel and the Tk Toolkit, Addison-Wesley, 1994.

[Owe 95] "HyperVis - Teaching Scientific Visualization Using Hypermedia" - Project Director: G. Scott Owen - http:// tapioca.icmsc.sc.usp.br/ vtk/hypervis.htm, 14/04/98.

[Pac 97] Pacheco, M. L. - "Funções Sonoras de Apoio à Sonificação" - Relatório final de Iniciação Científica - FAPESP, Outubro, 1997.

[Reu 90] Reuter, L. H.; Tukey, P.; Maloney, L. T.; Pani, J. R.; Smith, S. - Panel: "Human Perception and Visualization", Proceedings of IEEE Visualization'90, pp.401-406.

[Rum 91] Rumbaugh, J.; Blaha, M. - Object-Oriented Modeling and Design, Prentice-Hall, 1991.

[Sca 91] Scaletti, C.; Craig, A. B. - Using Sound to Extract Meaning from Complex Data Proceedings of SPIE - Extracting Meaning from Complex Data II, Vol. 1459, 1991, pp. $207-219$.

[Sca 94] Scaletti, C.; "Sound Synthesis Algorithms for Auditory Data Representations", em Kramer, G. (ed.), Auditory Display: Sonification, Audification and Auditory Interfaces - The Proceedings of ICAD'92, the First International Conference on Auditory Display, Addison-Wesley , 1994, pp.223-252.

[Sch 97] Schroeder, W. J.; Martin, K.; Lorensen, W. - The Visualization Toolkit - An ObjectOriented Approach to 3D Graphics, Prentice-Hall, 2:. Edição, 1997.

[Shi 97] Shimabukuro, M. H. - "Dentes Virtuais: Visualização para Apoio a Atividades Odontológicas” - monografia aprovada para qualificação de mestrado, ICMC-USP, 1997.

[Smi 90] Smith, S; Bergeron, R. D.; Grinstein, G. G. - "Stereophonic and Surface Sound Generation for Exploratory Data Analysis”, Proceedings of ACM CHI'90, pp. 125-132, 1990, também em Multimedia Interface Design, ed. M. M Blattner and R. B. Dannenberg, Addison-Wesley ,1992, pp. 173-184. Re-impresso em Blattner, M. M.; 
Dannenberg, R. B. (eds.) - Multimedia Interface Design, Addison-Wesley ,1992, pp.173-184.

[Sum 86] Sumikawa, D. A.; Blattner, M. M.; Joy, K. I., Greenberg, R. M. - "Guidelines for the Syntactic Design of Audio Cues in Computer Interfaces", Proceedings of the 9th Annual Hawaii International Conference on System Sciences, 1986, pp. 691-699.

[Wal 96] Walker, B. N.; Kramer, G. - "Mappings and Metaphors in Auditory Displays: An Experimental Assessment", Proceeding of ICAD'96, http://www.santafe.edu/ icad/ICAD96/proc96/walker.htm, 1996, 16/04/98.

[Wil 93b] Wilson; Bargar, R. - "Audible Image for Microsoft Windows" em Evans, B. (organizador), Bargar, R.; Scaletti, C. (palestrante), An Introduction to Data Sonification, Course Notes 81, SIGGRAPH 93.

[Wil 94] Williams, S. M. - "Perceptual Principles in Sound Grouping" - em Kramer, G. (ed.) Auditory Display: Sonification, Audification and Auditory Interfaces - The Proceedings of ICAD'92, the First International Conference on Auditory Display, Addison-Wesley, 1994,pp.95-126.

[Wil 96] Wilson,C. M.; Lodha, S. K. - "Listen: A Data Sonification Toolkit", Proceedings of ICAD'96, http://www.santafe.edu/ icad/ICAD96/proc96/lodha.htm, 1996, 16/04/98.

[Yeu 80] Yeung, E. S. - "Pattern Recognition by Audio Representation of Multivariate Analytical Data", Analytical Chemistry, vol. 52, no. 7, pp. 1120-1123, Junho 1990. 


\section{Apêndice A - MIDI Kernel e Sound Library}

\section{Métodos da classe KERNEL}

\begin{tabular}{|c|c|c|c|}
\hline Nome & Entrada & Saída & Retorno \\
\hline $\begin{array}{l}\text { MIDIcommandSingle } \\
\text { Inicializa um pacote com } \\
\text { uma mensagem MIDI } \\
\text { simples }\end{array}$ & \begin{tabular}{lr|} 
Mensagem a ser \\
incluída, \\
Canal para a mensagem, \\
Parâmetros \\
Mensagem
\end{tabular} & - & Pacote de Mensagens inicializado \\
\hline $\begin{array}{l}\text { MIDIcommandInclude } \\
\text { Inclui uma mensagem em } \\
\text { um pacote já inicializado }\end{array}$ & $\begin{array}{l}\text { Mensagem a ser } \\
\text { incluída, } \\
\text { Pacote de Mensagens } \\
\text { ainda não enviado, } \\
\text { Canal para a mensagem, } \\
\text { Parâmetros } \\
\text { Mensagem }\end{array}$ & $\begin{array}{l}\text { Pacote de Mensagens } \\
\text { adaptado }\end{array}$ & Falso se o pacote está cheio \\
\hline $\begin{array}{l}\text { StartUp_MIDI } \\
\text { Inicializa a porta, driver } \\
\text { e temporização MIDI }\end{array}$ & - & $\begin{array}{l}\text { Um ponteiro para o } \\
\text { cliente criado }\end{array}$ & O número de referência para o Cliente \\
\hline \begin{tabular}{l} 
ShutDown_MIDI \\
Libera memória e \\
reinicializa \\
comunicação MIDI para \\
\multicolumn{2}{l}{ um cliente específico } \\
\end{tabular} & Ponteiro para o cliente & - & - \\
\hline 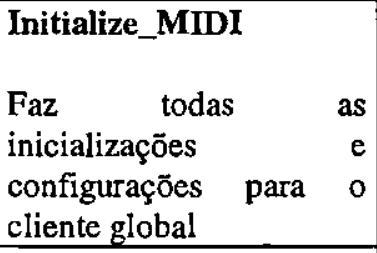 & - & - & Falso se a inicialização falha \\
\hline $\begin{array}{l}\text { Shut_MIDI } \\
\text { Libera memória e } \\
\text { reinicializa } \\
\text { comunicação MIDI para } \\
\text { o cliente global }\end{array}$ & - & - & - \\
\hline Get_Next_Channel & Número de incrementos & - & Falso se não há o canal \\
\hline
\end{tabular}




\begin{tabular}{|l|l|l|l|}
\hline $\begin{array}{l}\text { Muda o canal corrente } \\
\text { para um posterior }\end{array}$ & para o canal & & \\
\hline $\begin{array}{l}\text { Get_Previous_Channel } \\
\text { Muda o canal corrente } \\
\text { para um anterior }\end{array}$ & $\begin{array}{l}\text { Número de } \\
\text { decrementos para o } \\
\text { canal }\end{array}$ & - & Falso se não há o canal \\
\hline $\begin{array}{l}\text { Get_Specific_Channel } \\
\text { Cunal para ser posto } \\
\text { como o canal corrente } \\
\text { para um especifico }\end{array}$ & - & Falso se falha \\
\hline $\begin{array}{l}\text { Initialize_Channel } \\
\text { Seta o canal inicial }\end{array}$ & - & - & $\begin{array}{l}\text { Falso se a Estrutura de Dados não foi } \\
\text { inicializada }\end{array}$ \\
\hline $\begin{array}{l}\text { Send_Message } \\
\text { Envia pacote para porta } \\
\text { MIDI }\end{array}$ & pacote de mensagem & última mensagem & Falso se comunicação falha. \\
\hline
\end{tabular}

\section{Métodos da classe MAPPING}

\begin{tabular}{|c|c|c|}
\hline Nome & Entrada & Retorno \\
\hline $\begin{array}{l}\text { Value_to_MIDIfrequency } \\
\text { Mapeia um valor inteiro dentro de } \\
\text { um intervalo para uma freqüência } \\
\text { MIDI mais um pitch bend }\end{array}$ & $\begin{array}{l}\text { Valor para ser mapeado; } \\
\text { Extremos do intervalo } \\
\end{array}$ & $\begin{array}{l}\text { Freqüência mapeada; } \\
\text { Pitch Bend mapeado }\end{array}$ \\
\hline $\begin{array}{l}\text { Major_Third } \\
\text { Calcula a terceira da escala maior } \\
\text { para uma frequêencia dada }\end{array}$ & $\begin{array}{l}\text { Freqüência central e seu pitch bend; } \\
\text { Ordem do acorde (up, down, middle) }\end{array}$ & $\begin{array}{l}\text { Freqüência e pitch bend mapeados da } \\
\text { Terceira Maior }\end{array}$ \\
\hline $\begin{array}{l}\text { Major_Fifth } \\
\text { Calcula a quinta da escala maior } \\
\text { para uma frequêencia dada }\end{array}$ & \begin{tabular}{|l|} 
Freqüência central; \\
Pitch bend (da freqüência); \\
Ordem do acorde (up, down ou \\
middle)
\end{tabular} & $\begin{array}{l}\text { Freqüência e pitch bend mapeados da } \\
\text { Quinta Maior }\end{array}$ \\
\hline $\begin{array}{l}\text { Pan } \\
\text { Mapeia um valor dado para um } \\
\text { valor MIDI que produzira uma } \\
\text { distribuição campo estéreo }\end{array}$ & \begin{tabular}{|l|} 
Extremos do intervalo; \\
Valor a ser mapeado; \\
Direção do "pan" (esquerda, direita \\
ou centro)
\end{tabular} & Valor MIDI para a distribuição \\
\hline $\begin{array}{l}\text { MIDI_map } \\
\text { Mapeia um valor float linearmente } \\
\text { dentro de um intervalo para um } \\
\text { valor MIDI }\end{array}$ & $\begin{array}{l}\text { Valor; } \\
\text { Limite inferior do intervalo; } \\
\text { Limite superior do intervalo } \\
\end{array}$ & Valor MIDI \\
\hline $\begin{array}{l}\text { MIDI_inverse_map } \\
\text { Mapeia um valor float linearmente } \\
\text { e inversamente dentro de um } \\
\text { intervalo para um valor MIDI }\end{array}$ & $\begin{array}{l}\text { Valor a ser mapeado; } \\
\text { Limite inferior do intervalo; } \\
\text { Limite superior do intervalo }\end{array}$ & Valor MIDI \\
\hline
\end{tabular}




\section{Métodos da classe MULTIPLE_STREAM}

\begin{tabular}{|c|c|c|}
\hline Nome & Entrada & Retorno \\
\hline $\begin{array}{l}\text { Play_Value_on } \\
\text { Liga notas nos três canais pré- } \\
\text { selecionados e dá o campo de } \\
\text { distribuição estéreo }\end{array}$ & $\begin{array}{l}\text { Cliente; } \\
\text { As três freqüûncias; } \\
\text { Os três campos de distribuiçăo } \\
\text { estéreo; } \\
\text { Tempo para espera } \\
\end{array}$ & - \\
\hline $\begin{array}{l}\text { Play_Value_off } \\
\text { Desliga notas específicas em canais } \\
\text { pré selecionados }\end{array}$ & $\begin{array}{l}\text { Cliente; } \\
\text { Notas; } \\
\text { Tempo para espera } \\
\end{array}$ & - \\
\hline $\begin{array}{l}\text { Play_Value_no_Bend } \\
\text { Mesmo que Play_Value_on() sem } \\
\text { ajuste de pitch bend }\end{array}$ & $\begin{array}{l}\text { Cliente; } \\
\text { Vetor com as freqüências e pan's; } \\
\text { Tempo para espera }\end{array}$ & - \\
\hline $\begin{array}{l}\text { All_Notes_off } \\
\begin{array}{l}\text { Silencia os três canais pré- } \\
\text { selecionados }\end{array}\end{array}$ & $\begin{array}{l}\text { Cliente; } \\
\text { Tempo para espera antes do } \\
\text { silenciamento dos canais }\end{array}$ & - \\
\hline $\begin{array}{l}\text { Multiple_pan } \\
\text { Constrói mensagens para ajustar o } \\
\text { campo estéreo para três canais } \\
\text { dados }\end{array}$ & $\begin{array}{l}\text { Três valores "pan" e três canais onde } \\
\text { aplicar esses valores }\end{array}$ & - \\
\hline $\begin{array}{l}\text { Multiple_Pitch_Bend } \\
\text { Constroi mensagens para ajustar o } \\
\text { pitch bend para três canais dados }\end{array}$ & $\begin{array}{l}\text { Três valores de pitch bend e três } \\
\text { canais onde aplicar }\end{array}$ & - \\
\hline $\begin{array}{l}\text { Multiple_Note_Canal } \\
\text { Constrói mensagens para ajustar } \\
\text { notas para três canais dados }\end{array}$ & $\begin{array}{l}\text { Três valores de notas e três canais } \\
\text { onde aplicar }\end{array}$ & - \\
\hline $\begin{array}{l}\text { Play_Value_on_Global } \\
\text { Liga notas nos três canais pré- } \\
\text { selecionados com campos de } \\
\text { distribuição estéreo para o cliente } \\
\text { global }\end{array}$ & $\begin{array}{l}\text { Três freqüências; } \\
\text { Três pans; } \\
\text { Tempo para espera } \\
\end{array}$ & - \\
\hline $\begin{array}{l}\text { Play_Value_off_Global } \\
\text { Desliga notas específicas em canais } \\
\text { pré-selecionados do cliente global }\end{array}$ & $\begin{array}{l}\text { Notas; } \\
\text { Tempo para espera } \\
\end{array}$ & - \\
\hline $\begin{array}{l}\text { begin_play } \\
\text { Inicia 'Boolean-play' memorizado }\end{array}$ & $\begin{array}{l}\text { Valor booleanol inicial; } \\
\text { Valor booleano2 inicial; } \\
\text { Valor booleano3 inicial } \\
\end{array}$ & - \\
\hline $\begin{array}{l}\text { play_with_memory } \\
\text { Faz 'Boolean-play' com memória } \\
\text { de valores anteriores }\end{array}$ & $\begin{array}{l}\text { Novo valor booleanol; } \\
\text { Novo valor booleano2; } \\
\text { Novo valor booleano3 }\end{array}$ & - \\
\hline $\begin{array}{l}\text { play } \\
\text { Toca uma de duas notas nos três } \\
\text { canais pré-selecionados de acordo }\end{array}$ & $\begin{array}{l}\text { Valor booleano1; } \\
\text { Valor booleano2; } \\
\text { Valor booleano3 }\end{array}$ & - \\
\hline
\end{tabular}




\begin{tabular}{|c|c|c|}
\hline com os três valores booleanos & & \\
\hline $\begin{array}{l}\text { JustPlayIt } \\
\text { Toca três notas em três canais pré- } \\
\text { selecionados por um tempo fixo }\end{array}$ & $\begin{array}{l}\text { Notas; } \\
\text { Tempo para espera }\end{array}$ & - \\
\hline $\begin{array}{l}\text { JustStart } \\
\text { Começa a tocar nos três canais pré- } \\
\text { selecionados }\end{array}$ & $\begin{array}{l}\text { Valores para tocar em cada canal; } \\
\text { Tempo para espera }\end{array}$ & - \\
\hline $\begin{array}{l}\text { Sound_off } \\
\text { Silencia os três canais pré- } \\
\text { selecionados no cliente global }\end{array}$ & Tempo para espera & $\cdot$ \\
\hline $\begin{array}{l}\text { Initialize_Memory_Play } \\
\text { Inicializa valores para 'memory- } \\
\text { play' }\end{array}$ & - & - \\
\hline
\end{tabular}

\section{Métodos da classe SINGLE_STREAM}

\begin{tabular}{|l|l|l|}
\hline Nome & Entrada & Retorno \\
\hline Pitch_Bend_64 & $\begin{array}{l}\text { Canal; } \\
\text { Valor do pitch bend; } \\
\text { Cliente }\end{array}$ & False se falha \\
$\begin{array}{l}\text { Altera o pitch bend de um canal } \\
\text { particular }\end{array}$ & $\begin{array}{l}\text { Cliente; } \\
\text { Nota; } \\
\text { Canal; } \\
\text { Play_Single_off }\end{array}$ & - \\
$\begin{array}{l}\text { Desliga uma freqüência num canal para espera } \\
\text { e cliente específicos }\end{array}$ & $\begin{array}{l}\text { Cliente; } \\
\text { Freqüência; } \\
\text { Pan; } \\
\text { Play_Single_no_Bend }\end{array}$ & $\begin{array}{l}\text { Canal; } \\
\text { Tempo para espera }\end{array}$ \\
$\begin{array}{l}\text { Toca uma frequiência } \\
\text { combinada num canal dado }\end{array}$ & $\begin{array}{l}\text { Nota; } \\
\text { Canal; } \\
\text { Cliente; } \\
\text { On/Off }\end{array}$ & - \\
\hline $\begin{array}{l}\text { Write_Note_Channel } \\
\text { Liga ou desliga uma nota em um } \\
\text { canal }\end{array}$ & $\begin{array}{l}\text { Canal; } \\
\text { Cliente; } \\
\text { Pan }\end{array}$ & - \\
\hline $\begin{array}{l}\text { Select_Pan } \\
\text { Seleciona a distribuição 'pan' de } \\
\text { um canal particular para o de saída }\end{array}$ & $\begin{array}{l}\text { Valor de pitch bend e canal onde } \\
\text { aplicar }\end{array}$ & - \\
\hline $\begin{array}{l}\text { Single_Pitch_Bend } \\
\text { Constrói mensagem para ajustar o } \\
\text { pitch bend para um canal dado }\end{array}$ & $\begin{array}{l}\text { Valor "pan" e canal onde aplicar } \\
\text { esse valor }\end{array}$ & - \\
\hline $\begin{array}{l}\text { Single_Pan } \\
\text { Canstrói mensagem para ajustar ostéreo para um canal dado }\end{array}$ & & - \\
\hline
\end{tabular}




\begin{tabular}{|c|c|c|}
\hline $\begin{array}{l}\text { Single_Volume } \\
\text { Constrói mensagens para ajustar o } \\
\text { volume para um canal dado }\end{array}$ & Valor volume e canal onde aplicá-lo & - \\
\hline $\begin{array}{l}\text { Single_Note_Channel } \\
\text { Constrói mensagem para ajustar } \\
\text { nota para um canal dado }\end{array}$ & Valor da nota e canal onde aplicar & - \\
\hline $\begin{array}{l}\text { Play_Single_Vol_Pan } \\
\text { Toca uma nota no canal corrente }\end{array}$ & $\begin{array}{l}\text { Nota; } \\
\text { Pan; } \\
\text { Volume; } \\
\text { Tempo para espera } \\
\end{array}$ & - \\
\hline $\begin{array}{l}\text { Play_Value_with_Volume } \\
\text { Toca uma nota com um certo } \\
\text { volume por um certo tempo }\end{array}$ & $\begin{array}{l}\text { Nota; } \\
\text { Volume; } \\
\text { Tempo para espera }\end{array}$ & - \\
\hline $\begin{array}{l}\text { Play_Drum_with_Volume } \\
\text { Toca um timbre pré-fixado por um } \\
\text { tempo fixo }\end{array}$ & $\begin{array}{l}\text { Tipo de efeito ('drum'); } \\
\text { Volume; } \\
\text { Tempo para espera }\end{array}$ & - \\
\hline $\begin{array}{l}\text { JustPlayIt_Single } \\
\text { Toca três notas em três canais pré- } \\
\text { selecionados por um tempo fixo no } \\
\text { cliente global }\end{array}$ & $\begin{array}{l}\text { Nota; } \\
\text { Canal; } \\
\text { Tempo para espera }\end{array}$ & - \\
\hline $\begin{array}{l}\text { JustSilence_Single } \\
\text { Desliga uma nota no cliente global }\end{array}$ & $\begin{array}{l}\text { Nota; } \\
\text { Canal; } \\
\text { Tempo para espera }\end{array}$ & - \\
\hline $\begin{array}{l}\text { Write_Note } \\
\text { Liga ou desliga uma nota em um } \\
\text { canal do cliente global }\end{array}$ & $\begin{array}{l}\text { Nota; } \\
\text { Canal; } \\
\text { On/Off }\end{array}$ & - \\
\hline $\begin{array}{l}\text { Select_Global_Pan } \\
\text { Seleciona a roteamento de saída do } \\
\text { canal corrente para o canal de saída } \\
\text { do cliente global }\end{array}$ & $\begin{array}{l}\text { Canal; } \\
\text { Tipo de distribuicao (todos os } \\
\text { canais, A e B, C, D, C e D) }\end{array}$ & ( \\
\hline $\begin{array}{l}\text { Change_Timbre_up } \\
\text { Seleciona um timbre mais grave } \\
\text { que o atual }\end{array}$ & Número relativo do timbre & $\begin{array}{l}\text { Falso se a operação falha. Se falso, o } \\
\text { timbre corrente é mantido }\end{array}$ \\
\hline $\begin{array}{l}\text { Change_Timbre_down } \\
\text { Seleciona um timbre mais agudo } \\
\text { que o atual }\end{array}$ & Número relativo do timbre & $\begin{array}{l}\text { Falso se a operação falha. Se falso, o } \\
\text { timbre corrente é mantido }\end{array}$ \\
\hline $\begin{array}{l}\text { Wait_Time } \\
\text { Suspende a execução por um tempo } \\
\text { fixo }\end{array}$ & $\begin{array}{l}\text { Tempo em ticks de Clock; } \\
\text { Cliente proprietário do clock }\end{array}$ & - \\
\hline
\end{tabular}




\section{Métodos da classe INITIALISATION_CALIBRATION}

\begin{tabular}{|c|c|c|}
\hline $\begin{array}{l}\text { Initialize_Sound } \\
\text { Faz as inicializações necessárias } \\
\text { para usar a Sound Tools } \\
\text { Library }\end{array}$ & - & - \\
\hline $\begin{array}{l}\text { Shut_Sound } \\
\text { Termina a Sound Tools Library }\end{array}$ & - & - \\
\hline $\begin{array}{l}\text { Set_Initial_Timbre } \\
\text { Ajusta o timbre inicial para o mais } \\
\text { agudo do conjunto }\end{array}$ & - & - \\
\hline $\begin{array}{l}\text { just_wait } \\
\text { Suspende a execução por um tempo } \\
\text { fixo baseado no clock do cliente }\end{array}$ & Tempo & ( \\
\hline $\begin{array}{l}\text { SendMessage } \\
\text { Envia um mensagem particular } \\
\text { para o "MIDI Manager" }\end{array}$ & $\begin{array}{l}\text { Cliente global; } \\
\text { Tempo para espera depois do envio }\end{array}$ & $\begin{array}{l}\text { Falso se não foi possível o envio da } \\
\text { mensagem para o modulo de som }\end{array}$ \\
\hline $\begin{array}{l}\text { Calibrate } \\
\text { Calibra o sintetizador }\end{array}$ & $\begin{array}{l}\text { Cliente global; } \\
\text { Tempo para espera }\end{array}$ & - \\
\hline $\begin{array}{l}\text { Calibrate_Current_Timbre } \\
\text { Ajusta o campo de distribuição } \\
\text { estéreo e o volume do canal } \\
\text { corrente }\end{array}$ & - & - \\
\hline
\end{tabular}




\section{Hierarquia dos Objetos de Sonificação}

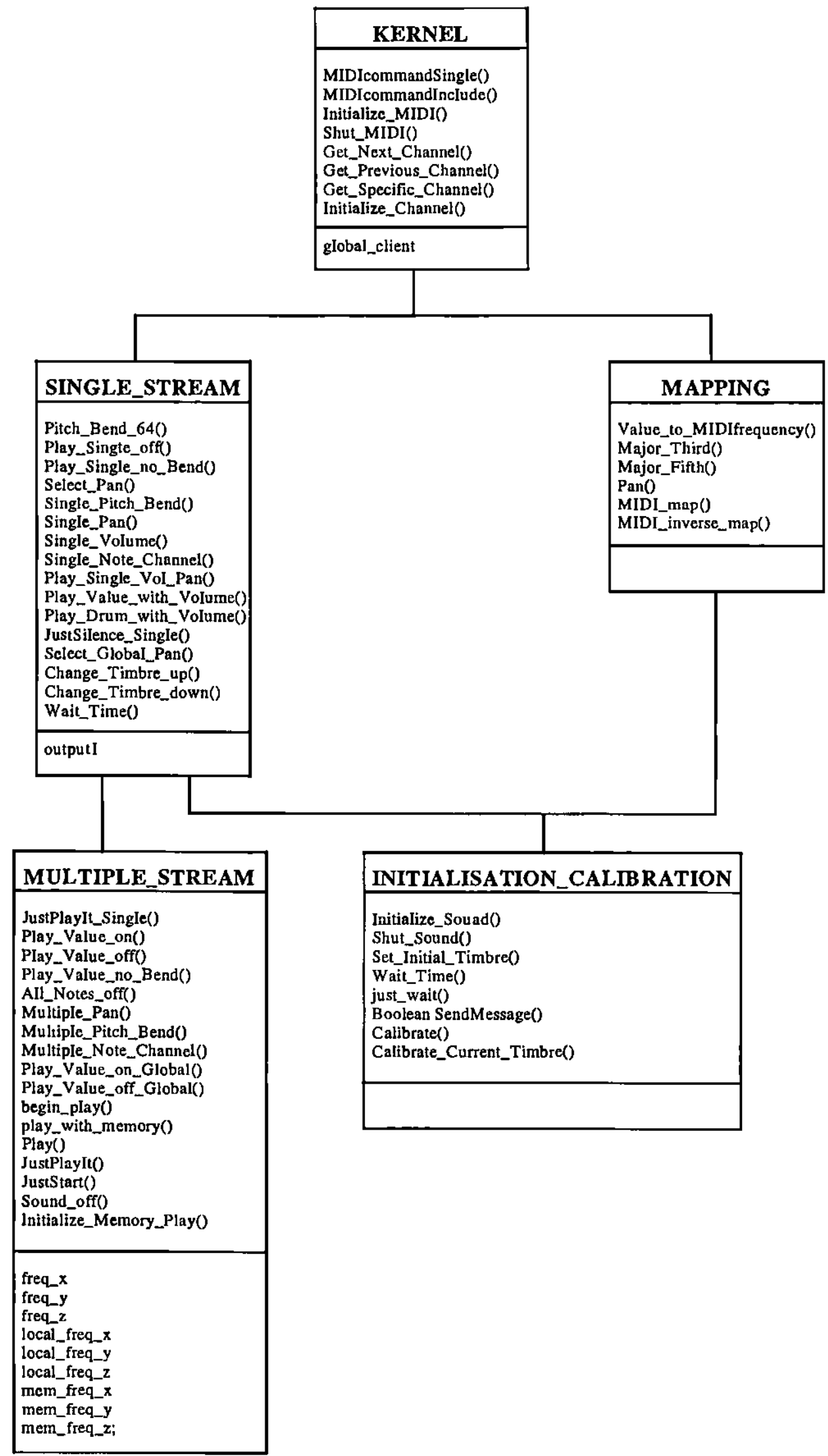




\section{Apêndice B - vtkStructuredPointsSubVolume}

\section{NOME}

vtkStructuredPointsSubVolume - extrai um sub-volume do volume original

\section{RESUMO}

\#include "../vtkStructuredPointsSubVolume.h"

class vtkStructuredPointsSubVolume : public vtkStructuredPointsToStructuredPointsFilter

vtkStructuredPointsSubVolume();

$\sim$ vtkStructuredPointsSubVolume();

const char *GetClassName() \{return "vtkStructuredPointsSubVolume";\};

void SetExtent(float xMin, float xMax, float yMin, float yMax, float $\mathrm{zMin}$, float $\mathrm{zMax}$ );

\section{DESCRIÇÃO}

vtkStructuredPointsSubVolume é um filtro de propósito geral que extrai um subvolume de um conjunto de dados de pontos estruturados.

Este filtro aceita como entrada conjuntos de dados de pontos estruturados e gera como saída um outro conjunto de dados de pontos

estruturados.

\section{SUMÁRIO}

void SetExtent(float xMin, float xMax, float yMin, float yMax, float $\mathrm{zMin}$, float $\mathrm{zMax}$ )

Especifica um limite (xmin, xmax, ymin,ymax, zmin,zmax) para o conjunto de dados de entrada. 